\title{
Improved Hydrogen Gas Getters for TRU Waste - Final Report
}

\author{
Mark Stone \\ Michael Benson
}

Christopher Orme

Thomas Luther

Eric Peterson

John Kaszuba

Marc Haga

Kirk Hollis

Eugene Mroz

September 2005

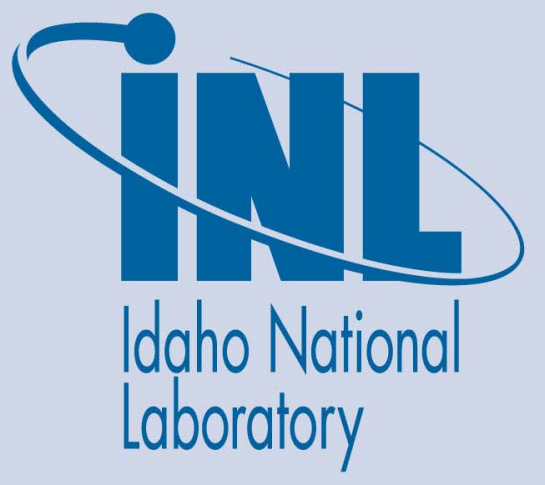

The INL is a U.S. Department of Energy National Laboratory operated by Battelle Energy Alliance 
INL/EXT-05-00805

LANL LA-UR-05-7316

\title{
Improved Hydrogen Gas Getters for TRU Waste - Final Report
}

\author{
Mark Stone ${ }^{a}$ \\ Michael Benson ${ }^{a}$ \\ Christopher Orme ${ }^{a}$ \\ Thomas Luther $^{a}$ \\ Eric Peterson, Principal Investigator ${ }^{a}$ \\ John Kaszuba, Principal Investigator ${ }^{b}$ \\ Marc Haga ${ }^{b}$ \\ Kirk Holllis ${ }^{b}$ \\ Eugene $\mathrm{MrOz}^{\mathrm{b}}$
}

${ }^{\mathrm{a}}$ INL

${ }^{b}$ LANL

September 2005

Idaho National Laboratory Idaho Falls, Idaho 83415

Prepared for the

U.S. Department of Energy

Assistant Secretary for Environmental Management

Under DOE Idaho Operations Office

Contract DE-AC07-05ID14517 


\begin{abstract}
Alpha radiolysis of hydrogenous waste and packaging materials generates hydrogen gas in radioactive storage containers. For that reason, the Nuclear Regulatory Commission limits the flammable gas (hydrogen) concentration in the Transuranic Package Transporter-II (TRUPACT-II) containers to $5 \mathrm{vol} \%$ of hydrogen in air, which is the lower explosion limit. Consequently, a method is needed to prevent the build up of hydrogen to $5 \mathrm{vol} \%$ during the storage and transport of the TRUPACT-II containers (up to 60 days). One promising option is the use of hydrogen getters. These materials scavenge hydrogen from the gas phase and irreversibly bind it in the solid phase. One proven getter is a material called 1,4-bis (phenylethynyl) benzene, or DEB, characterized by the presence of carbon-carbon triple bonds. Carbon may, in the presence of suitable precious metal catalysts such as palladium, irreversibly react with and bind hydrogen. In the presence of oxygen, the precious metal may also eliminate hydrogen by catalyzing the formation of water. This reaction is called catalytic recombination. DEB has the needed binding rate and capacity for hydrogen that potentially could be generated in the TRUPACT II.
\end{abstract}

Phases 1 and 2 of this project showed that uncoated DEB performed satisfactorily in lab scale tests. Based upon these results, Phase 3, the final project phase, included larger scale testing. Test vessels were scaled to replicate the ratio between void space in the inner containment vessel of a TRUPACT-II container and a payload of seven 55-gallon drums. The tests were run with an atmosphere of air for 63.9 days at ambient temperature $\left(15-27^{\circ} \mathrm{C}\right)$ and a scaled hydrogen generation rate of $2.60 \mathrm{E}-07$ moles per second $(0.35 \mathrm{cc} / \mathrm{min})$.

A second type of getter known as VEI, a proprietary polymer hydrogen getter characterized by carbon-carbon double bonds, was also tested in Phase 3. Hydrogen was successfully "gettered" by both getter systems. Hydrogen concentrations remained below $5 \mathrm{vol} \%$ (in air) for the duration of the tests.

However, catalytic reaction of hydrogen with carbon triple or double bonds in the getter materials did not take place. Instead, catalytic recombination was the predominant gettering mechanism in both getter materials as evidenced by (1) consumption of oxygen in the belljars, (2) production of free water in the belljars, and (3) absence of chemical changes in both getter materials as shown by nuclear magnetic resonance spectra. 


\section{SUMMARY}

This development project addresses the implementation of efficient getters for the TRUPACT-II containers to limit the hydrogen gas concentrations to $5 \mathrm{vol} \%$ for 60 days. The focus of our activity is the use of a specific getter called DEB. This is a joint project between the Idaho National Laboratory (INL) and the Los Alamos National Laboratory (LANL). Phase 1 accomplishments included selection of appropriate getter material by INL and evaluation of getter testing ability by LANL. Phase 2 focused upon getter testing. The end result was that the uncoated getter performed above the figure of merit. The conclusions drawn from Phase 2 about the getter performance relative to the programmatically specified parameters include:

- Over the complete temperature range and maximum poison concentration, $5.7 \mathrm{~kg}$ of getter provided the required capacity and rate

- In the temperature range of 160 to $77^{\circ} \mathrm{F}$ the getter rates exceed the minimum programmatic requirement by at least $100 \mathrm{X}$

- In the temperature range of 23 to $-20^{\circ} \mathrm{F}$ the getter rates exceed the minimum programmatic requirements by at least $10 \mathrm{X}$

- Reducing the hydrogen concentrations from $5 \%$ to $1 \%$ in nitrogen had no significant effect on the rate

- Reaction rates are higher in air than in nitrogen due to recombination plus gettering reactions

- The gettering reaction was not found to be sensitive to pressure or radiation, and was shown not to be reversible

- Under the worst case conditions (low temperature, air, and in the presence of $\mathrm{CCl}_{4}$ ), the observed rate was greater than $8 \mathrm{X}$ the minimum programmatic requirement.

The results showed that in lab scale testing, the DEB getter was able to remove the hydrogen needed. Thus Phase 3, the final project phase, was implemented to prove that in actual drum-scale experiments, the removal rate of the hydrogen would be sufficient to show that getters could be used to safely transport the waste to the designated final storage facilities. The scaled up testing was performed at LANL. In addition to DEB, a proprietary polymer hydrogen getter known as VEI was also tested. The two getter systems were evaluated in test vessels comprised of a Gas Generation Test Program (GGTP) style of belljar and a drum equipped with a composite drum filter. The vessels were scaled to replicate the ratio between void space in the inner containment vessel of a TRUPACT-II container and volume of a payload of seven 55-gallon drums. The tests were run with an atmosphere of air for 63.9 days at ambient temperature $\left(15-27^{\circ} \mathrm{C}\right)$ and a scaled hydrogen generation rate of $2.60 \mathrm{E}-07$ moles per second (0.35 cc/min).

Hydrogen was successfully "gettered" by both getter systems. Hydrogen concentrations remained below $5 \mathrm{vol} \%$ (in air) for the duration of the tests. However, catalytic reaction of hydrogen with carbon triple or double bonds in the getter materials did not take place. Instead, catalytic recombination was the predominant gettering mechanism in both getter materials as evidenced by consumption of oxygen and production of free water in the belljars.

INL performed two Phase 3 tasks. One of INL's tasks was to serve as subject matter experts on the scale-up work. INL's second task was to investigate, at a more detailed level, the optimal conditions that 
achieved the maximum getter conversion rates. Samples of the getter were exposed to varying amounts of hydrogen at different rates to determine the effect upon the getter of such varied exposure rates. The before and after getter samples were analyzed using nuclear magnetic resonance (NMR) spectroscopy. The high hydrogen introduction rates yielded NMR spectra with multiple lines that were hard to interpret. On the other hand, the samples exposed at slower rates gave clean NMR spectra. A simple integration of the NMR spectra gives the amount of triple to single bond conversion, which then can be expressed as a hydrogen capacity. These experiments showed that when hydrogen is introduced to the DEB at high rates, low getter capacities for hydrogen removal resulted. When the hydrogen was introduced to the DEB at a slower rates, triple to single bond conversions of over $90+\%$ were observed, with concomitant increases in hydrogen capacity.

The INL also performed analyses on the samples used in the scaled up tests. NMR spectra of the two types of getters before and after the experiments yielded the surprising result that the catalytic recombination reaction of the hydrogen with the oxygen in the container free space was the dominant mechanism observed under the conditions of the experiments. 


\section{CONTENTS}

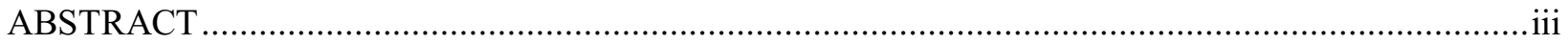

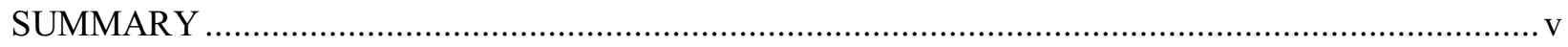

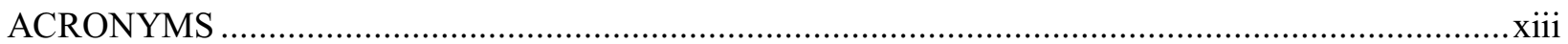



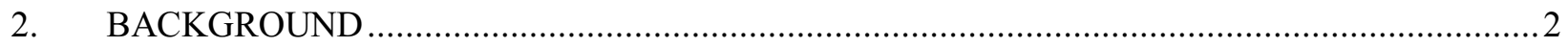

2.1 Transuranic Waste Transportation Problem..............................................................

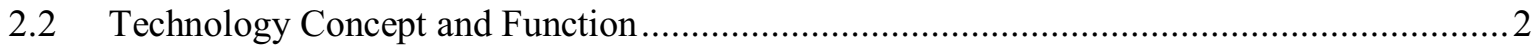

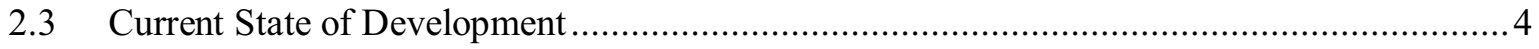

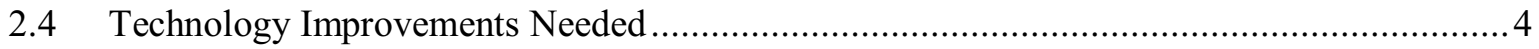

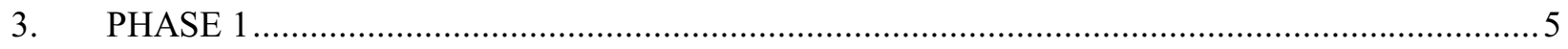

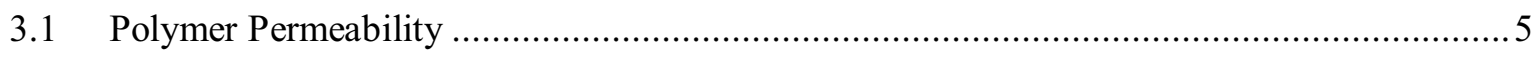

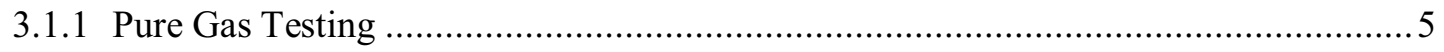

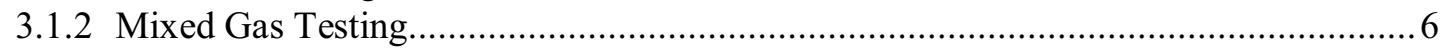

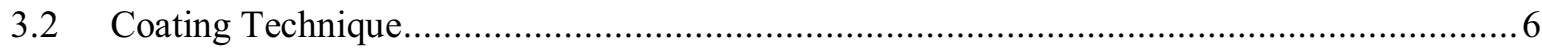





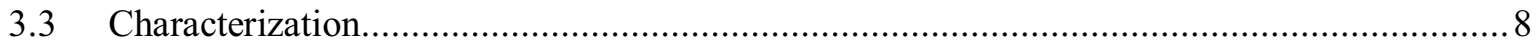

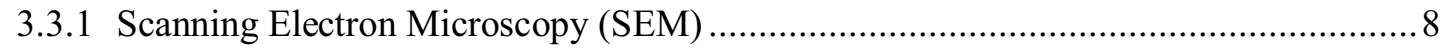

3.3.2 Optical Fluorescence Microscopy ……............................................................ 8

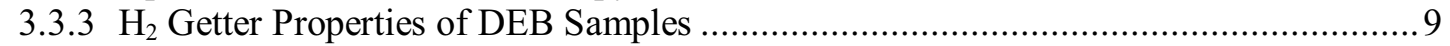

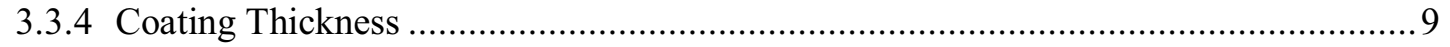

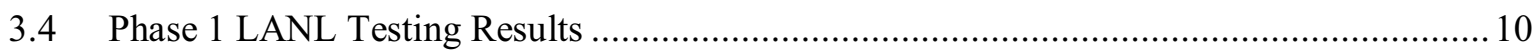

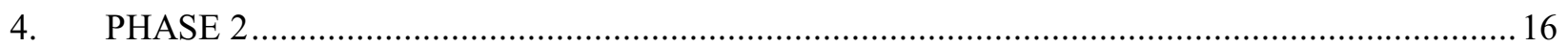



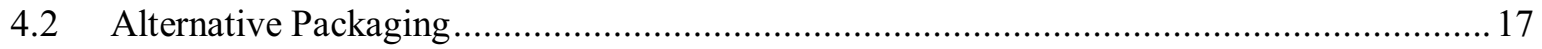

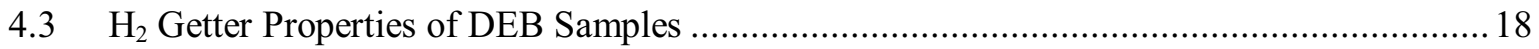

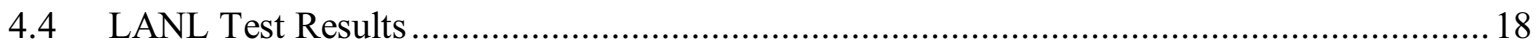




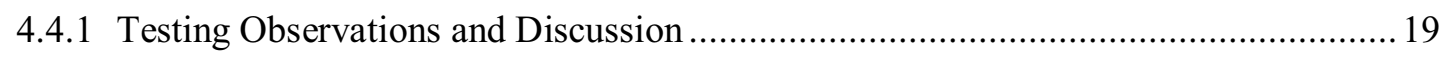

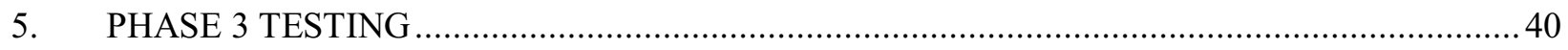

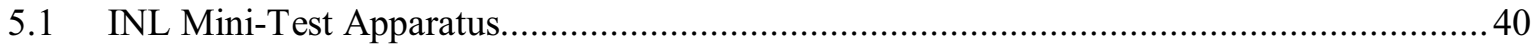

5.2 INL Mini-Test Apparatus Results And Discussion ................................................ 41

5.2.1 Hydrogen Sorption Using Nuclear Magnetic Resonance (NMR) Spectroscopy......... 41

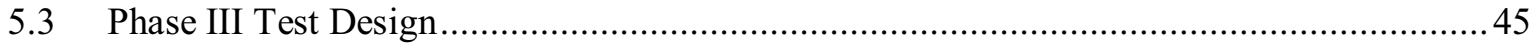



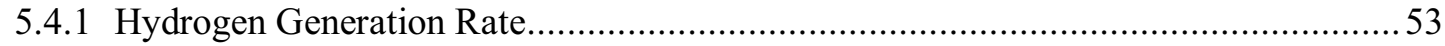

5.4.2 Temperature-Pressure History and Integrity of Test Systems ..................................53

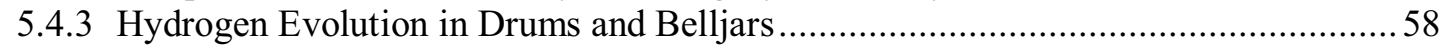

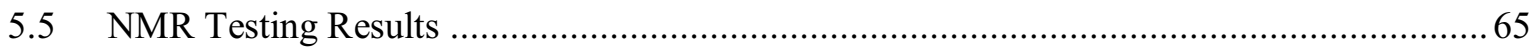

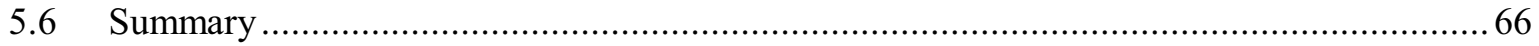

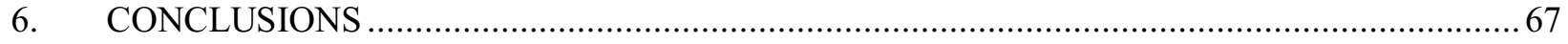

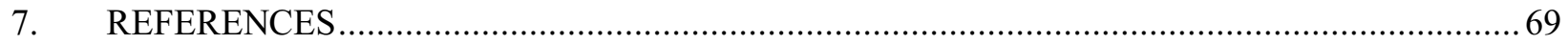

\section{FIGURES}

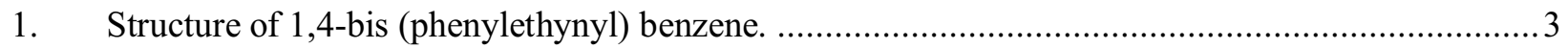

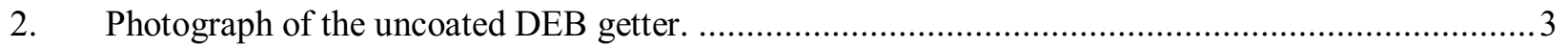

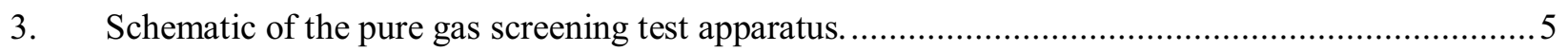

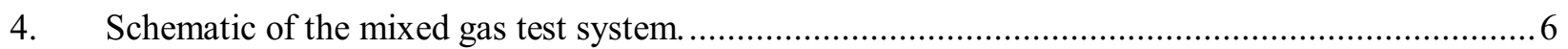

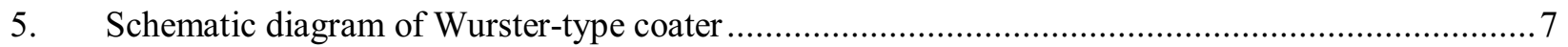

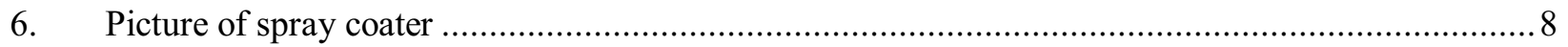

7. SEM photographs of DEB coated with polybenzyl methacrylate …..................................... 8

8. Optical fluorescence microphotograph of a polymer encapsulated DEB particle ......................... 9

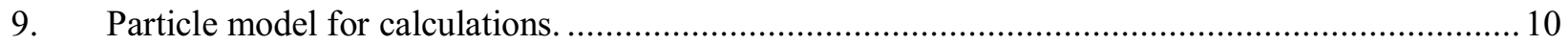

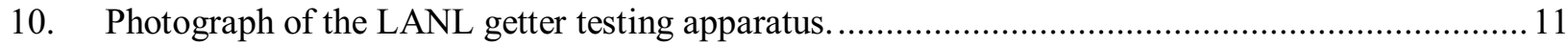

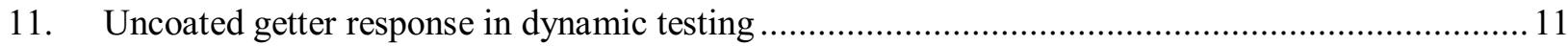

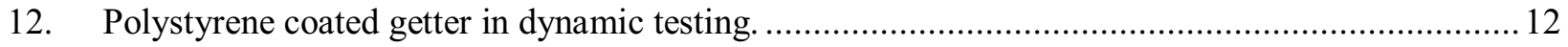


13. Poly (vinylchloride) coated getter in dynamic testing

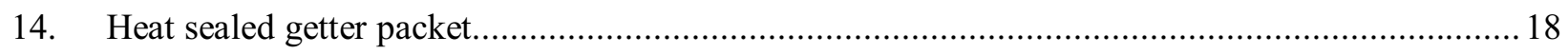

15. Replicate samples and variability of hydrogen removal rate in DEB ......................................20

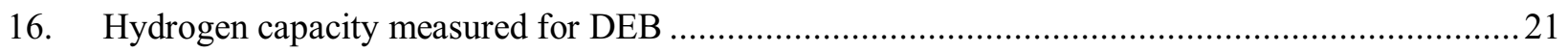

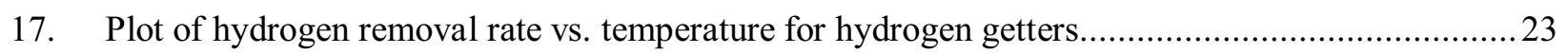

18. Arrhenius plot (hydrogen removal rate vs. temperature) for uncoated DEB (lot x170), polystyrene-coated DEB, and polybenzylmethacrylate-coated DEB in an atmosphere of 5\%

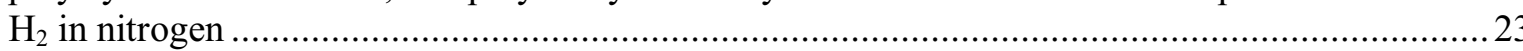

19. Arrhenius plot (hydrogen removal rate vs. temperature) for uncoated DEB (lots x170 and $\mathrm{x} 245)$, polystyrene-coated DEB, and polybenzylmethacrylate-coated DEB in an atmosphere of $3 \% \mathrm{H}_{2}$ in air

20. Comparison of hydrogen removal rates in uncoated DEB (lot x170 and x245), polystyrenecoated DEB, and polybenzylmethacrylate-coated DEB in an atmosphere of 1 and $5 \% \mathrm{H}_{2}$ in nitrogen .26

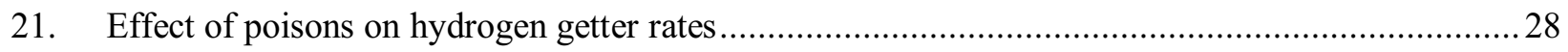

22. Effect of carbon tetrachloride on hydrogen getter rates .....................................................29

23. Effect of poisons on uncoated DEB (lot x245), polystyrene-coated DEB, and polybenzylmethacrylate-coated DEB getter rates in an atmosphere of $3 \% \mathrm{H}_{2}$ in air

24. Effect of carbon tetrachloride on uncoated DEB (lot x245), polystyrene-coated DEB, and polybenzylmethacrylate-coated DEB getter rates in an atmosphere of $3 \% \mathrm{H}_{2}$ in air

26. Effect of aging on hydrogen getter rates of uncoated DEB (lots x170 and x245), polystyrene-coated DEB, and polybenzylmethacrylate-coated DEB in an atmosphere of 5\% $\mathrm{H}_{2}$ in nitrogen

27. Arrhenius plot (hydrogen removal rate vs. temperature) determined for uncoated DEB and polystyrene-coated DEB by dynamic and static test methods. Tests were performed in an atmosphere of $5 \% \mathrm{H}_{2}$ in nitrogen

28. Arrhenius plot (hydrogen removal rate vs. temperature) determined for uncoated DEB and polystyrene-coated DEB by dynamic and static test methods. Tests were performed in an atmosphere of hydrogen in air

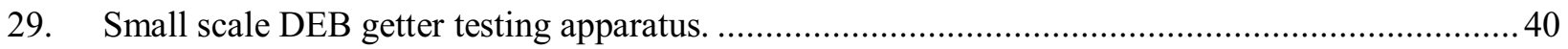

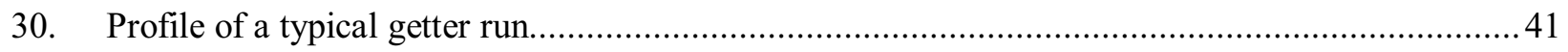

31. Schematic diagram of the NMR equivalent hydrogen atoms on the unreacted DEB getter...........42

32. NMR spectral assignment of the hydrogens on the DEB as diagramed in Figure $31 \ldots \ldots \ldots \ldots \ldots \ldots . . . .42$ 
33. Schematic diagram of the potential NMR equivalent hydrogen atoms on the reacted DEB getter.

34. NMR spectrum with assigned peaks of DEB getter that has been saturated with hydrogen

35. DEB getter NMR of 'all at once' introduction of the hydrogen

36. NMR of DEB getter with slow introduction of the hydrogen .44

37. Pressure profiles with slow introduction of hydrogen.

38. Conceptual design......

39. Photograph of the instrumented bell jars. .50

40. Two views of the scaled setup. 50

41. Getter assemblies .52

42. DEB getter hydrogenation reaction. .53

43. TRUGETTER hydrogenation reaction. .53

44. Recombination reaction. .53

45. Hydrogen introduced into drum of DEB test, as recorded by data logging system .54

46. Hydrogen introduced into drum of duplicate DEB test .55

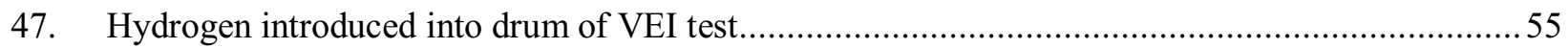

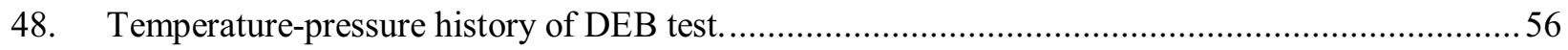

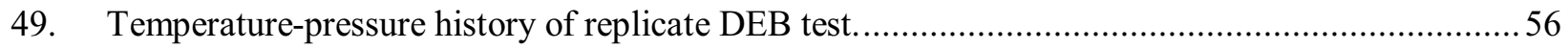

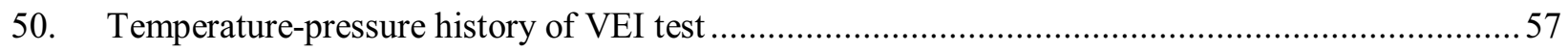

51. Gas evolution as a function of time for ICV (headspace) of belljar containing DEB...................59

52. Gas evolution as a function of time for headspace of drum within belljar containing DEB ........... 60

53. Gas evolution as a function of time for ICV (headspace) of replicate belljar test containing DEB

54. Gas evolution as a function of time for headspace of drum within replicate belljar test containing DEB

55. Gas evolution as a function of time for ICV (headspace) of belljar containing VEI.....................61

56. Gas evolution as a function of time for headspace of drum within belljar containing VEI ............62

57. Hydrogen in drum of DEB test compared to system temperature in test vessel ........................6 63 


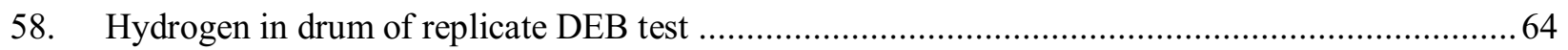

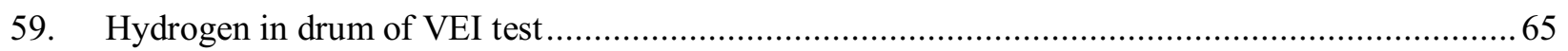

60. NMR spectra from unexposed getters, getters used in this set of tests, and samples of the two getters after they were saturated with hydrogen

\section{TABLES}

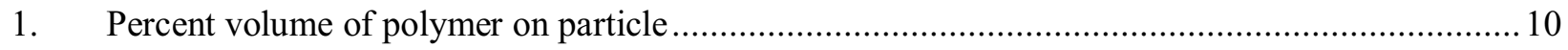

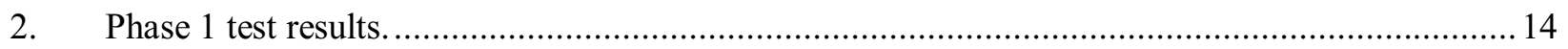



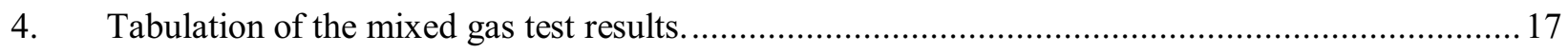

5. A listing of the getter samples sent to LANL for testing. ................................................. 18

6. Replicate samples and variability of hydrogen removal rate in DEB ......................................20

7. Comparison of hydrogen removal rate relative to theoretical and empirical hydrogen capacity of DEB.

8. Hydrogen removal rate for hydrogen getters in an atmosphere of $5 \% \mathrm{H}_{2}$ in nitrogen at temperatures of 160 to $23^{\circ} \mathrm{F}$

9. Hydrogen removal rate for uncoated DEB, polystyrene-coated DEB, and polybenzylmethacrylate-coated DEB in an atmosphere of $3 \% \mathrm{H}_{2}$ in air at temperatures of 160 to $-20^{\circ} \mathrm{F}$

10. Poisons for getter screening.

11. Effect of poisons on hydrogen removal rates of DEB and coated DEB at $77^{\circ} \mathrm{F}$ in an atmosphere of $5 \%$ hydrogen in nitrogen.....

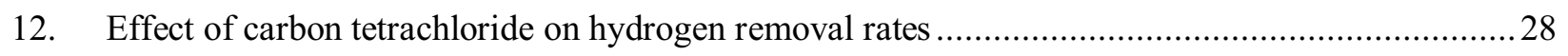

13. Comparison of hydrogen removal rates in the presence and absence of 1,000 ppm carbon tetrachloride.

14. Effect of poisons on hydrogen removal rates of uncoated DEB, polystyrene-coated DEB, and polybenzylmethacrylate-coated DEB at $77^{\circ} \mathrm{F}$ in an atmosphere of $3 \%$ hydrogen in air

15. Effect of carbon tetrachloride on hydrogen removal rates of uncoated DEB, polystyrenecoated DEB, and polybenzylmethacrylate-coated DEB at $160^{\circ} \mathrm{F}$ in an atmosphere of $3 \%$ hydrogen in air.

16. Effect of carbon tetrachloride plus carbon monoxide on hydrogen removal rates of uncoated DEB, polystyrene-coated DEB, and polybenzylmethacrylate-coated DEB at $77^{\circ} \mathrm{F}$ in an atmosphere of 5\% hydrogen in nitrogen. 
17. Effect of water vapor on hydrogen removal rates (mole $\mathrm{H}_{2} \mathrm{~s}^{-1} \mathrm{~kg}^{-1}$ ) of uncoated DEB, polystyrene-coated DEB, and polybenzylmethacrylate-coated DEB at $77^{\circ} \mathrm{F}$ in an atmosphere of $5 \%$ hydrogen in nitrogen

18. Effect of pressure on hydrogen removal rate for uncoated DEB (lot x245) and polystyrenecoated DEB.

19. Effect of radiation on hydrogen removal rate for uncoated DEB (lot $\mathrm{x} 245$ ) and polystyrenecoated DEB.

20. Hydrogen removal rate for polymer-zeolite getter in an atmosphere of $5 \% \mathrm{H}_{2}$ in nitrogen and $3 \% \mathrm{H}_{2}$ in air at temperatures of 160 to $-20^{\circ} \mathrm{F}$

21. Comparison of hydrogen removal rate determined for uncoated DEB (lot x245) and polystyrene-coated DEB by dynamic and static test methods.

22. Capacity data for DEB samples as determined by SRTC in the static test method

23. Phase 3 test plan matrix.

24. Hydrogen gas getter performance specification. ................................................................ 47

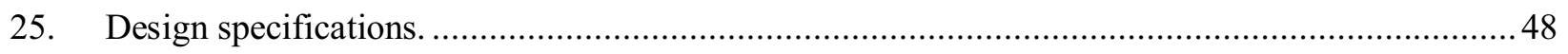

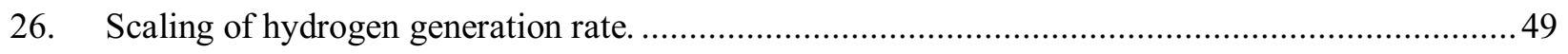

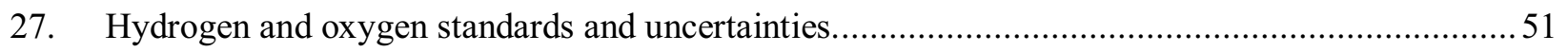

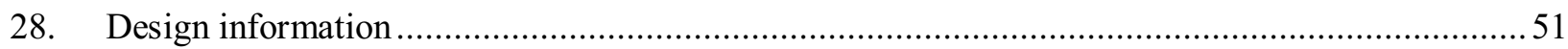

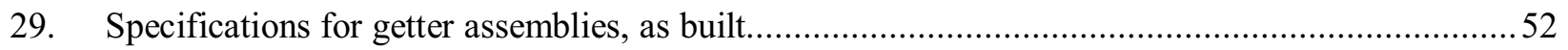

30. Summary of hydrogen introduced into drums of DEB and VEI tests.......................................54

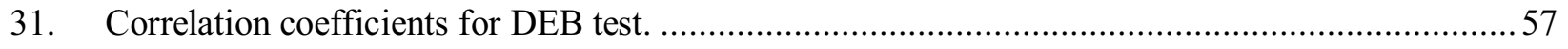

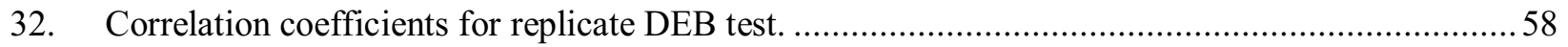






\section{ACRONYMS}

CH-TRU Contact-handled transuranic

CofC Certificate of Compliance

DEB 1,4-bis (phenylethynyl) benzene

DOE U.S. Department of Energy

INL Idaho National Laboratory

LANL Los Alamos National Laboratory

NRC U.S. Nuclear Regulatory Commission

PS Polystyrene

PVC Poly(vinylchloride)

SARP Safety Analysis Report for Packaging

TRU Transuranic

TRUPACT-II Transuranic Package Transporter-II

VOC Volatile organic compound

WIPP Waste Isolation Pilot Plant 


\section{Improved Hydrogen Gas Getters for TRU Waste-Final Report}

\section{INTRODUCTION}

This document reports the results of Phases 1, 2, and 3 testing of the "Improved Hydrogen gas getters for TRU Waste" program for DOE's Transuranic and Mixed Waste Focus Area (TMFA) carried out jointly by the Idaho National Laboratory (INL) and Los Alamos National Laboratory (LANL).

All of the getters being investigated by all parties in this getter program use a precious metal hydrogenation catalyst to chemically react free molecular hydrogen with some type of unsaturated organic/polymeric material. Early testing showed that certain chemicals reduced the activity of the catalyst enough to warrant the investigation of ways to protect the getter system from these poisons. The Phase 1 approach proposed, peer reviewed, and investigated by the INL/LANL group provides a semipermeable barrier that allows the hydrogen through to the getter and prevents the permeation of the poison. The results for the coated getter systems are reported in this document. Many polymers were used to encapsulate and protect the getter, 1,4-bis (phenylethynyl) benzene, or DEB, and its catalyst from poisons such as volatile organic compounds (VOCs). Phase 1 results indicated that there is no inherent reason why polymer-coated getters cannot work. The background of the project and Phase 1 results are described.

In Phase 2 tests were conducted to determine the actual gettering ability of the coated DEB getter particles. Once the upper limit of hydrogen production in the TRUPACT-II containers was agreed upon, tests were conducted on the as is and coated getters to see if they could remove the hydrogen fast enough to prevent its build up past the safe DOT stated levels. Tests were conducted in air, in nitrogen, and in the presence of organic vapor poisons. After extensive testing it was determined that the uncoated DEB getter had a high enough rate and capacity to meet the DOT requirements, so no coating was required.

Phase 3 focused upon larger scale testing to verify the results observed during the previous phases. The void space in the inner containment vessel (ICV) of a TRUPACT-II is 2.68 times greater than the volume occupied by the payload of seven 55-gallon drums. A GGTP-style bell jar and a drum equipped with a composite drum filter were scaled to these dimensions in order to test the getter assembly under conditions that represent deployment. Tests were conducted for 60 days utilizing both the DEB getter and a TRUGETTER (known as VEI) from Savannah River Technology Center. NMR spectra were used to analyze the changes in the double and triple bond content of the getters as a measure of their activity. Both getter systems preferentially start removing hydrogen by combining it with the oxygen in the atmosphere to form water. When the oxygen is depleted the getters then continue to remove hydrogen by saturating the double and triple bonds in the respective systems. The final results indicated that there was enough oxygen in the containers to remove all of the hydrogen over the specified time period at a rate fast enough to prevent any concentration build up. Therefore if one placed a palladium or platinum on carbon powder and a water absorber in the containers, that would remove enough of the hydrogen to allow the safe transport of the waste to the Waste Isolation Pilot Plant (WIPP) facility without the need for any actual organic/polymeric getter. 


\section{BACKGROUND}

\subsection{Transuranic Waste Transportation Problem}

The Transuranic Package Transporter-II (TRUPACT-II) was developed for the U.S. Department of Energy (DOE) primarily for shipment of contact-handled transuranic (CH-TRU) waste from DOE generator/storage sites to the Waste Isolation Pilot Plant. The TRUPACT-II was designed in accordance with the requirements for Type B packaging found in Title 10, Code of Federal Register Part 71. The Nuclear Regulatory Commission (NRC) granted a certificate of compliance (CofC) for the TRUPACT-II in 1989. The CofC specifies limits on the authorized payload in a TRUPACT-II to ensure safety during transport. These limits are based on the results of testing and analyses, which were documented in the TRUPACT-II Safety Analysis Report for Packaging (SARP) and submitted by the DOE to the NRC (NRC 1996).

The NRC has imposed a flammable gas (i.e., hydrogen) concentration limit on CH-TRU waste transported using the TRUPACT-II to minimize the potential for loss of containment during transport. This limit is set at the lower explosive limit of $5 \mathrm{vol} \%$ of hydrogen in air. Accident scenarios and the resulting safety analysis, developed as part of the TRUPACT-II SARP, require that this limit be met for a period of 60 days. The NRC limit of $5 \mathrm{vol} \%$ hydrogen applies to the innermost layer of confinement within a drum or standard waste box.

Hydrogen gas generation and accumulation is the result of alpha radiolysis of hydrogenous waste and packaging materials coupled within waste packaging configurations. The combination of high activity wastes with multiple layers of packaging results in significant quantities of wastes that do not meet transportation requirements for hydrogen gas concentration. Payload expansion to support the shipment of high activity wastes drives the use of hydrogen gas getters in the TRUPACT-II. Hydrogen gas getters are solid materials that irreversibly remove hydrogen from the gas phase. One potential solution for a waste drum over 0.5 watts is to use a getter to allow drum shipment. These wattage levels are seen primarily in two waste types: the plutonium-238 (heat source plutonium) wastes at LANL and Savannah River Site, and americium-contaminated wastes at Hanford, INL, Oak Ridge National Laboratory, and Rocky Flats Environmental Technology Site.

Another solution for these high activity wastes is to repackage the waste to a configuration that has two layers of confinement with filter vents on the bagging material. The addition of a hydrogen getter material then allows for up to 5 grams of heat source plutonium in the drum. This scenario results in minimal volume expansion for these waste streams.

\subsection{Technology Concept and Function}

Preferred hydrogen getters are solid materials that scavenge hydrogen $\left(\mathrm{H}_{2}\right)$ from the gas Phase and chemically and irreversibly bind it in the solid state. 1,4-bis (phenylethynyl)benzene (DEB) (Figure 1) belongs to a class of compounds called alkynes, which are characterized by the presence of carbon-carbon triple bonds. The triply-bonded carbon atoms in alkyne compounds will, in the presence of suitable catalysts such as palladium $(\mathrm{Pd})$, irreversibly react with hydrogen to form the corresponding saturated alkane compounds. DEB, as a hydrogen getter, does not require the presence of oxygen to be effective. DEB does not produce water as a reaction product when reacting with the hydrogen. However, in the presence of oxygen, recombination reactions on the Pd catalyst will produce water in addition to hydrogenating the dialkyne. Thus, the material acts as both a getter and recombiner in the presence of air. The getters also have been found to be hygroscopic in air environments. Thus, exposure of the getter to oxygen and water needs to be minimized. 


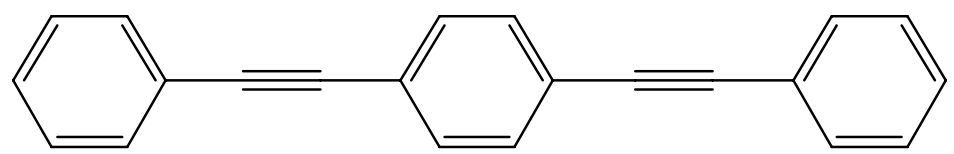

Figure 1. Structure of 1,4-bis (phenylethynyl) benzene.

Many potential hydrogen gettering compounds and formulations have been tested (Sheppod et al. 1989; Smith and Sheppod 1990). The best performance has been achieved with DEB, a nontoxic, nonmutagenic, solid. Because DEB is a dialkyne (containing two triple bonds), one mole of DEB reacts with 4 moles of hydrogen ( 2 moles of hydrogen react to form the corresponding dialkene, an additional 2 moles of hydrogen react to form the dialkane). DEB melts at $+179^{\circ} \mathrm{C}$, whereas the fully hydrogenated product melts at $+87^{\circ} \mathrm{C}$. The standard formulation for the "DEB getter" is a mixture of $75 \%$ DEB and $25 \%$ carbon catalyst ( $5 \% \mathrm{Pd}$ on carbon). The production process is quite simple: the two materials are mixed together in a ceramic jar mill for several hours after which the DEB getter is ready for use. It has been shown to be stable in the absence of hydrogen for up to 18 months (at $+70^{\circ} \mathrm{C}$, under $\mathrm{N}_{2}$ ). The uncoated getter granules are shown in Figure 2.

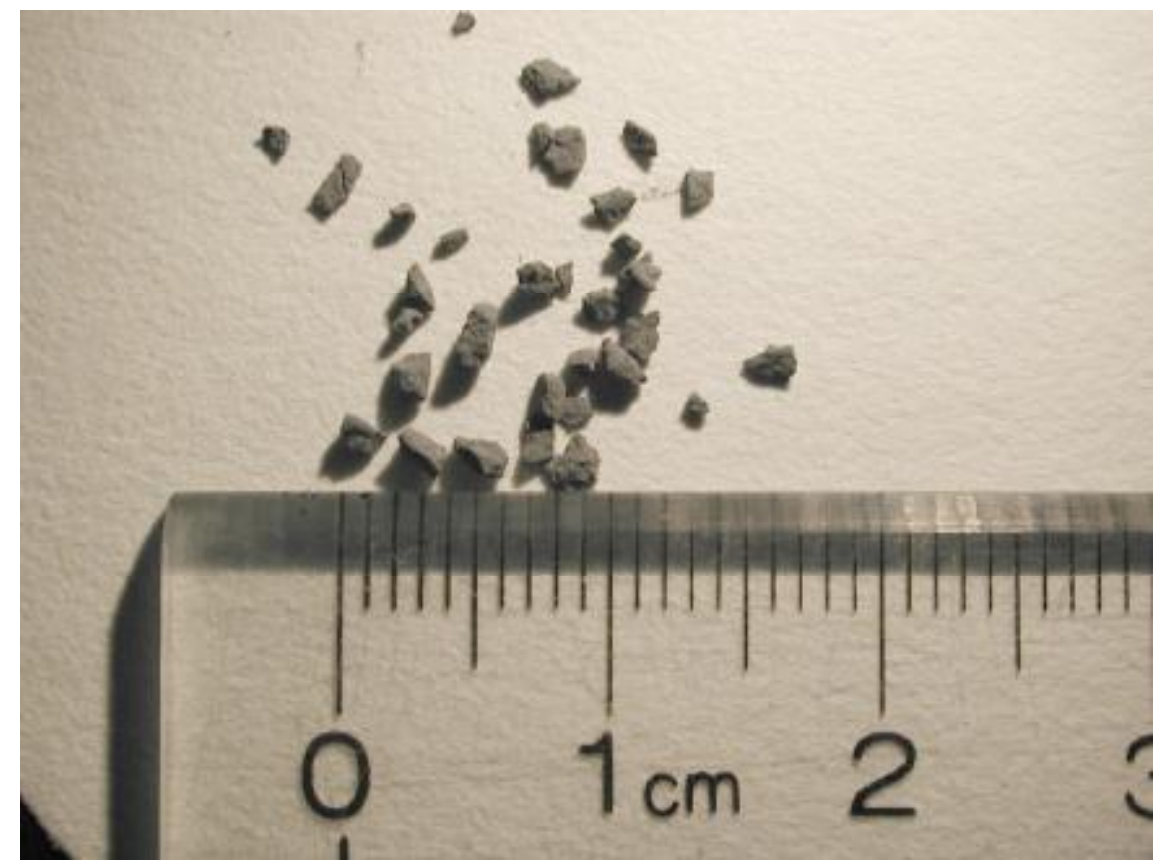

Figure 2. Photograph of the uncoated DEB getter (X20).

The DEB getter reacts rapidly, exothermically $\left(\sim 30 \mathrm{Kcal} / \mathrm{mole}_{2}\right)$, and irreversibly with hydrogen. It has a capacity of 240 to $330 \mathrm{~cm}^{3}$ hydrogen per gram. The reaction is nearly stoichiometric and proceeds to $>90 \%$ of the theoretical capacity. In experiments in a nitrogen atmosphere with a hydrogen addition rate of about $10^{-3} \mathrm{~cm}^{3} / \mathrm{sec}$, the hydrogen concentration was maintained at less than $5 \mathrm{ppm}$ until the getter had reacted to $>90 \%$ of its theoretical capacity. The reaction rate with hydrogen is temperature-dependent and proceeds more rapidly as the temperature is increased.

In FY 1998, experiments were performed at LANL to investigate whether other compounds expected to be present in the headspace of TRU waste containers would affect the performance of the DEB getter. These tests showed that DEB was unaffected by toluene, hexane, acetone and methanol. However, carbon monoxide (CO) and several chlorinated volatile organic compounds (VOCs) (e.g. 
carbon tetrachloride, trichloroethylene, trichloroethane, chloroform, and methylene chloride) did inhibit the reaction of hydrogen with DEB. The figure of merit for hydrogen removal in the inner containment volume of the TRUPACT-II container had not been determined at that time, therefore, the impact of VOCs on DEB reaction could not be quantitatively assessed. It was determined, at the time, that a solution to the poisoning problem must be found for DEB to maintain its effectiveness for removal of hydrogen from TRU waste. Microencapsulation of the DEB particles was proposed, peer reviewed, and studies initiated to evaluate coated DEB as a potential solution to this pressing problem for DOE.

\subsection{Current State of Development}

The DEB-Pd/C formulation has been successfully incorporated into several forms, including powder, pellets, shaped polyethylene composite, a urethane adhesive film, and a castable room temperature-vulcanizing (RTV) silicone. The material has been in regular production for use in DOE nuclear weapons components and assemblies since 1977. However, the needs of these other applications are quite different from the TRUPACT II.

Microencapsulation technology is not new. The technology forms the basis for many of the commercial time- or pressure-released components found in the food, drug, perfume, and agricultural industries. Commercial applications of microencapsulation include carbonless carbon paper, time-release pharmaceuticals, herbicides, scents, catalysts, and polymerization initiators. Application of microencapsulation technology to hydrogen getters for the nuclear industry is a new concept and is the reason for the Phase 1 project.

\subsection{Technology Improvements Needed}

There are two aspects to achieving the desired Phase 1 goal. One is the development of useable microencapsulation methods and techniques and the other is performing the microencapsulation with materials that possess the desired permeation properties. Investigating both of these areas is essential because new materials are needed to meet the requirements of the TMFA. As possible encapsulating materials were identified, it was necessary to develop the methods needed to apply them (either as single layers or multiple layers) surrounding the getter. It was also necessary to measure the permeabilities of the as-produced layers. The technology improvements gained from this work made it possible to deploy the hydrogen getters in many applications and made it possible to safely transport materials in the TRUPACT-II containers. 


\section{PHASE 1}

The thrust of this project is to microencapsulate the DEB particles in hydrogen-permeable polymer coatings. Our approach has been three-phased: (1) choose the best coating material(s) based on hydrogen permeability tests, (2) investigate methods for encapsulating the DEB/Pd-C containing particles and, (3) transfer the formation process to a larger scale. Phase 1 was a feasibility study consisting of two prime components: (1) can the irregular shaped getter particles be coated with thin dense films of hydrogen permeable membranes?, and (2) will the coated particles show the needed gettering activity level to function in the TRUPACT-II containers? Phase 1 objectives were achieved. Solution and spray methods were used for encapsulation; spray coating was found to be more efficient and versatile than solution methods. Permeabilities of several gases were measured by the time-lag method for a variety of polymers. Three polymers, polyvinyl chloride (PVC), polystyrene, and polysulfone, were chosen as the initial encapsulation materials based on their hydrogen permeabilities and on ease of processing. Eight encapsulated DEB samples, containing PVC, polystyrene, both PVC and polystyrene, or polysulfone, were tested at LANL for their hydrogen getter properties in a dynamic (flowing) system. The polystyrenecontaining materials performed the best.

\subsection{Polymer Permeability}

\subsubsection{Pure Gas Testing}

The first task of Phase 1 was to select potentially useful polymers. Membranes having thicknesses in the range of 50 to 200 microns were tested in a pure (single) gas facility at the INL (Figure 3 ). The primary focus of the pure gas test screening has been to determine if the polymers being considered have a $\mathrm{H}_{2}$ permeability high enough to allow $\mathrm{H}_{2}$ to pass through the polymer at the same rate as it is produced, $\sim 5 \times 10^{-10} \mathrm{~cm} \times \mathrm{cm}^{3} / \mathrm{sec} \times \mathrm{cm}^{2} \mathrm{~cm} \mathrm{Hg}$. Each polymer was initially tested using six gases that might be seen in a container: $\mathrm{He}, \mathrm{H}_{2}, \mathrm{~N}_{2}, \mathrm{O}_{2}, \mathrm{CH}_{4}$, and $\mathrm{CO}_{2}$. All of the pure gas tests were performed at $30^{\circ} \mathrm{C}$ and 30 psi feed gas pressure. Figure 3 shows the set-up for the tests. A membrane is evacuated on both sides, then isolated, then one side is exposed to a feed gas, and the pressure increase as a function of time on the permeate side gives the information necessary to calculate the permeabilities. The results of all Phase 1 and 2 pure gas testing are given later in the Phase 2 results. Some of the later polymers were tested against a reduced set of gases. Several polymers met the requirements.

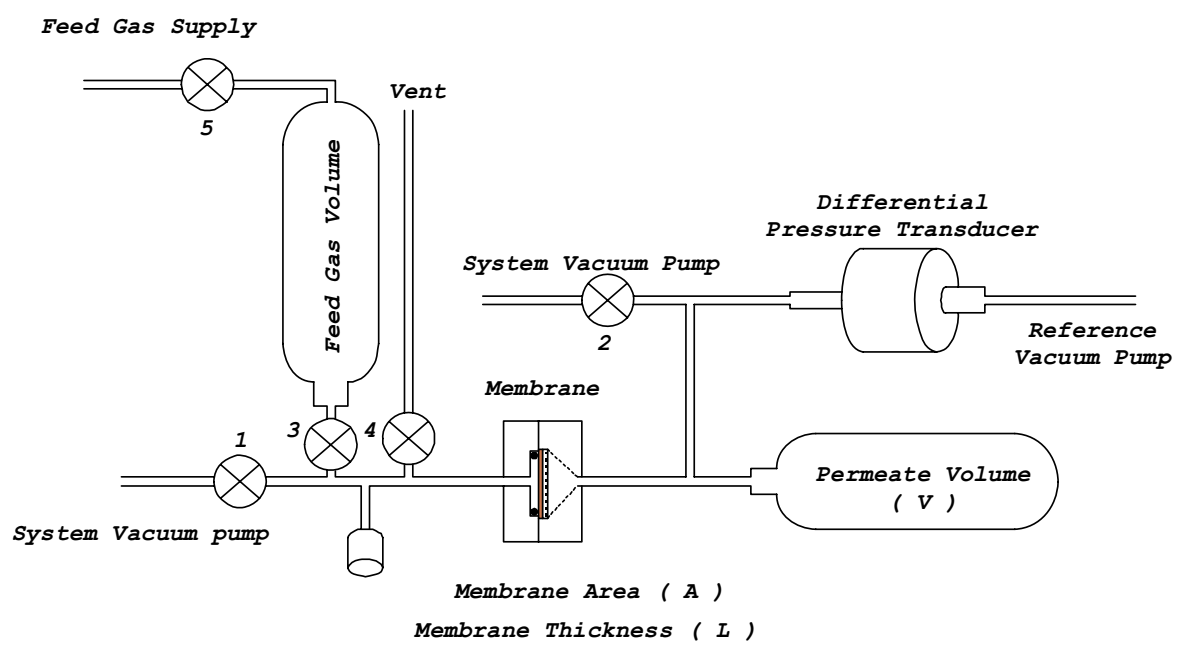

Figure 3. Schematic of the pure gas screening test apparatus. 


\subsubsection{Mixed Gas Testing}

The mixed gas screening test differs from the pure gas test in two ways. (1) It is a flowing test where the pure gas is a stagnant test, and (2) the feed gas contains mixtures of gases. In the mixed gas experiments a pressurized feed gas flows at a constant rate over the surface of the membrane. Any permeant gases are entrained in a sweep gas that transports them to a set of gas chromatographs (GC) for analysis. The schematic is shown in Figure 4. Since some of the screening studies were continued into Phase 2, all of the mixed gas test results are reported in the Phase 2 section. The importance of the mixed gas test is that it allows the use of a more realistic set of gases, including some of the suspected catalyst poisons.

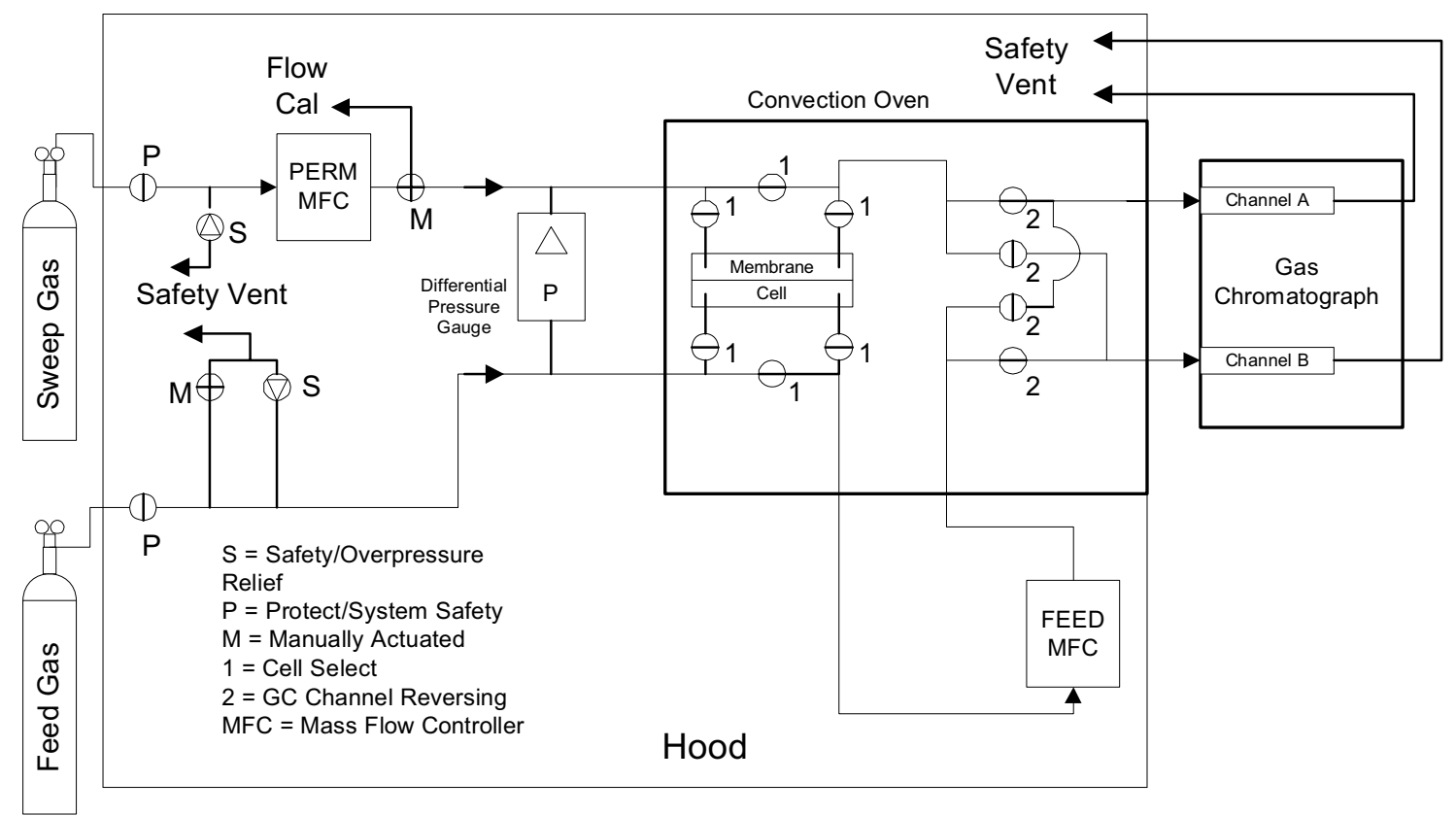

Figure 4. Schematic of the mixed gas test system.

\subsection{Coating Technique}

All method development experiments were carried out using carbon particles in place of the more expensive DEB particles. Carbon is the support for the catalyst in the DEB particles, making activated carbon an excellent test case while the coating techniques were developed. Spray coating is a convenient method, but it is limited to polymers that are soluble in volatile solvents. Melt thermoforming offers another technique for polymers that are not soluble in the volatile solvents necessary for spray forming.

\subsubsection{Solution Methods}

Complex coacervation was the only solution coating technique attempted. gelatin and gum arabic were used as the coating material, with glutaric dialdehyde as the crosslinking agent. A large amount of polymer was needed to completely coat the particles due to microsphere formation. Solution techniques are generally used to encapsulate a liquid with a microsphere. After a microsphere is formed (with no particle inside), that material can no longer coat a solid particle. When a large excess of polymer was not used, the particles were not completely coated. Spray coating was being investigated simultaneously, and was found to be much more efficient and versatile for coating solids, so solution methods were not continued. 


\subsubsection{Spray Coating}

Spray coating has several advantages over solution methods for this application. Although DEB is not very soluble, it is slightly soluble in specific solvents, such as toluene and acetone. Spray coating does not allow prolonged exposure of the DEB to the solvent, preventing DEB from dissolving and being separated from the catalyst and support. Spray coating also has the advantage of versatility. Solution methods are much more restricted in the polymers that can be applied. For example, complex coacervation requires a positive and a negative component (gelatin and gum arabic, respectively). Also, optimal conditions for obtaining a specific coating thickness and for separating and drying the particles without clumping are harder to determine for solution methods. Spray coating dries the particles while the polymer is being applied, and, in general, if a polymer can be dissolved it can be spray coated.

Commercial spray coaters require large quantities of material, such as $>500 \mathrm{~g}$. The ability to coat gram quantities was needed for this project, so a small-scale spray coater was constructed. Two types of spray coaters are used industrially. In one type, the solution is sprayed down onto a fluidized bed from the top; in the other, the solution is sprayed from the bottom (the Wurster Spray Coater, Figure 5). Both setups were constructed to coat the small quantities of materials needed for testing. The top-down spray system coated the particles, but not very efficiently and only with very thin coatings. The Wurster-type coater was found to be very efficient, and could quickly coat up to 5 gram quantities. The spray coater is pictured in Figure 6.



Figure 5. Schematic diagram of Wurster-type coater. The aspirator assembly introduces the polymer solution as a fine mist, while the fluidized bed gas flow keeps the particles circulating through the mist. The circulation keeps the particles from sticking together, while the combined gas flows quickly evaporate the solvent. 

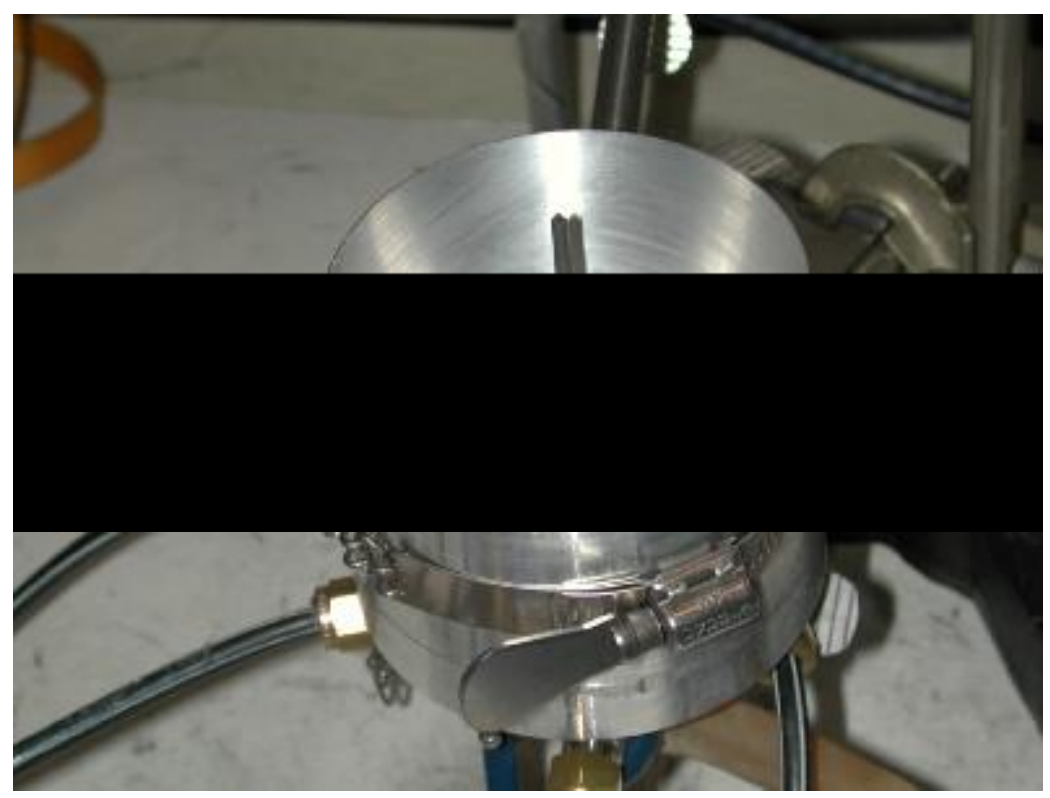

Figure 6. Picture of spray coater. The plastic tube has been removed for clarity.

\subsection{Characterization}

\subsubsection{Scanning Electron Microscopy (SEM)}

The most direct way to examine the physical nature of the coated particles was to look at them under the SEM. Some of the particles were used as produced and others were cut in half so the profile of the coating could be used to measure the thickness and the continuity of the membrane, Figure 7.

\subsubsection{Optical Fluorescence Microscopy}

It is important to be able to check the continuity of the spray coated polymer layer. Optical fluorescence microscopy worked well for this purpose. A small quantity of fluorescein was dissolved into a polymer solution. This mixture was spray coated onto the particles in the usual fashion. Next, the reddish appearing particles were potted in an epoxy and a section containing the coated particles was cut through and polished. Finally, the prepared sample was placed under an optical fluorescence microscope
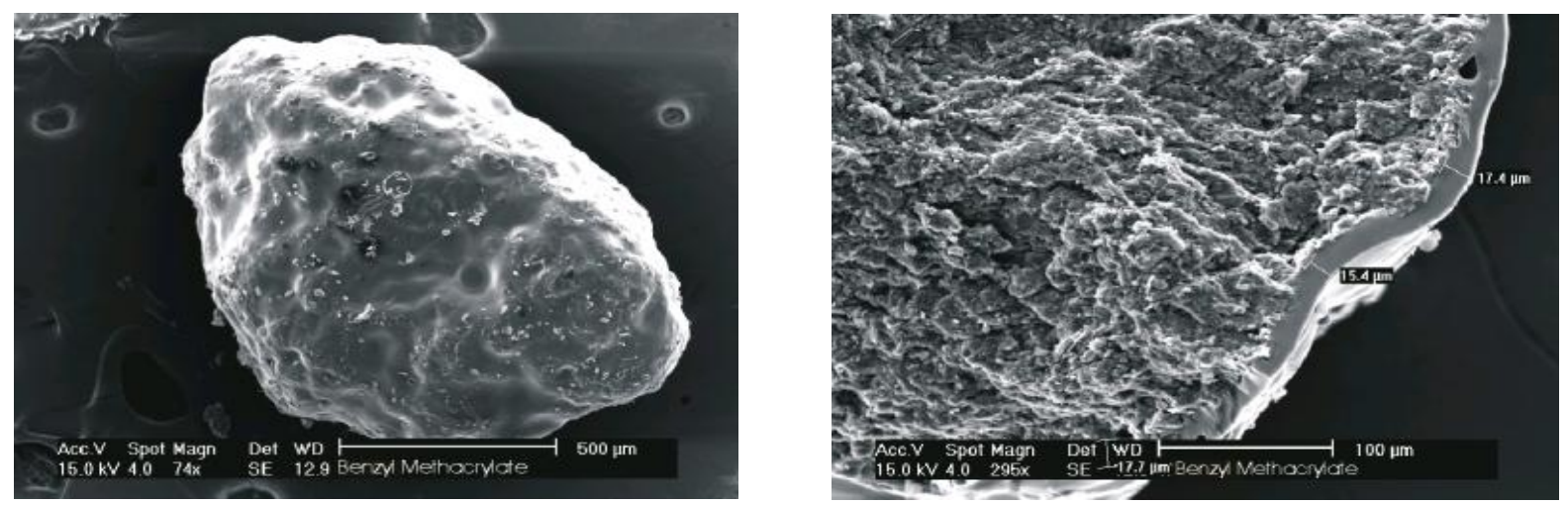

Figure 7. SEM photographs of DEB coated with polybenzyl methacrylate. The image on the left shows an entire coated particle and the image on the right shows a particle that has been cut in half. 
and with the proper filters and lenses the coating was subjected to a wavelength of light that caused the dye containing polymer coating to fluoresce the photograph in Figure 8 was the resulting image. It shows the nicely coated, irregular shaped surface of the DEB particle.

\subsection{3 $\mathrm{H}_{2}$ Getter Properties of DEB Samples}

Eight samples were sent to LANL and tested in Phase 1. There were differences among the coated materials showing the coating was involved. Some were unsuitable and others worked fine, indicating the approach was valid and proceeding to Phase 2 was appropriate.

\subsubsection{Coating Thickness}

The percent by volume of polymer on the DEB particle is needed to accurately determine the efficiency of the polymer/DEB combination, and is determined from the coating thickness. The hydrogen capture efficiency (total amount of hydrogen scavenged) will depend on the amount of DEB, so the polymer weight must be subtracted from the sample weight. To ensure that the polymer is not interfering with the hydrogen scavenging capability of the DEB, the efficiency must be determined for each sample. The rate of hydrogen scavenging will vary depending on the coating and the thickness. Assuming the efficiency of the DEB is not decreased, the rate of hydrogen scavenging will be the performance indicator for the polymer coatings. Most of the coatings were in the 5 to 40 micron range.

Coating thickness was determined using SEM. For each sample, at least three measurements were used to determine the average thickness. If one measurement was significantly different from the others, more measurements were used for the average. Table 1 lists the $\%$ coating by volume for each sample, along with the numbers used to calculate the $\%$ volume. The particle size used in the calculations is $700 \mu \mathrm{m}$ (particle volume $=180,000,000 \mu \mathrm{m}^{3}$ ). The average particle size was determined with a sonic sifter, using 8 sieves between 300 and $1180 \mu \mathrm{m}$. The calculations assume spherical particles (see Figure 9).

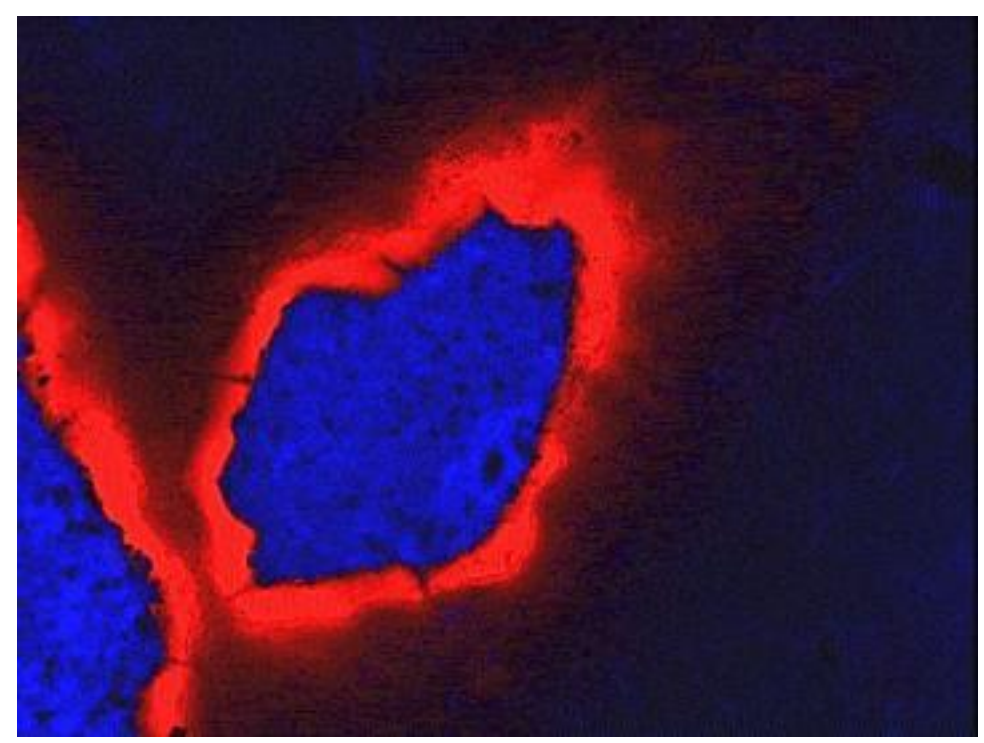

Figure 8. Optical fluorescence microphotograph of a polymer encapsulated DEB particle. The orange/red is the polymer coating fluorescing and the blue is the DEB fluorescing. 
Table 1. Percent volume of polymer on particle.

\begin{tabular}{|c|c|c|c|c|c|c|}
\hline Sample $^{\mathrm{a}}$ Number. & $\begin{array}{c}\text { Average Coating } \\
\text { Thickness } \\
(\mu \mathrm{m})\end{array}$ & $\begin{array}{c}\mathrm{R}_{1} \\
(\mu \mathrm{m}) \\
\end{array}$ & $\begin{array}{c}\mathrm{R}_{2} \\
(\mu \mathrm{m}) \\
\end{array}$ & $\begin{array}{c}\text { Coating Volume } \\
\left(\mu \mathrm{m}^{3}\right)\end{array}$ & $\begin{array}{c}\text { Total Volume } \\
\left(\mu \mathrm{m}^{3}\right)\end{array}$ & $\begin{array}{c}\% \text { Coating } \\
\text { Volume }\end{array}$ \\
\hline PS (25 ml) & -9.3 & 359.3 & 350 & 14763910 & 194267244 & 7.6 \\
\hline PS $(50 \mathrm{ml})$ & 25.1 & 375.1 & 350 & 41454589 & 220957922 & 18.8 \\
\hline PVC (50 ml) & 16.6 & 366.6 & 350 & 26715011 & 206218344 & 13.0 \\
\hline PVC (100 ml) & 27.8 & 377.8 & 350 & 46260435 & 225763768 & 20.5 \\
\hline $\begin{array}{l}\mathrm{PVC} / \mathrm{PS}(50 \mathrm{ml} \\
\text { mixture) }\end{array}$ & 15.9 & 365.9 & 350 & 25591922 & 205095255 & 12.5 \\
\hline $\begin{array}{l}\text { PVC layer then } \\
\text { PS layer }\end{array}$ & 32.3 & 382.3 & 350 & 54362982 & 233866315 & 23.2 \\
\hline $\begin{array}{l}\text { PS layer then } \\
\text { PVC layer }\end{array}$ & 39.8 & 389.8 & 350 & 68527287 & 248030620 & 27.6 \\
\hline $\begin{array}{l}\text { Polysulfone } \\
(50 \mathrm{ml})\end{array}$ & 12.8 & 362.8 & 350 & 20423101 & 199926434 & 10.2 \\
\hline
\end{tabular}

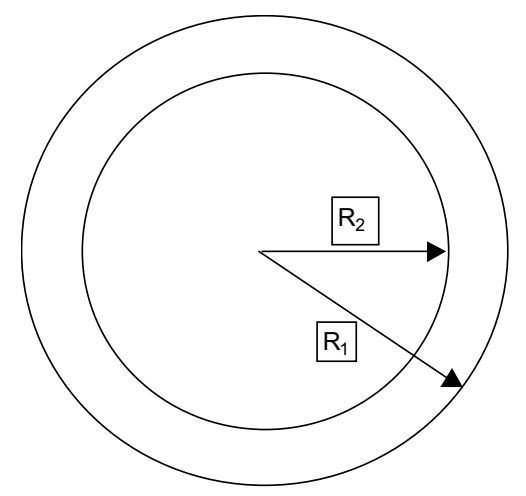

Figure 9. Particle model for calculations.

\subsection{Phase 1 LANL Testing Results}

Dynamic testing is performed by flowing a gas mixture (typically $5 \%$ hydrogen in nitrogen) over a sample of the getter material at a constant temperature. A photograph of the experimental set up appears in Figure 10. The concentration of the hydrogen passing out of the system as a function of time is recorded. When the experiment is initiated using the uncoated getter, a rapid rise in hydrogen is observed first in the outlet gas (Figure 11, the time axis is from right to left). This reaches a peak after about 5 minutes and then the concentration starts to decline to a minimum followed by a long, slow, gradual increase in concentration that asymptotically approaches the concentration of the inlet gas. The interpretation is that the initial peak represents an activation or absorption step wherein hydrogen is being loaded onto the catalyst surface. When enough hydrogen gets loaded, the reaction rate with the getter is faster than the absorption kinetics and the concentration in the exit gas stream declines to a minimum. The concentration of hydrogen in the exit gas stream gradually approaches the concentration of the inlet gas as the getter is consumed and the reaction rate declines. 


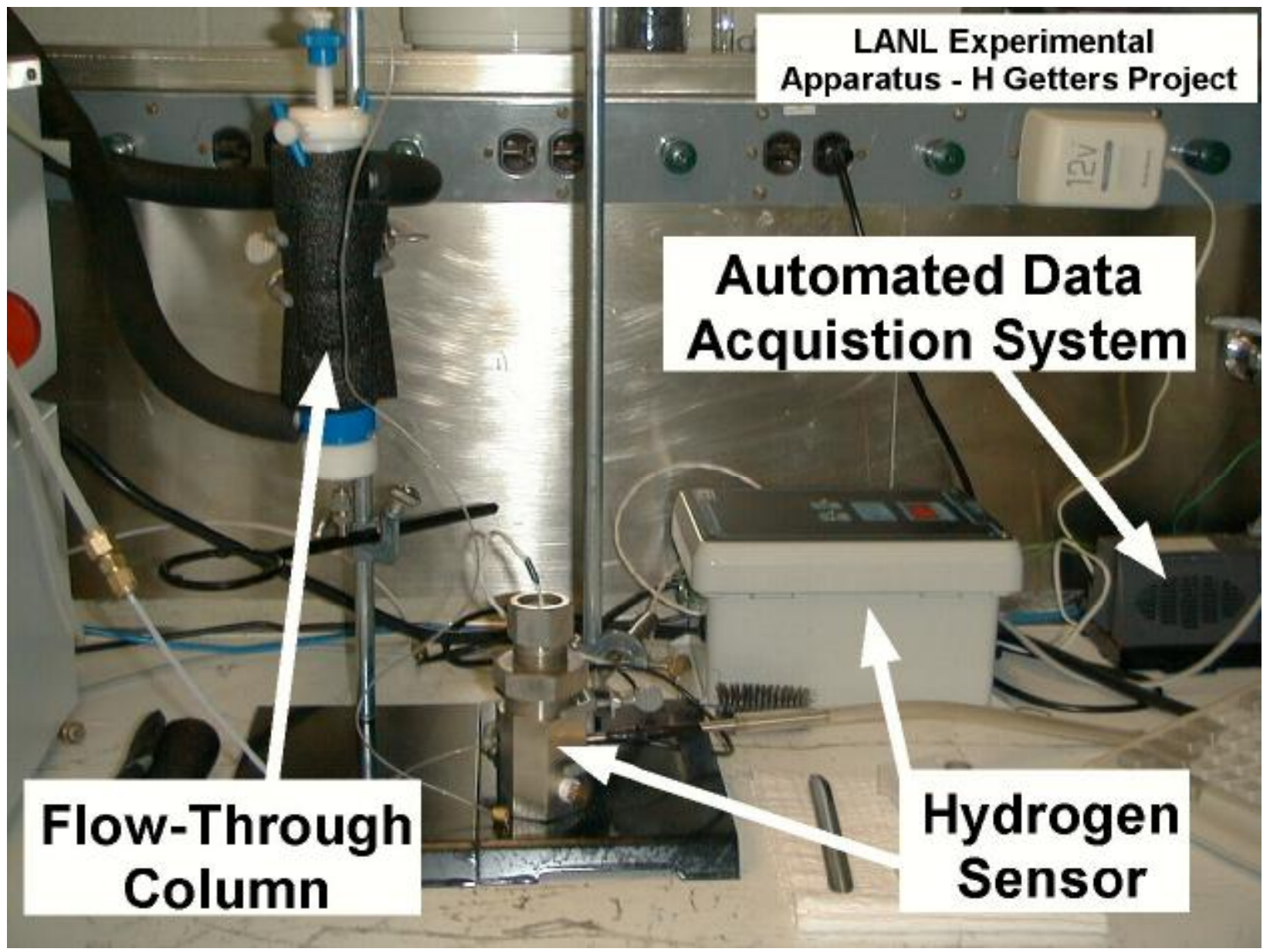

Figure 10. Photograph of the LANL getter testing apparatus. The automated data acquisition system that is pictured was installed during Phase 2 Testing. A chart recording system was used in Phase 1.

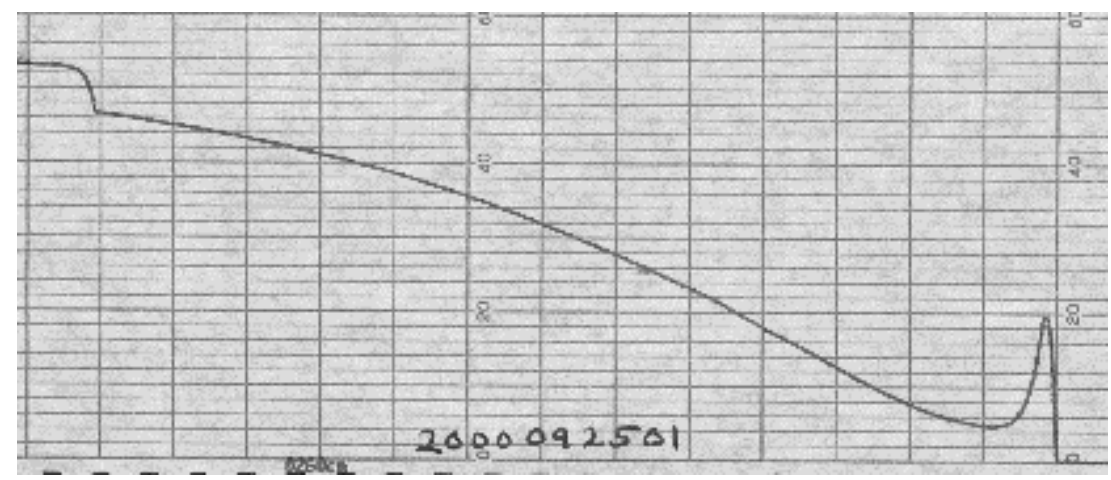

Figure 11. Uncoated getter response in dynamic testing. The time axis is from right to left; each division on the chart paper is 10 minutes. The initial peak can be seen, followed by the gradual increase in hydrogen concentration as time goes by. The final increase at the left end of the chart is where the operator directs the input gas directly into the detector for calibration. 
To evaluate the performance of the coated getters, a parameter called T50 was calculated from a strip chart record as shown in Figure 11. T50 is defined as the time required for one gram of material to react with $50 \%$ of its stoichiometric capacity when exposed to a gas mixture of $5 \%$ hydrogen in nitrogen flowing through a column of the getter material at $10 \mathrm{~cm}^{3}$-atm/min at constant temperature. The strip chart is optically scanned and digitized. The cumulative amount of hydrogen reacted as a function of time is calculated and T50 is determined from the mass of the sample and the known capacity of DEB for hydrogen $\left(241 \mathrm{~cm}^{3}\right.$-atm $\mathrm{H}_{2} /$ gram $)$.

The plot for polystyrene (PS) coated getter reacting with hydrogen, Figure 12, has the same overall shape and features as the plot for the uncoated getter but the time frame is longer. This reflects the fact that the coating slows the overall process, but does not change the final outcome.

The plot for hydrogen reacting with a PVC-coated getter material, Figure 13, is substantially different from the previous two. Notice that at the start of the experiment the concentration of the hydrogen increases rapidly so that in just a few minutes it has reached the $\mathrm{H}_{2}$ inlet concentration, indicating that the PVC-coated material is unsuitable for this application.

The hydrogen permeability of PS is about 25 whereas that of PVC is about 6 . The difference in the permeabilities may, in part, be due to the differences in the morphologies of the polymers, to their different densities (the more permeable PS has a density of approximately 1.1 while that of PVC is 1.4), or to the effectiveness of the coatings.

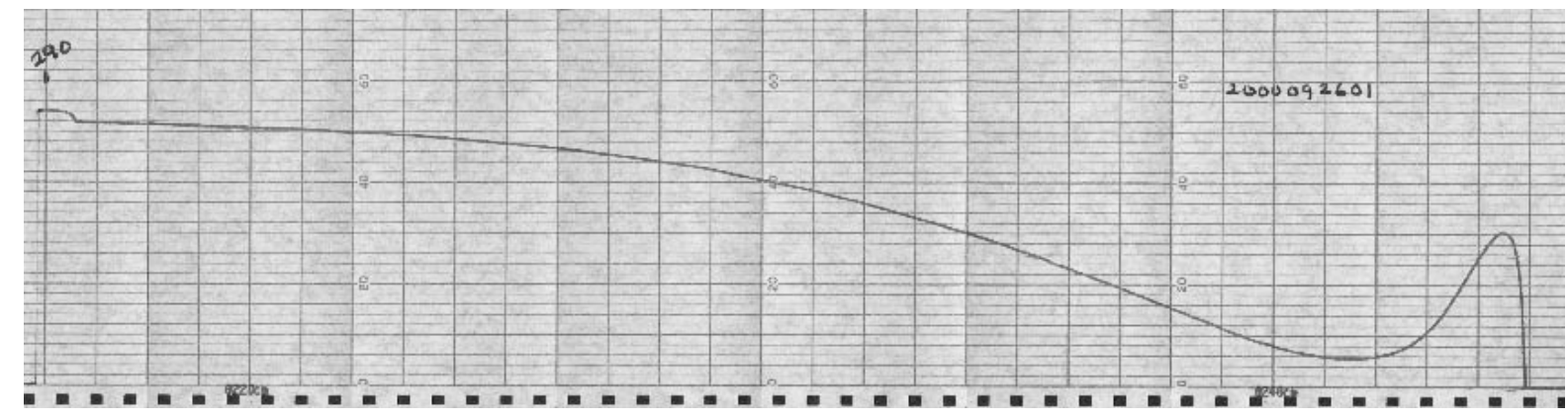

Figure 12. Polystyrene coated getter in dynamic testing. Time axis is from right to left.

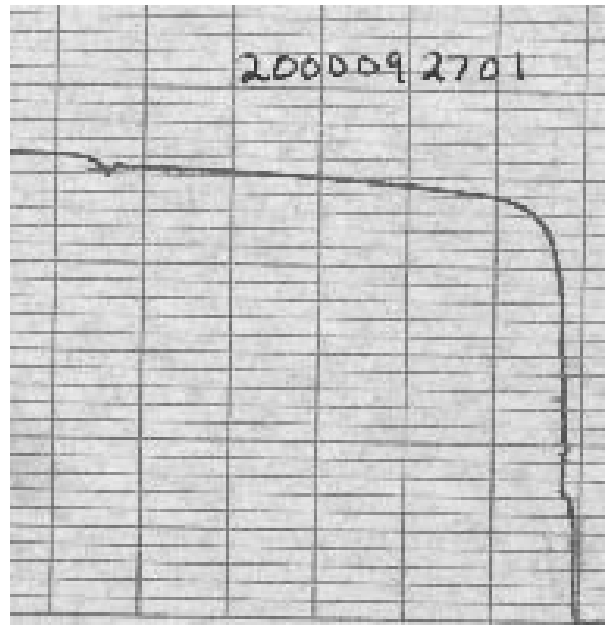

Figure 13. Poly (vinylchloride) coated getter in dynamic testing. Time axis is from right to left. 
A complete test consists of two experimental runs, a Control Run and a Test Run. The Control Run exposes the material to a mixture of $5 \% \mathrm{H}_{2}$ in $\mathrm{N}_{2}$ with no $\mathrm{CCl}_{4}$. The Test Run exposes the material to a mixture of $\mathrm{CCl}_{4}$ vapors in $5 \% \mathrm{H}_{2}$ in $\mathrm{N}_{2}$. Comparison of the $\mathrm{T} 50$ values for each run shows the effect of the coating on hydrogen gettering performance in the presence of a known poison, $\mathrm{CCl}_{4}$.

The thinnest coating of PVC (i.e. materials \#3 or \#5 in Table 1) was sufficient to prevent any permeation of hydrogen through to the active getter material and yielded curves such as can be seen in Figure 13. Experiments conducted at both 20 and $40^{\circ} \mathrm{C}$ obtained the same result. No further tests were conducted with PVC containing materials.

All of the experiments discussed above were conducted with a gas mixture of hydrogen in nitrogen. In this environment, the only reaction mechanism removing hydrogen is addition of hydrogen atoms across the unsaturated bonds of the DEB molecule. In a hydrogen-air mixture, the addition reaction is supplemented by the catalytic recombination reaction forming water. We estimate that in an air environment, about $13 \%$ of the hydrogen reacting with DEB is removed via the recombination reaction and the remaining $87 \%$ undergoes the addition reaction. Experiments showed that the recombination reaction is also rapidly poisoned by $\mathrm{CCl}_{4}$. A summary of tests performed in Phase 1 is presented in Table 2 . 


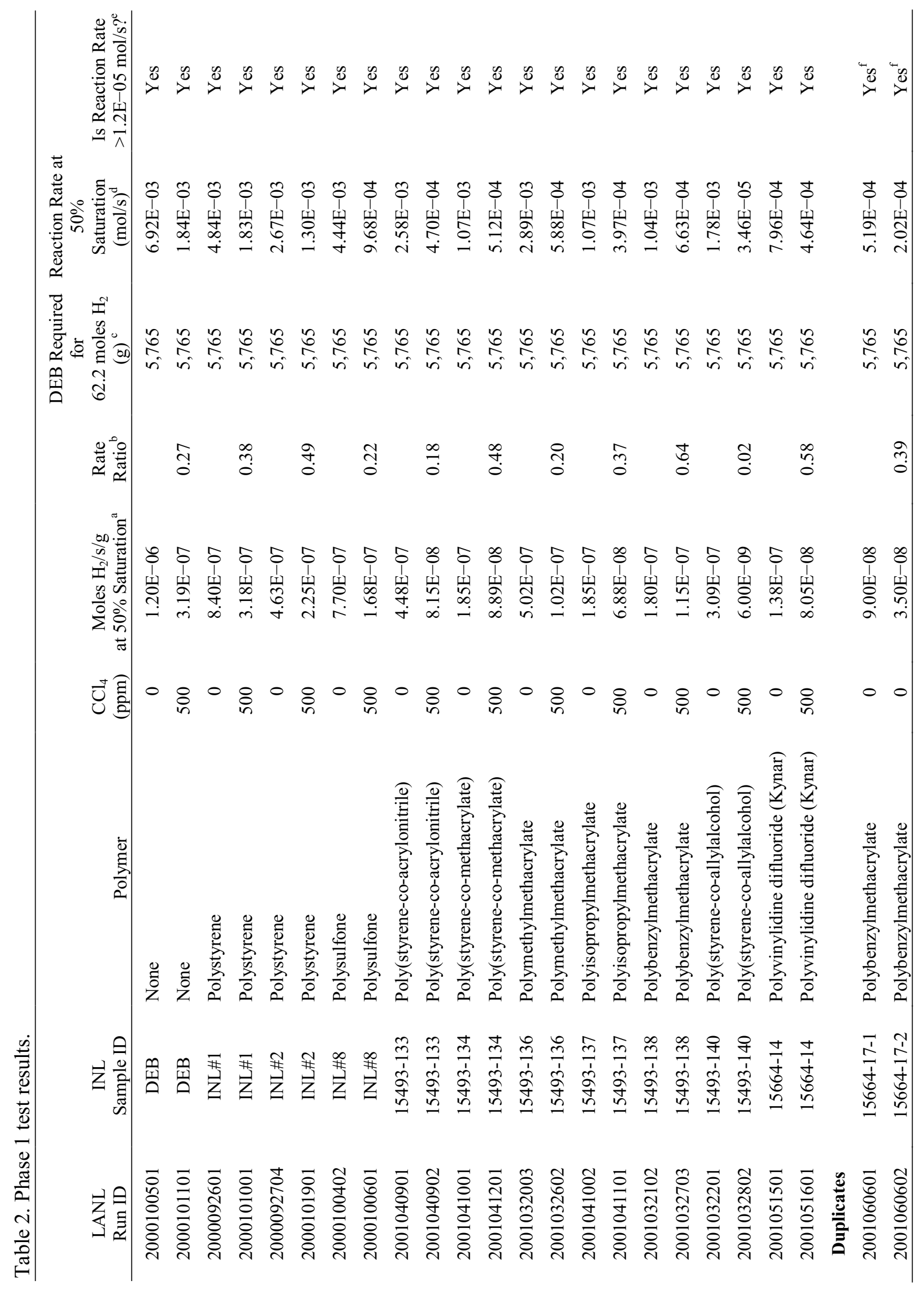




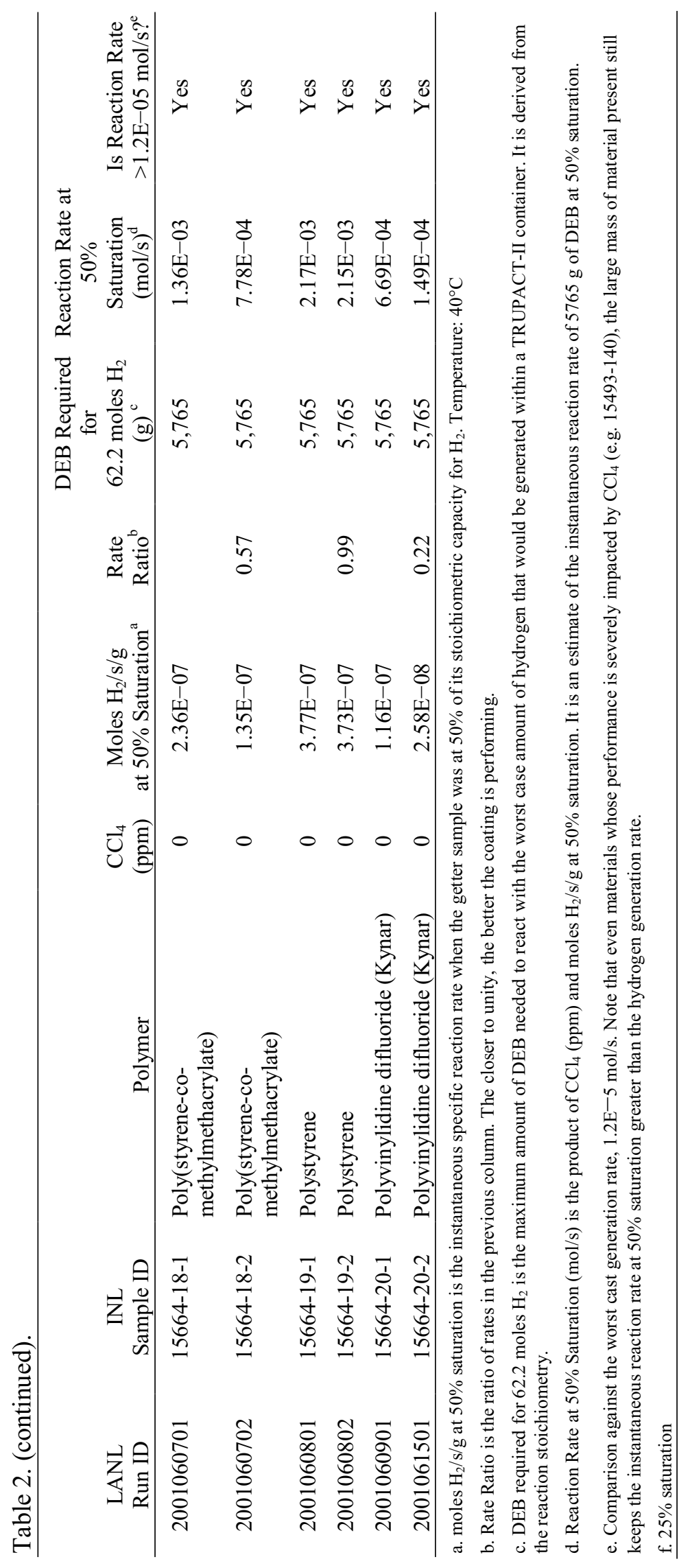




\section{PHASE 2}

In Phase 2 tests were conducted to determine the actual gettering ability of the coated DEB getter particles. Once the upper limit of hydrogen production in the TRUPACT containers was agreed upon, tests were conducted on the as is and coated getters to see if they could remove the hydrogen fast enough to prevent its build up past the safe DOT stated levels. Tests were conducted in air, in nitrogen, and in the presence of organic vapor poisons. After extensive testing it was determined that the uncoated DEB getter had a high enough rate and capacity to meet the DOT requirements. So no coating was required.

\subsection{INL Screening Test Results}

Table 3 summarizes the pure gas test screening. A wide variety of hydrogen permeabilities were observed. These tests were performed at $30^{\circ} \mathrm{C}$.

Table 3. Hydrogen-getter polymer testing summary.

\begin{tabular}{|c|c|c|c|c|c|c|}
\hline \multirow[b]{2}{*}{ Polymer } & \multicolumn{6}{|c|}{$\begin{array}{r}\text { Permeability } \\
\text { (barrers, or } \times 10^{-10} \mathrm{~cm} \times \mathrm{cm}^{3} /[\mathrm{se}\end{array}$} \\
\hline & $\mathrm{H}_{2}$ & $\mathrm{He}$ & $\mathrm{N}_{2}$ & $\mathrm{O}_{2}$ & $\mathrm{CH}_{4}$ & $\mathrm{CO}_{2}$ \\
\hline $\begin{array}{l}\text { PTMSP } \\
\text { Poly trimethyl silylpropyne }\end{array}$ & 13244 & 5942 & 2899 & 6131 & 6464 & 24492 \\
\hline $\begin{array}{l}\text { PDMS } \\
\text { Poly dimethyl silicone }\end{array}$ & 565 & 316 & 255 & 497 & 761 & 2318 \\
\hline $\begin{array}{l}\text { PVC/Unplasticized } \\
\text { Poly(vinylchloride) }\end{array}$ & 6.4 & 7.7 & & 1.1 & 0.3 & 1.2 \\
\hline $\begin{array}{l}\mathrm{PE} / \mathrm{Bag} \\
\text { Polyethylene }\end{array}$ & 17.3 & 11.1 & 4.2 & 6.3 & 7.7 & 17.9 \\
\hline Polysulfone $\mathrm{MW}=26 \mathrm{~K}$ & 12 & 10.5 & 0.8 & 1.7 & 0.4 & 6 \\
\hline Polysulfone $\mathrm{MW}=35 \mathrm{~K}$ & 11.3 & 13.3 & 1.8 & 2.6 & 0.1 & 3.4 \\
\hline $\begin{array}{l}\text { Poly(ethylene terephthalate) } \\
\text { pop bottle }\end{array}$ & 3.7 & 6.2 & 5.1 & 5 & 6.7 & 6.1 \\
\hline Poly methyl methacrylate $\mathrm{MW}=350 \mathrm{~K}$ & 2.4 & 13 & & 3.3 & 0.6 & 0.6 \\
\hline Polystyrene (weigh boat) & 25.4 & 19.5 & 0.5 & 2.3 & 0.7 & 3.2 \\
\hline Polystyrene, $\mathrm{MW}=280 \mathrm{~K}$ & 27.1 & 0.63 & 0.47 & 0.39 & 1.21 & 16.4 \\
\hline $\mathrm{PVC}$ viscosity $=0.62$ & 4.59 & 4.55 & 0.16 & 0.37 & 0.22 & 0.7 \\
\hline $\mathrm{PVC}$ viscosity $=1.02$ & 5.3 & 1.28 & 0.52 & 0.64 & 0.38 & 1.08 \\
\hline Poly bis(trifluoroethoxy) phosphazene & 101.9 & - & 43.6 & 77.9 & 78.1 & 282 \\
\hline Poly bis(p-fluorophenoxy) phosphazene & 5.84 & - & 0.43 & 1.44 & 0.91 & 9.46 \\
\hline $\begin{array}{l}\text { Eypel F (fluorinated alkoxy substituted } \\
\text { phosphazene) }\end{array}$ & 79.9 & - & 32.2 & 64.9 & 40.6 & 375.6 \\
\hline $\begin{array}{l}\text { CMS-3 (perfluoro amorphous } \\
\text { copolymer) }\end{array}$ & 996 & - & 170 & 403 & 113 & 986 \\
\hline Polystyrene co-methyl methacrylate & 73.10 & - & - & - & 37.05 & 51.40 \\
\hline Polystyrene co-acrylonitrile & 12.10 & - & - & - & 3.00 & 9.25 \\
\hline Polyvinyl butyral & 10.95 & - & - & - & 1.15 & 8.05 \\
\hline Poly styrene co-butadiene & 8.15 & - & - & - & 2.30 & 14.85 \\
\hline Polyvinyl acetate & 14.65 & - & - & - & 0.80 & 11.95 \\
\hline
\end{tabular}


The results of the mixed gas tests are given in Table 4 .

Table 4. Tabulation of the mixed gas test results.

\begin{tabular}{|c|c|c|c|c|}
\hline \multirow[b]{2}{*}{ Polymer } & \multicolumn{2}{|c|}{$\begin{array}{l}\text { Permeability } \\
\text { (Barrers) }\end{array}$} & \multicolumn{2}{|c|}{ Perm Selectivity } \\
\hline & Hydrogen & $\begin{array}{c}\text { Carbon } \\
\text { Tetrachloride } \\
\end{array}$ & $\mathrm{H}_{2} / \mathrm{CCl}_{4}$ & $\mathrm{CCl}_{4} / \mathrm{H}_{2}$ \\
\hline Poly(dimethyl Siloxane) PDMS & $375-425$ & $10000-15000$ & 0.032 & 31.25 \\
\hline Polystyrene & 21.4 & 24000 & 0.001 & 1121.5 \\
\hline Poly(vinylidene Fluoride) Kynar & 2.5 & 9.4 & 0.266 & 3.76 \\
\hline Poly(benzyl methacrylate) & 2.8 & 20.5 & 0.137 & 7.321 \\
\hline Poly(propylene) & 3.5 & 1.65 & 2.121 & 0.471 \\
\hline Poly(benz-imidazol) PBI & 1.8 & 1.7 & 1.059 & 0.944 \\
\hline Poly(ethylene vinyl alcohol) EVAL & 0.11 & 1.2 & 0.092 & 10.909 \\
\hline Poly(ethylene terephthalate) PET & 0.13 & 0.45 & 0.289 & 3.462 \\
\hline CMS-3 perfluoro amorphous copolymer & 169.6 & 9.2 & 18.435 & 0.054 \\
\hline Poly(butadiene) & 68.4 & 3644.5 & 0.019 & 4.572 \\
\hline $\begin{array}{l}\text { Poly(p-sec-butyl, p-methoxy, o-allyl) } \\
\text { phenoxy phosphazene, Lot\# Z-1009-A }\end{array}$ & 8.6 & 5.98 & 1.438 & 0.695 \\
\hline $\begin{array}{l}\text { Poly(trifluoroethoxy) phosphazene } 1 \% \text { o- } \\
\text { allyl, Lot\# TE1-78 }\end{array}$ & 77.8 & 190.7 & 0.408 & 2.451 \\
\hline $\begin{array}{l}\text { Eypel-F Mixed fluoroalkoxy } \\
\text { phosphazene }\end{array}$ & 61.9 & 283 & 0.219 & 4.572 \\
\hline $\begin{array}{l}\text { CMS- } 3 \text { cast in house from } \\
\text { perfluorohexane }\end{array}$ & 533.4 & 16.6 & 32.133 & 0.031 \\
\hline Polyethylene & 45 & 79 & 0.570 & 1.756 \\
\hline
\end{tabular}

\subsection{Alternative Packaging}

Some of the tested polymers that showed good permeability values are materials not particularly amenable to spray coating due to their insolubility in suitable solvents or the solvents are very expensive. A number of variations of heat and solvent sealing of these types of polymer films was conducted to produce small bags containing the getter. The advantages of the bags are that they are simple to make and they form nice packages that are easily handled. The disadvantage is that the surface absorption area is significantly less than the individually coated particles. Nevertheless, several packages containing DEB were produced (Figure 14) and successfully tested, making this a viable getter containment alternative for highly permeable polymers. 

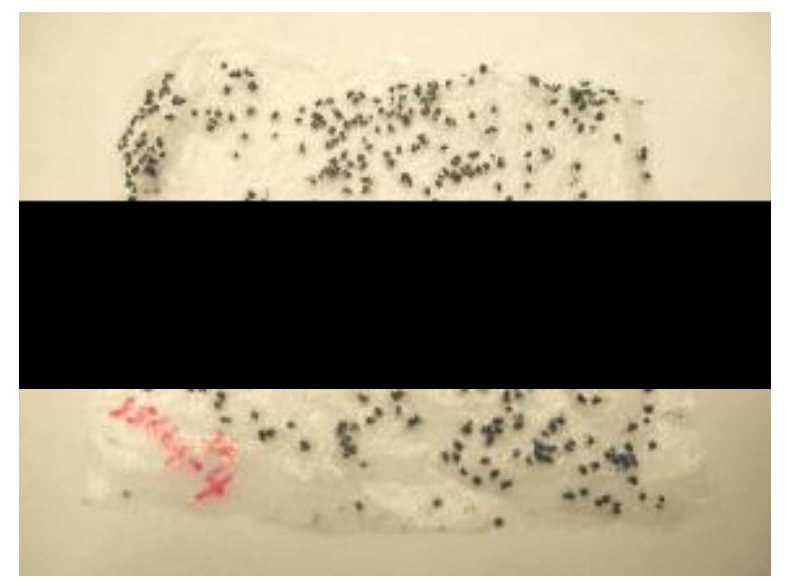

Figure 14. Heat sealed getter packet.

\section{3 $\quad \mathrm{H}_{2}$ Getter Properties of DEB Samples}

The samples considered to have the best properties were sent to LANL for $\mathrm{H}_{2}$ getter property testing and are listed in Table 5. For the Phase 2 testing, a new batch of DEB getter was purchased and new polymer coated samples were produced, all from the same batch of DEB. The getter was purchased from Honeywell FM\&T, P/N 1473067-000, Name: DEB getter, granulated PRJ049755-001, Lot No. X245, Quantity: 200 grams, Date of Manufacture: 10/22/01, and received 10/30/01. Two samples made from the Phase 1 batch of getter were included for comparison; 6 and 7 in Table 5.

Table 5. A listing of the getter samples sent to LANL for testing.

\begin{tabular}{ll} 
& \multicolumn{1}{c}{ Coating } \\
\hline 1 & None: uncoated DEB getter to serve as a control \\
2 & Polystyrene \\
3 & Poly styrene-co-methylmethacrylate \\
4 & Poly vinylidine fluoride (Kynar $\left.{ }^{\mathrm{TM}}\right)$ \\
5 & CMS-3 ${ }^{\mathrm{TM}}$ a perfluorinated amorphous copolymer \\
6 & Poly benzyl methacrylate \\
7 & Poly isopropyl methacrylate \\
\hline
\end{tabular}

\subsection{LANL Test Results}

The testing was performed in accordance with the TWFA coordinated Consolidated Test Plan that resulted from a meeting with all parties involved. The document describes the parameters that are to be measured and which parties would do the measurements. It gave the detail necessary to determine what ranges and bracketing values that needed to be produced in order to have a sufficient set of data to determine if the various formulations of the getters met the requirements. The following sections provide the results of those tests. 


\subsubsection{Testing Observations and Discussion}

Phase 2 tests were performed in accordance with the requirements of the Consolidated Test Plan for Hydrogen getters (Revision 3, December 20, 2001). Phase 2 dynamic testing was performed in the same manner as in Phase 1. The chart recording system employed in Phase 1 was replaced by an automated data acquisition system (Figure 10) midway through Phase 2. The "T50" parameter used in Phase 1 was refined and modified in Phase 2 per the Test Plan. "T50" was replaced with a more meaningful evaluation of getter performance, the hydrogen removal rate at $50 \%$ capacity. The dynamic test apparatus measures hydrogen removal rates in moles of hydrogen per second per unit mass $\left(\mathrm{mol} \mathrm{H}_{2} \mathrm{~s}^{-1} \mathrm{~kg}^{-1}\right)$. As stated in the Test Plan, hydrogen absorption rates will be expressed in these same units.

The getter test program is designed to fulfill the following programmatic requirements:

1. Minimum rate for hydrogen removal of $1.2 \times 10^{-5} \mathrm{~mol} \mathrm{H}_{2} \mathrm{~s}^{-1}$ for 60 days.

2. Sufficient getter material within the TRUPACT-II to ensure that no more than $50 \%$ of getter material is consumed during the 60 days.

3. Adequate hydrogen removal rate from the getter reaction in the absence of the recombination reaction of hydrogen to produce water.

This conservative approach provides a measure of safety for waste shipments by ensuring that sufficient getter material is present and by not taking credit for the recombination reaction. The rationale for measuring and reporting the hydrogen removal rate at $50 \%$ getter capacity is thus derived. The unit specified in the Test Plan for the minimum rate of hydrogen removal $\left(\mathrm{mol} \mathrm{H}_{2} \mathrm{~s}^{-1}\right)$ is converted to the unit measured in the test apparatus $\left(\mathrm{mol} \mathrm{H}_{2} \mathrm{~s}^{-1} \mathrm{~kg}^{-1}\right.$ ) through division by $5.765 \mathrm{~kg}$, the mass of DEB required to absorb 62.2 moles of hydrogen. This figure is further divided by a factor of two, to account for the second programmatic requirement. The result is $1.0 \times 10^{-6} \mathrm{~mol} \mathrm{H}_{2} \mathrm{~s}^{-1} \mathrm{~kg}^{-1}$. getter performance is compared to this figure in the rest of this report.

Tests to evaluate operating temperature range and poison effects in an atmosphere of $5 \% \mathrm{H}_{2}$ in $\mathrm{N}_{2}$ were performed on all materials (6 getters consisting of various coatings on DEB plus uncoated DEB as a control, Table 5. In conjunction with information on process knowledge and material costs, results from these tests were used to select 2 coated getters (polystyrene-coated DEB and polybenzylmethacrylatecoated DEB) for additional testing. Uncoated DEB was also the subject of continued testing as a control measure. A phased test strategy was needed to focus testing on a manageable number of materials, consistent with schedule and funding constraints.

Two types of data plots for getter materials are presented: (1) plots of hydrogen removal rate versus reciprocal temperature and (2) histograms comparing rates under a range of test conditions other than temperature. All hydrogen removal rates are calculated relative to the theoretical hydrogen capacity of DEB. This methodology provides a uniform datum from which to compare empirically measured variations in DEB capacity.

The following are sources of uncertainty in the dynamic tests:

1. Weighing of materials ( \pm 0.0005 grams)

2. Gas composition $( \pm 2 \%)$

3. Gas flow rate $( \pm 2 \%)$ 


\section{Measurement of hydrogen $( \pm 0.13)$}

5. Stoichiometric variation

a. Within the same lot of DEB due to sample size heterogeneity

b. Between lots of DEB.

Error analysis of these uncertainties (excluding stoichiometric variation) produces a total uncertainty of $\pm 33 \%$ for hydrogen removal rates at $50 \%$ saturation. To assess uncertainties from stoichiometric variation due to the size of the sample used within rate measurement tests $(0.10$ to 0.25 grams), rate measurements were performed on replicate samples from three DEB stocks (lot x170, lot $\mathrm{x} 245$, and lot $\mathrm{x} 222$ ) (Table 6 and Figure 15). Three rate measurements performed on lots $\mathrm{x} 245$ and x 222 produced results within $2 \%$ and $19 \%$, respectively. Of three rate measurements performed on lot $\mathrm{x} 170$, two were within the $15 \%$ but a third was within $50 \%$. Uncertainties due to stoichiometric variation and compositional heterogeneity are discussed below.

Table 6. Replicate samples and variability of hydrogen removal rate (mole $\mathrm{H}_{2} \mathrm{~s}^{-1} \mathrm{~kg}^{-1}$ at $50 \%$ capacity) in DEB lots $\mathrm{x} 170, \mathrm{x} 245$, and $\mathrm{x} 222$ in an atmosphere of $5 \% \mathrm{H}_{2}$ in nitrogen at a temperature of $77^{\circ} \mathrm{F}\left(25^{\circ} \mathrm{C}\right)$. Minimum programmatic criterion is $1.0 \times 10^{-6} \mathrm{~mol} \mathrm{H}_{2} \mathrm{~s}^{-1} \mathrm{~kg}^{-1}$.

\begin{tabular}{crrrrr}
\hline Uncoated DEB & \multicolumn{5}{c}{ Replicate Tests } \\
\hline Lot $\times 170$ & $2.34 \mathrm{E}-04$ & $1.45 \mathrm{E}-04$ & $2.74 \mathrm{E}-04$ & - & $2.18 \pm 0.66 \mathrm{E}-04$ \\
Lot $\times 245$ & $6.84 \mathrm{E}-04$ & $7.00 \mathrm{E}-04$ & $6.89 \mathrm{E}-04$ & - & $6.91 \pm 0.08 \mathrm{E}-04$ \\
Lot $\times 222$ & $6.31 \mathrm{E}-04$ & $5.31 \mathrm{E}-04$ & $5.43 \mathrm{E}-04$ & $5.88 \mathrm{E}-04$ & $5.73 \pm 0.46 \mathrm{E}-04$ \\
\hline
\end{tabular}

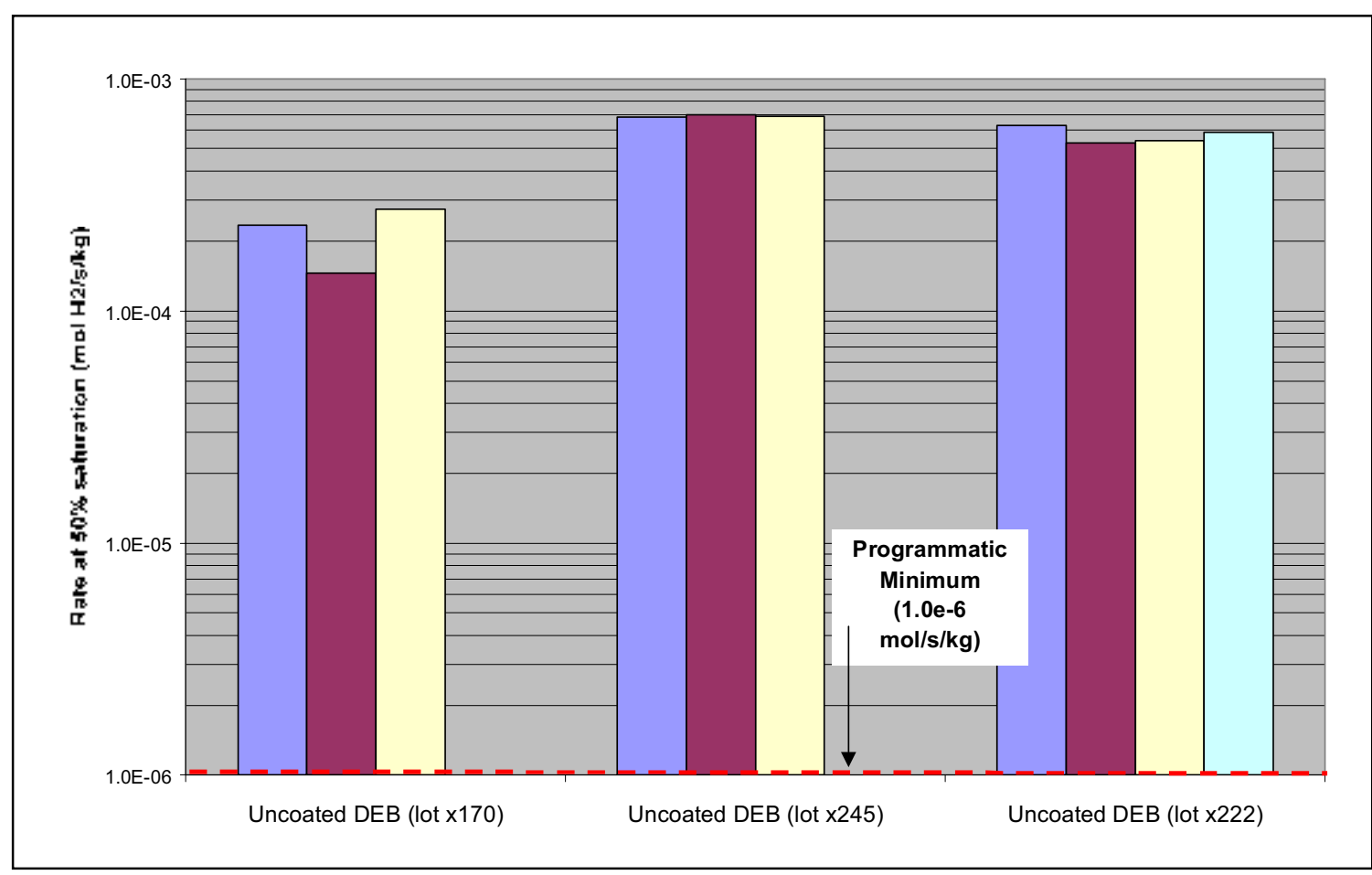

Figure 15. Replicate samples and variability of hydrogen removal rate in DEB (mole $\mathrm{H}_{2} \mathrm{~s}^{-1} \mathrm{~kg}^{-1}$ at $50 \%$ of capacity) lots $\mathrm{x} 170, \mathrm{x} 245$, and $\mathrm{x} 222$ in an atmosphere of $5 \% \mathrm{H}_{2}$ in nitrogen at a temperature of $77^{\circ} \mathrm{F}$. 
4.4.1.1 Capacity of Getter Materials. Capacity measurements were performed on uncoated DEB lot $\mathrm{x} 170$ and lot $\mathrm{x} 245$. The results are plotted in Figure 16. The theoretical capacity of DEB, 10.8 moles hydrogen per kilogram $\left(\mathrm{mol} \mathrm{H}_{2} \mathrm{~kg}^{-1}\right)$, is also plotted. The empirically measured capacity for lot $\mathrm{x} 170$, $9.1 \mathrm{~mol} \mathrm{H}_{2} \mathrm{~kg}^{-1}$, is approximately $15 \%$ less than the theoretical capacity. In contrast, the empirically measured capacity for lot $\mathrm{x} 245,18.5 \pm 0.68 \mathrm{~mol} \mathrm{H}_{2} \mathrm{~kg}^{1}$, is approximately $72 \%$ greater than the theoretical capacity. The variation in empirical capacity may represent the actual stoichiometric variation between different lots of DEB, as suggested by the variation in hydrogen removal rates depicted in Figure 15.

Empirically measured capacities for polystyrene- $\left(16.4 \mathrm{~mol} \mathrm{H}_{2} \mathrm{~kg}^{-1}\right)$ and polybenzylmethacrylate(16.1 $\mathrm{mol} \mathrm{H}_{2} \mathrm{~kg}^{-1}$ ) coated DEB (lot x245) are approximately $10 \%$ less than the capacity measured for uncoated DEB. The coatings are a very small fraction of the total mass of getter material, much less than $1 \%$ (by weight). Therefore, it is not known why coated DEB yields a smaller capacity compared to uncoated DEB. However, this relationship may be due to the slower hydrogen removal rates of the coated materials and the finite time of the capacity measurements. The slightly reduced capacity measured for coated DEB is consistent with the capacities measured by SRTC using an alternate method, as discussed later in this report.

The apparent variation in hydrogen capacity between DEB lots x170 and x245 (Figure 16) is smaller than the variation in hydrogen removal rate (at 50\% saturation) measured for these lots (Figure 15). This difference is due to the method of calculating rate based on theoretical capacity. Rates that are calculated from empirically measured capacities (Table 7) produce results that are consistent with the empirically measured variation in hydrogen capacity. It should be noted that the difference in the removal rate that is based on theoretical capacity and the rate that is based on empirical capacity is within the uncertainty of the dynamic test method.

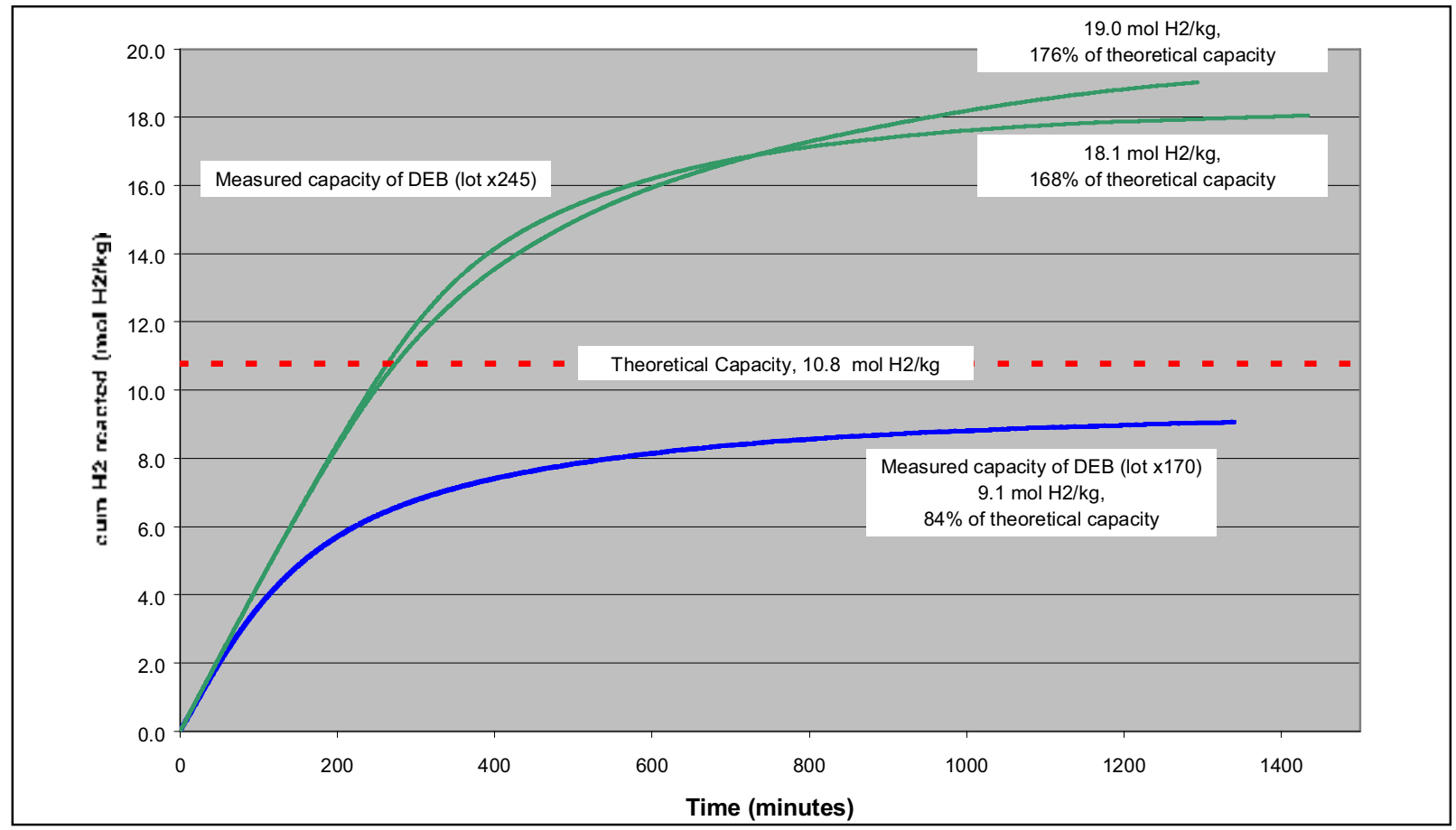

Figure 16. Hydrogen capacity measured for DEB lots x170 and $\mathrm{x} 245$ in an atmosphere of $5 \% \mathrm{H}_{2}$ in nitrogen at a temperature of $77^{\circ} \mathrm{F}\left(25^{\circ} \mathrm{C}\right)$. Two replicate tests are shown for DEB lot $\mathrm{x} 245$. 
Table 7. Comparison of hydrogen removal rate relative to theoretical and empirical hydrogen capacity of DEB. Note that these data are reported for one test and do not reflect mean rates based on replicated tests reported elsewhere in this report.

\begin{tabular}{|c|c|c|c|}
\hline \multicolumn{4}{|c|}{$\begin{array}{l}\text { Rate at } 50 \% \text { Saturation } \\
\quad\left(\mathrm{mol} \mathrm{H} \mathrm{S}^{-1} \mathrm{~kg}^{-1}\right)\end{array}$} \\
\hline & $\begin{array}{c}\text { Based on Theoretical } \\
\text { Capacity }\end{array}$ & $\begin{array}{c}\text { Based on Empirical } \\
\text { Capacity }\end{array}$ & Relative Difference \\
\hline DEB lot $\mathrm{x} 170$ & $2.74 \mathrm{E}-04$ & $3.73 \mathrm{E}-04$ & $+36 \%$ \\
\hline DEB lot x245 & $7.00 \mathrm{E}-04$ & $6.38 \mathrm{E}-04$ & $-9 \%$ \\
\hline
\end{tabular}

4.4.1.2 Operating Temperature Range. Temperatures required by the Test Plan to evaluate the operating temperature range of getter materials are $160,77,23$, and $-20^{\circ} \mathrm{F}\left(71.1,25,-5\right.$, and $\left.-28.9^{\circ} \mathrm{C}\right)$. Additional tests were performed at $122^{\circ} \mathrm{F}\left(50^{\circ} \mathrm{C}\right)$ in an atmosphere of hydrogen in nitrogen. Additional tests at $122^{\circ} \mathrm{F}\left(50^{\circ} \mathrm{C}\right)$ were performed to evaluate getter behavior at a temperature midway between ambient temperature and the hottest temperatures expected in the TRUPACT-II.

4.4.1.2.1 Hydrogen in Nitrogen-Rate measurements were performed on all materials (Table 5) in an atmosphere of $5 \% \mathrm{H}_{2}$ in $\mathrm{N}_{2}$ over the temperature range of 160 to $77^{\circ} \mathrm{F}\left(71.1\right.$ to $\left.25^{\circ} \mathrm{C}\right)$. Test results are summarized in Table 8 and presented in Figure 17. In general, uncoated DEB exhibits the largest rate of hydrogen removal relative to the various coated DEB materials. However, all materials exhibit hydrogen removal rates that exceed the programmatic minimum for this temperature range. Hydrogen removal rates exceed the programmatic minimum by 1.5 to 2.5 orders of magnitude in these tests.

Results from tests performed in nitrogen for the limited temperature range (160 to $23^{\circ} \mathrm{F}, 71.1$ to $-5^{\circ} \mathrm{C}$ ) were used to select 2 coated getters (polystyrene-coated DEB and polybenzylmethacrylate-coated DEB) for additional testing. Uncoated DEB was also the subject of continued testing as a control measure. Additional rate measurements were performed on uncoated DEB, polystyrene-coated DEB, and polybenzylmethacrylate-coated DEB in an atmosphere of $5 \% \mathrm{H}_{2}$ in $\mathrm{N}_{2}$ at $-20^{\circ} \mathrm{F}\left(-28.9^{\circ} \mathrm{C}\right)$. Test results for these three materials are summarized in Table 8 and presented as Arrhenius plots (Figure 18) for the full temperature interval $\left(160\right.$ to $-20^{\circ} \mathrm{F}, 71.1$ to $\left.-28.9^{\circ} \mathrm{C}\right)$ specified in the Test Plan. All three materials exhibit hydrogen removal rates that exceed the programmatic minimum for this temperature range. At $-20^{\circ} \mathrm{F}$ $\left(-28.9^{\circ} \mathrm{C}\right)$, hydrogen removal rates exceed the programmatic minimum by approximately 1 (polystyrenecoated DEB and polybenzylmethacrylate-coated DEB) to 2 (uncoated DEB) orders of magnitude.

Table 8. Hydrogen removal rate (mole $\mathrm{H}_{2} \mathrm{~s}^{-1} \mathrm{~kg}^{-1}$ at $50 \%$ capacity) for hydrogen getters in an atmosphere of $5 \% \mathrm{H}_{2}$ in nitrogen at temperatures of 160 to $23^{\circ} \mathrm{F}\left(71.1\right.$ to $\left.-5^{\circ} \mathrm{C}\right)$. Removal rates are also reported for uncoated DEB (lot $\times 170)$, polystyrene-coated DEB, and polybenzylmethacrylate-coated DEB at a temperature of $-20^{\circ} \mathrm{F}\left(-28.9^{\circ} \mathrm{C}\right)$. Minimum programmatic criterion is $1.0 \times 10^{-6} \mathrm{~mol} \mathrm{H}_{2} \mathrm{~s}^{-1} \mathrm{~kg}^{-1}$.

\begin{tabular}{|c|c|c|c|c|c|c|c|c|c|c|c|}
\hline $\begin{array}{c}\mathrm{T} \\
(\mathrm{F})\end{array}$ & $\begin{array}{c}\mathrm{T} \\
(\mathrm{C}) \\
\end{array}$ & $\begin{array}{c}\mathrm{T} \\
(\mathrm{K}) \\
\end{array}$ & $\begin{array}{c}1000 / \mathrm{T} \\
(\mathrm{K})\end{array}$ & $\begin{array}{l}\text { Uncoated } \\
\text { DEB } \\
(\operatorname{lot} x 170)\end{array}$ & Polystyrene & $\begin{array}{c}\text { Polystyrene-co- } \\
\text { methylmethacrylate }\end{array}$ & $\begin{array}{c}\text { Polyiospropyl- } \\
\text { methacrylate }\end{array}$ & $\begin{array}{l}\text { Polybenzyl- } \\
\text { methacrylate }\end{array}$ & $\begin{array}{l}\text { Kynar } \\
\text { (PVDF) }\end{array}$ & CMS-3 & $\begin{array}{l}\text { CMS-3 } \\
\text { packet }\end{array}$ \\
\hline 160 & 71.1 & 344 & 2.90 & $6.06 \mathrm{E}-04$ & $2.81 \mathrm{E}^{-}-04$ & $1.13 \mathrm{E}-04$ & $3.48 \mathrm{E}-04$ & $1.16 \mathrm{E}-04$ & $2.00 \mathrm{E}-04$ & $6.50 \mathrm{E}-04$ & $3.00 \mathrm{E}-04$ \\
\hline 122 & 50 & 323 & 3.09 & $6.72 \mathrm{E}-04$ & $5.22 \mathrm{E}^{-}-04$ & $3.07 \mathrm{E}-04$ & $1.31 \mathrm{E}-04$ & $8.81 \mathrm{E}^{-}-05$ & $5.56 \mathrm{E}-05$ & $6.86 \mathrm{E}-04$ & $2.78 \mathrm{E}-04$ \\
\hline 77 & 25 & 298 & 3.35 & $2.18 \mathrm{E}-04$ & $3.83 \mathrm{E}^{-}-04$ & $1.90 \mathrm{E}-04$ & $9.05 \mathrm{E}-05$ & $2.36 \mathrm{E}-04$ & $1.16 \mathrm{E}-04$ & $6.07 \mathrm{E}-04$ & $2.27 \mathrm{E}^{-}-04$ \\
\hline 23 & -5 & 268 & 3.73 & $1.41 \mathrm{E}-04$ & $7.36 \mathrm{E}-05$ & $1.84 \mathrm{E}-04$ & - & $6.21 \mathrm{E}-05$ & $1.63 \mathrm{E}-04$ & $1.28 \mathrm{E}-04$ & - \\
\hline-20 & -28.9 & 244 & 4.09 & $1.25 \mathrm{E}-04$ & $1.75 \mathrm{E}^{-}-05$ & - & - & $1.24 \mathrm{E}-05$ & - & - & - \\
\hline
\end{tabular}






Figure 17. Plot of hydrogen removal rate vs. temperature (reciprocal Kelvin multiplied by 1000) for hydrogen getters in an atmosphere of $5 \% \mathrm{H}_{2}$ in nitrogen at temperatures of 160 to $23^{\circ} \mathrm{F}\left(71.1\right.$ to $\left.-5^{\circ} \mathrm{C}\right)$.

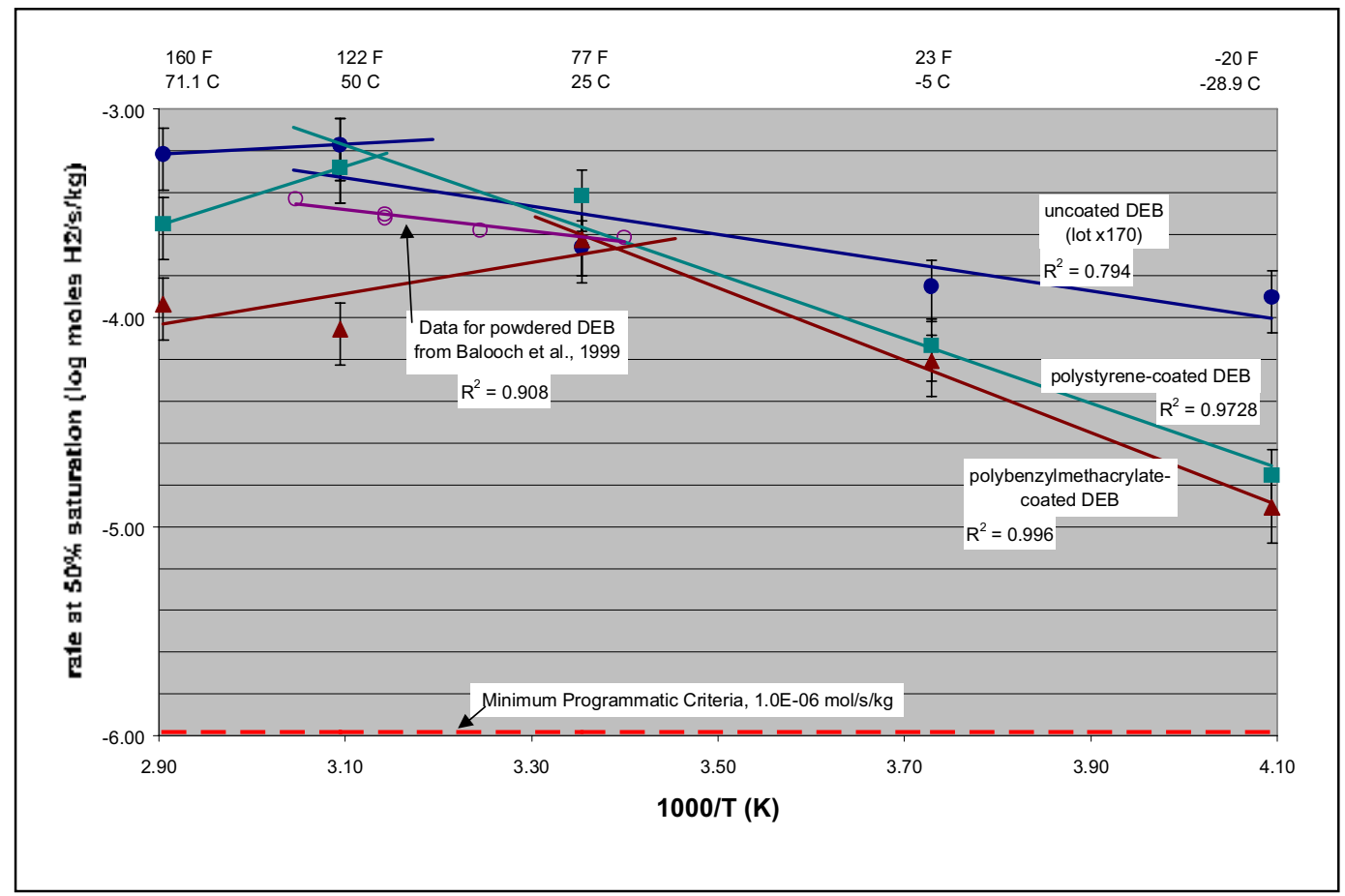

Figure 18. Arrhenius plot (hydrogen removal rate vs. temperature) for uncoated DEB (lot x170), polystyrene-coated DEB, and polybenzylmethacrylate-coated DEB in an atmosphere of 5\% $\mathrm{H}_{2}$ in nitrogen at temperatures of 160 to $-20^{\circ} \mathrm{F}\left(71.1\right.$ to $\left.-28.9^{\circ} \mathrm{C}\right)$. The hydrogen removal rate is plotted as $\log$ mole $\mathrm{H}_{2} \mathrm{~s}^{-1} \mathrm{~kg}^{-1}$ at $50 \%$ capacity and the temperature is plotted as reciprocal Kelvin multiplied by 1000 . Error bars represent maximum uncertainty. Plotted for comparison are data for powdered DEB reported by Balooch et al., 1999 for the temperature range of 21 to $55^{\circ} \mathrm{C}$. 
Uncoated DEB and polystyrene-coated DEB exhibit Arrhenius behavior over the temperature range of 122 to $-20^{\circ} \mathrm{F}$ ( 50 to $\left.-28.9^{\circ} \mathrm{C}\right)$. Arrhenius behavior is exhibited by polybenzylmethacrylate-coated DEB over a narrower temperature interval of 77 to $-20^{\circ} \mathrm{F}\left(25\right.$ to $\left.-28.9^{\circ} \mathrm{C}\right)$. A slope change of the Arrhenius plots occurs at temperatures greater than $122^{\circ} \mathrm{F}\left(50^{\circ} \mathrm{C}\right)$ for uncoated DEB and polystyrene-coated DEB and at a temperature greater than $77^{\circ} \mathrm{F}\left(25^{\circ} \mathrm{C}\right)$ for polybenzylmethacrylate-coated DEB. Non-Arrhenius behavior indicates a change in reaction mechanism, either due to a change in the actual chemical reaction that is taking place or to other physical or chemical influences. Materials recovered from tests performed at $160^{\circ} \mathrm{F}\left(71.1^{\circ} \mathrm{C}\right)$ exhibited physical changes, including adhesion of individual grains as sticky masses and plugs. Similar changes were observed in $122^{\circ} \mathrm{F}\left(50^{\circ} \mathrm{C}\right)$ tests with uncoated DEB and polystyrenecoated DEB. Polybenzylmethacrylate-coated DEB did not exhibit these changes in tests performed below $160^{\circ} \mathrm{F}\left(71.1^{\circ} \mathrm{C}\right)$. The general correlation between change in physical state of the materials and decrease in slope at higher temperature suggests that the two phenomena are related. However, despite these phenomena, hydrogen removal rates at elevated temperature exceed the programmatic minimum by approximately 2 to 2.5 orders of magnitude.

Little has been published on the kinetics of DEB hydrogenation. Balooch et al. (1999) evaluated the hydrogenation kinetics of DEB at four temperatures, $21^{\circ} \mathrm{C}, 35^{\circ} \mathrm{C}, 45^{\circ} \mathrm{C}$ and $55^{\circ} \mathrm{C}$. Their data set is reproduced in Figure 18 and agrees reasonably well with the kinetic data determined in this study for uncoated DEB. Balooch et al. (2001) examined the hydrogenation kinetics of DEB imbedded in silicone ( $40 \%$ DEB getter mixture and about $60 \%$ silicone by weight). They concluded that the hydrogenation kinetics of the DEB-silicone mix is mainly controlled by the diffusion of hydrogen in the silicone matrix. The results of Balooch et al. (2001) are not directly comparable to our work because the polymer coatings that we used comprise a much smaller proportion of the total mass in contrast to the DEB-silicone mix.

4.4.1.2.2 Hydrogen in Air-Additional rate measurements were performed on uncoated DEB, polystyrene-coated DEB, and polybenzylmethacrylate-coated DEB in an atmosphere of $3 \% \mathrm{H}_{2}$ in air for the temperature range of 160 to $-20^{\circ} \mathrm{F}\left(71.1\right.$ to $\left.-28.9^{\circ} \mathrm{C}\right)$. Test results for these three materials are summarized in Table 9 and presented as Arrhenius plots (Figure 19). All three materials exceed the programmatic minimum by approximately 2 to 2.5 orders of magnitude for this temperature range. The effect of carbon monoxide $(0.5 \%)$ is quite pronounced, reducing the coated and uncoated DEB performance by approximately one order-of-magnitude. This fall off in performance is most striking for the uncoated DEB, where the rate is reported for a saturation of $28 \%$ because reliable tests could not be performed to the $50 \%$ saturation level. The rate at $50 \%$ could not be projected from the existing data set, but is presumed to be less than the rate reported for $28 \%\left(2.04 \mathrm{E}-05 \mathrm{~mol} \mathrm{H}_{2} \mathrm{~s}^{-1} \mathrm{~kg}^{-1}\right)$.

Table 9. Hydrogen removal rate (mole $\mathrm{H}_{2} \mathrm{~s}^{-1} \mathrm{~kg}^{-1}$ at $50 \%$ capacity) for uncoated DEB, polystyrene-coated DEB, and polybenzylmethacrylate-coated DEB in an atmosphere of $3 \% \mathrm{H}_{2}$ in air at temperatures of 160 to $-20^{\circ} \mathrm{F}\left(71.1\right.$ to $\left.-28.9^{\circ} \mathrm{C}\right)$. Minimum programmatic criterion is $1.0 \times 10^{-6} \mathrm{~mol} \mathrm{H}_{2} \mathrm{~s}^{-1} \mathrm{~kg}^{-1}$.

\begin{tabular}{|c|c|c|c|c|c|c|c|}
\hline $\begin{array}{c}\mathrm{T} \\
(\mathrm{F})\end{array}$ & $\begin{array}{c}\mathrm{T} \\
(\mathrm{C})\end{array}$ & $\begin{array}{c}\mathrm{T} \\
(\mathrm{K})\end{array}$ & $\begin{array}{l}1000 / \mathrm{T} \\
(\mathrm{K})\end{array}$ & $\begin{array}{l}\text { Uncoated DEB } \\
(\text { lot } \times 170)\end{array}$ & $\begin{array}{l}\text { Uncoated DEB } \\
\quad(\operatorname{lot} \times 245)\end{array}$ & Polystyrene & Polybenzylmethacrylate \\
\hline 160 & 71.1 & 344 & 2.90 & $6.82 \mathrm{E}-04$ & $7.34 \mathrm{E}-04$ & $4.62 \mathrm{E}-04$ & $4.68 \mathrm{E}-04$ \\
\hline 77 & 25 & 298 & 3.35 & $5.51 \mathrm{E}-04$ & $6.53 \mathrm{E}-04$ & $3.81 \mathrm{E}-04$ & $3.37 \mathrm{E}-04$ \\
\hline 23 & -5 & 268 & 3.73 & - & $5.79 \mathrm{E}-04$ & $1.73 \mathrm{E}-04$ & $1.39 \mathrm{E}-04$ \\
\hline-20 & -28.9 & 244 & 4.09 & - & $5.17 \mathrm{E}-04$ & $2.49 \mathrm{E}-04$ & $3.59 \mathrm{E}-04$ \\
\hline
\end{tabular}




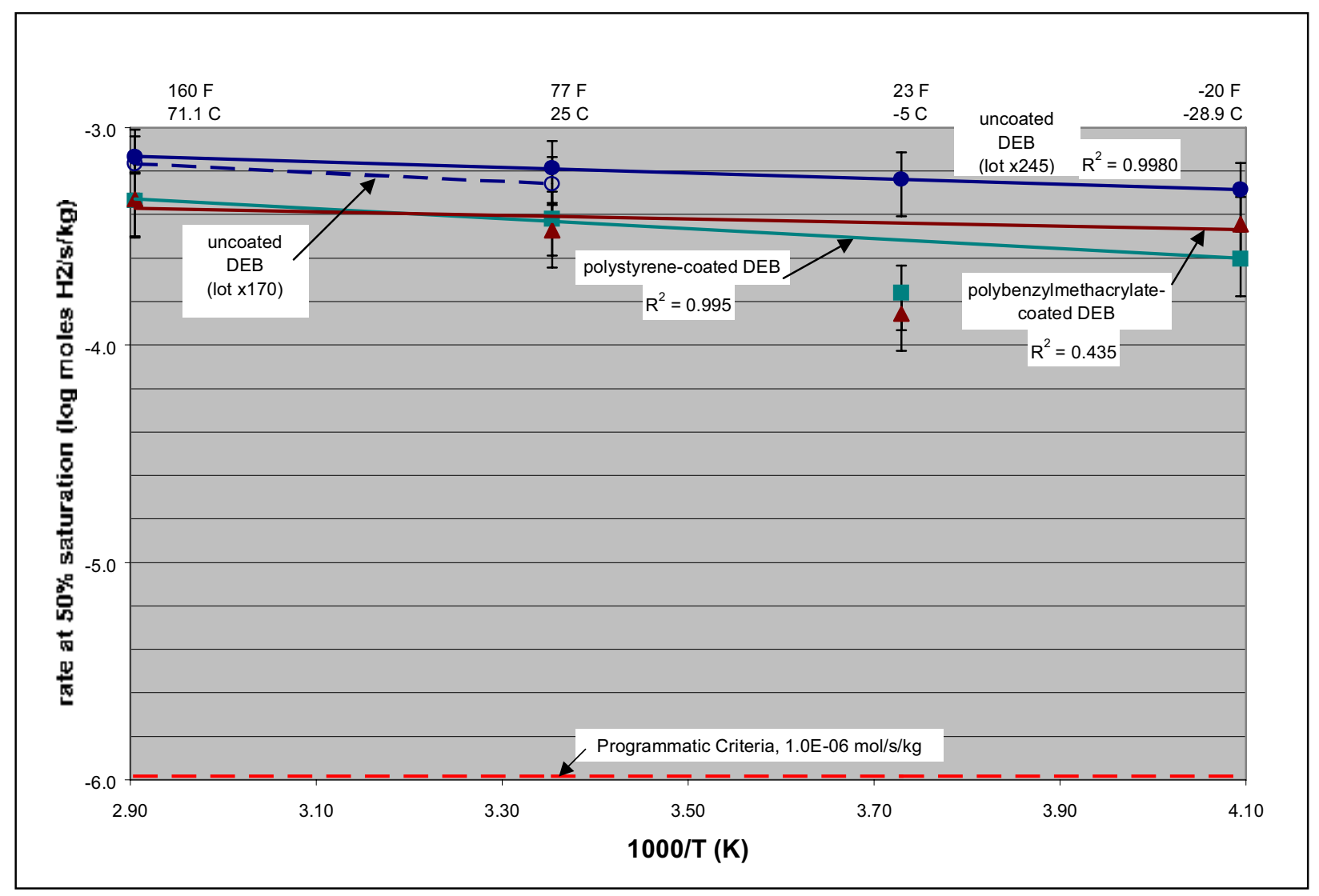

Figure 19. Arrhenius plot (hydrogen removal rate vs. temperature) for uncoated DEB (lots x170 and $\mathrm{x} 245$ ), polystyrene-coated DEB, and polybenzylmethacrylate-coated DEB in an atmosphere of $3 \% \mathrm{H}_{2}$ in air at temperatures of 160 to $-20^{\circ} \mathrm{F}\left(71.1\right.$ to $\left.-28.9^{\circ} \mathrm{C}\right)$. The hydrogen removal rate is plotted as $\log$ mole $\mathrm{H}_{2} \mathrm{~s}^{-1} \mathrm{~kg}^{-1}$ at $50 \%$ capacity and the temperature is plotted as reciprocal Kelvin multiplied by 1000 . Trend lines connect rate data at all temperatures except $23^{\circ} \mathrm{F}\left(-5^{\circ} \mathrm{C}\right)$. Error bars represent maximum uncertainty.

In contrast to rates measured in an atmosphere of nitrogen, uncoated DEB exhibits Arrhenius behavior over the entire temperature range that was tested. Polystyrene-coated DEB and polybenzylmethacrylate-coated $\mathrm{DEB}$ also exhibit Arrhenius behavior across the entire temperature range, with the exception of an anomaly at $23^{\circ} \mathrm{F}\left(-5^{\circ} \mathrm{C}\right)$. The cause of this anomaly is uncertain, but it may be the result of proximity to the freezing point of water.

Hydrogen removal rates for uncoated DEB, polystyrene-coated DEB, and polybenzylmethacrylatecoated DEB are greater in air compared to nitrogen because of the catalytic recombination reaction to form water. The difference between hydrogen removal rates measured in nitrogen and air is more pronounced at lower temperature, producing an Arrhenius plot for rates in air that is flatter than the plot for rates in nitrogen. The reason for the greater rate difference at lower temperature is uncertain, but may be due to the effect of the recombination reaction and the formation of ice.

4.4.1.3 Effect of Hydrogen Concentration. Rate measurements at two hydrogen concentrations were made to determine how rates of hydrogen removal are affected by hydrogen concentration. Measurements were performed on uncoated DEB (lot x170 and x245), polystyrene-coated DEB, and polybenzylmethacrylate-coated DEB in an atmosphere of $1 \% \mathrm{H}_{2}$ in $\mathrm{N}_{2}$ at the temperature of $77^{\circ} \mathrm{F}\left(25^{\circ} \mathrm{C}\right)$. Test results comparing rates in 1 and $5 \% \mathrm{H}_{2}$ are presented in a histogram (Figure 20). Removal rates do 


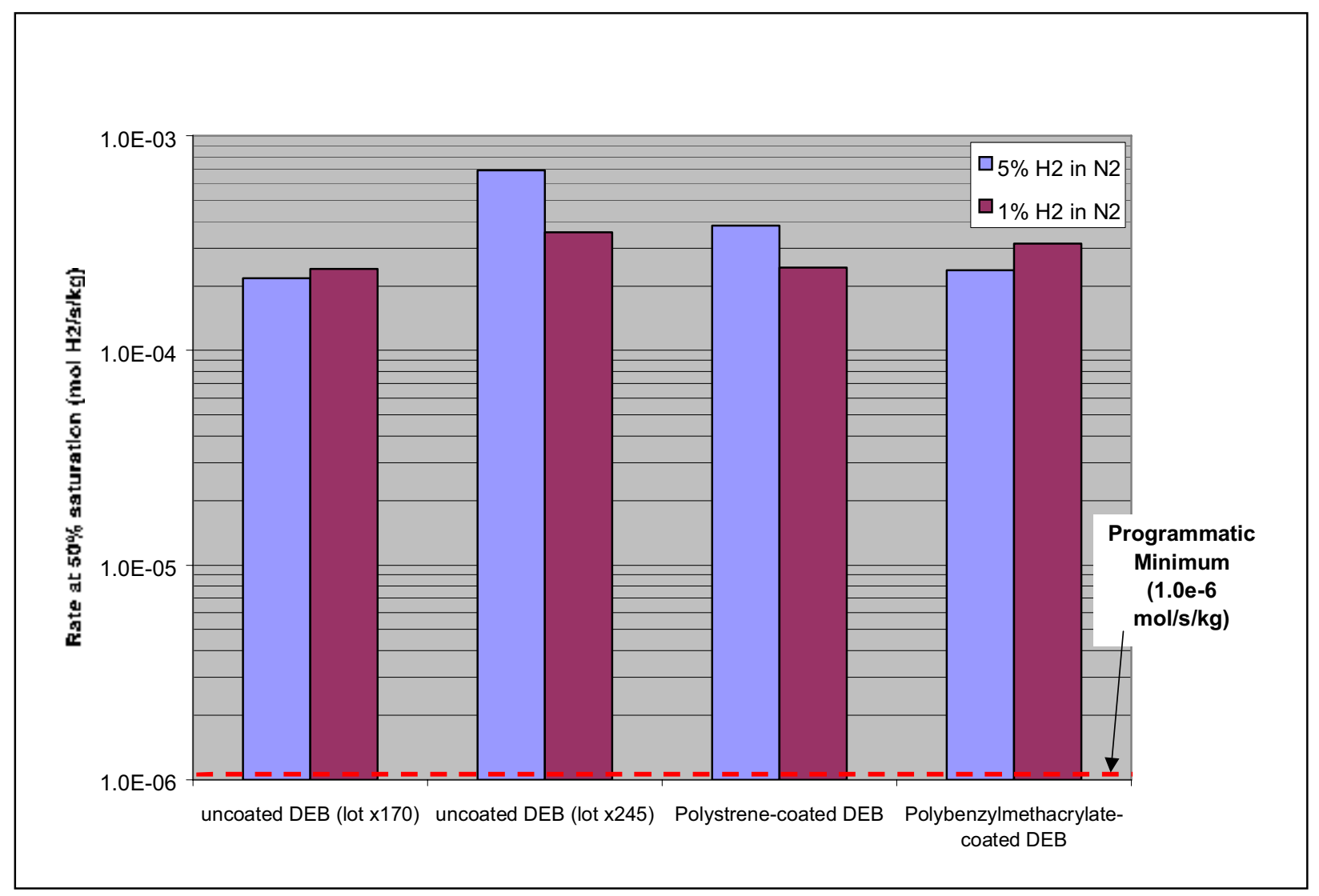

Figure 20. Comparison of hydrogen removal rates in uncoated DEB (lot x170 and x245), polystyrenecoated DEB, and polybenzylmethacrylate-coated DEB in an atmosphere of 1 and $5 \% \mathrm{H}_{2}$ in nitrogen at a temperature of $77^{\circ} \mathrm{F}\left(25^{\circ} \mathrm{C}\right)$.

not exhibit significant change between the two gas compositions for uncoated DEB lot x170, and polybenzylmethacrylate-coated DEB. The removal rate for uncoated DEB lot x245 exhibits a measurable rate decrease of approximately $50 \%$ for $1 \%$ hydrogen relative to $5 \%$ hydrogen. The removal rate for polystyrene-coated DEB also exhibits a measurable rate decrease of approximately $37 \%$. Based on these results, we conclude that hydrogen absorption rate is not affected by changes in hydrogen concentration for two of the four materials, and minimally diminished for the other two.

4.4.1.4 Poison Effects. The compounds selected for screening as potential poisons are listed in Table 10. The poison-screening tests were conducted in the presence of an excess of poison vapor. An organic vapor concentration of approximately 1000 part per million (ppm) was used. In the case of carbon monoxide, a gas concentration of approximately $1 \%$ was used.

4.4.1.4.1 Hydrogen in Nitrogen-Rate measurements were performed on all materials (Table 5) in an atmosphere of $5 \% \mathrm{H}_{2}$ in $\mathrm{N}_{2}$ at a temperature of $77^{\circ} \mathrm{F}\left(25^{\circ} \mathrm{C}\right)$ in the presence of the poisons listed in Table 10. The effect of poisons on hydrogen removal rate at $77^{\circ} \mathrm{F}\left(25^{\circ} \mathrm{C}\right)$ is summarized in Table 11 and plotted in Figure 21. Poisons impact the hydrogen removal rate of all of the materials at $77^{\circ} \mathrm{F}\left(25^{\circ} \mathrm{C}\right)$. However, all materials exhibit removal rates that exceed the programmatic minimum by at least 1 order of magnitude. 
Table 10. Poisons for getter screening.

\begin{tabular}{cc}
\hline Represented Class & Selected Compound(s) \\
\hline Aliphatic & Hexane \\
Aromatic & Toluene \\
Ketone & Acetone \\
Alcohol & Methanol \\
Chlorinated organic & Carbon tetrachloride \\
Inorganic gases & Carbon monoxide \\
\hline
\end{tabular}

Table 11. Effect of poisons on hydrogen removal rates $\left(\right.$ mole $\left.\mathrm{H}_{2} \mathrm{~s}^{-1} \mathrm{~kg}^{-1}\right)$ of DEB and coated DEB at $77^{\circ} \mathrm{F}$ $\left(25^{\circ} \mathrm{C}\right)$ in an atmosphere of 5\% hydrogen in nitrogen. The minimum programmatic criterion is $1.0 \times 10-6$ mol H $\mathrm{s}^{-1} \mathrm{~kg}^{-1}$.

\begin{tabular}{|c|c|c|c|c|c|c|c|}
\hline Material & No Poison & Hexane & Toluene & Acetone & Methanol & $\begin{array}{c}\text { Carbon } \\
\text { Tetrachloride } \\
\end{array}$ & $\begin{array}{c}\text { Carbon } \\
\text { Monoxide }\end{array}$ \\
\hline Uncoated DEB (x170) & $2.18 \mathrm{E}-04$ & - & - & $8.26 \mathrm{E}-05$ & - & - & - \\
\hline Uncoated DEB (x245) & $6.91 \mathrm{E}-04$ & $6.63 \mathrm{E}-04$ & $1.11 \mathrm{E}-03$ & - & $9.30 \mathrm{E}-04$ & $1.89 \mathrm{E}-04$ & $6.47 \mathrm{E}-05$ \\
\hline Polystyrene & $3.83 \mathrm{E}-04$ & $5.90 \mathrm{E}-04$ & $5.07 \mathrm{E}-04$ & $1.93 \mathrm{E}-04$ & $9.45 \mathrm{E}-05$ & $1.37 \mathrm{E}-04$ & $4.44 \mathrm{E}-05$ \\
\hline $\begin{array}{l}\text { Polystyrene-co- } \\
\text { methylmethacrylate }\end{array}$ & $1.90 \mathrm{E}-04$ & $5.34 \mathrm{E}-04$ & $4.14 \mathrm{E}-04$ & $2.33 \mathrm{E}-04$ & $2.16 \mathrm{E}-04$ & $1.37 \mathrm{E}-04$ & - \\
\hline Polyisopropylmethacrylate & $9.05 \mathrm{E}-05$ & $1.86 \mathrm{E}-04$ & $2.02 \mathrm{E}-04$ & $6.36 \mathrm{E}-05$ & $2.22 \mathrm{E}-04$ & $4.16 \mathrm{E}-05$ & - \\
\hline Polybenzylmethacrylate & $2.36 \mathrm{E}-04$ & $4.16 \mathrm{E}-04$ & $3.52 \mathrm{E}-04$ & $2.21 \mathrm{E}-04$ & $1.09 \mathrm{E}-04$ & $1.11 \mathrm{E}-04$ & $2.63 \mathrm{E}-05$ \\
\hline Kynar (PVDF) & $1.16 \mathrm{E}-04$ & $2.79 \mathrm{E}-04$ & $9.02 \mathrm{E}-04$ & $1.91 \mathrm{E}-04$ & $3.31 \mathrm{E}-04$ & $1.38 \mathrm{E}-04$ & - \\
\hline CMS-3 & $6.07 \mathrm{E}-04$ & - & - & $9.68 \mathrm{E}-04$ & $6.90 \mathrm{E}-04$ & $1.93 \mathrm{E}-04$ & - \\
\hline
\end{tabular}

At $77^{\circ} \mathrm{F}\left(25^{\circ} \mathrm{C}\right)$, toluene actually enhances hydrogen removal rates for all materials that were tested (Table 11 and Figure 21). Hexane enhances removal rates for all coated DEB tested. The cause of this enhancement is unknown. Acetone and methanol impact the various coatings differently, enhancing the removal rates of some materials (e.g. kynar-coated DEB), reducing rates for other materials (e.g. polystyrene-coated DEB), and having no measurable effect on others (e.g. acetone with polybenzylmethacrylate-coated DEB). The causes for these impacts are unknown. Carbon tetrachloride and carbon monoxide provide the greatest impact. Carbon tetrachloride reduces hydrogen removal rates for all materials except polystyrene-co-methylmethacrylate- and Kynar-coated DEB. These two materials appear to mitigate the effect of carbon tetrachloride. Carbon tetrachloride reduces rates for uncoated DEB by approximately 0.5 orders of magnitude. All of the coatings reduce the impact of carbon tetrachloride by a factor of two or more. Carbon monoxide reduces the removal rate for uncoated DEB and polybenzylmethacrylate-coated DEB by approximately one order of magnitude.

Rate measurements were performed on all materials (Table 5) in an atmosphere of $5 \% \mathrm{H}_{2}$ in $\mathrm{N}_{2}$ at a temperature of $160^{\circ} \mathrm{F}\left(71.1^{\circ} \mathrm{C}\right)$ in the presence of carbon tetrachloride. The effect of carbon tetrachloride at $160^{\circ} \mathrm{F}\left(71.1^{\circ} \mathrm{C}\right)$ is summarized in Table 12 and plotted in Figure 22. Carbon tetrachloride does not measurably impact hydrogen removal rates in uncoated DEB or in polystyrene-co-methylmethacrylate-, Polyiospropylmethacrylate-, and CMS-3 coated DEB. Hydrogen removal rates in polystyrene-coated DEB and PVDF-coated DEB appear to be slightly enhanced whereas the removal rate 


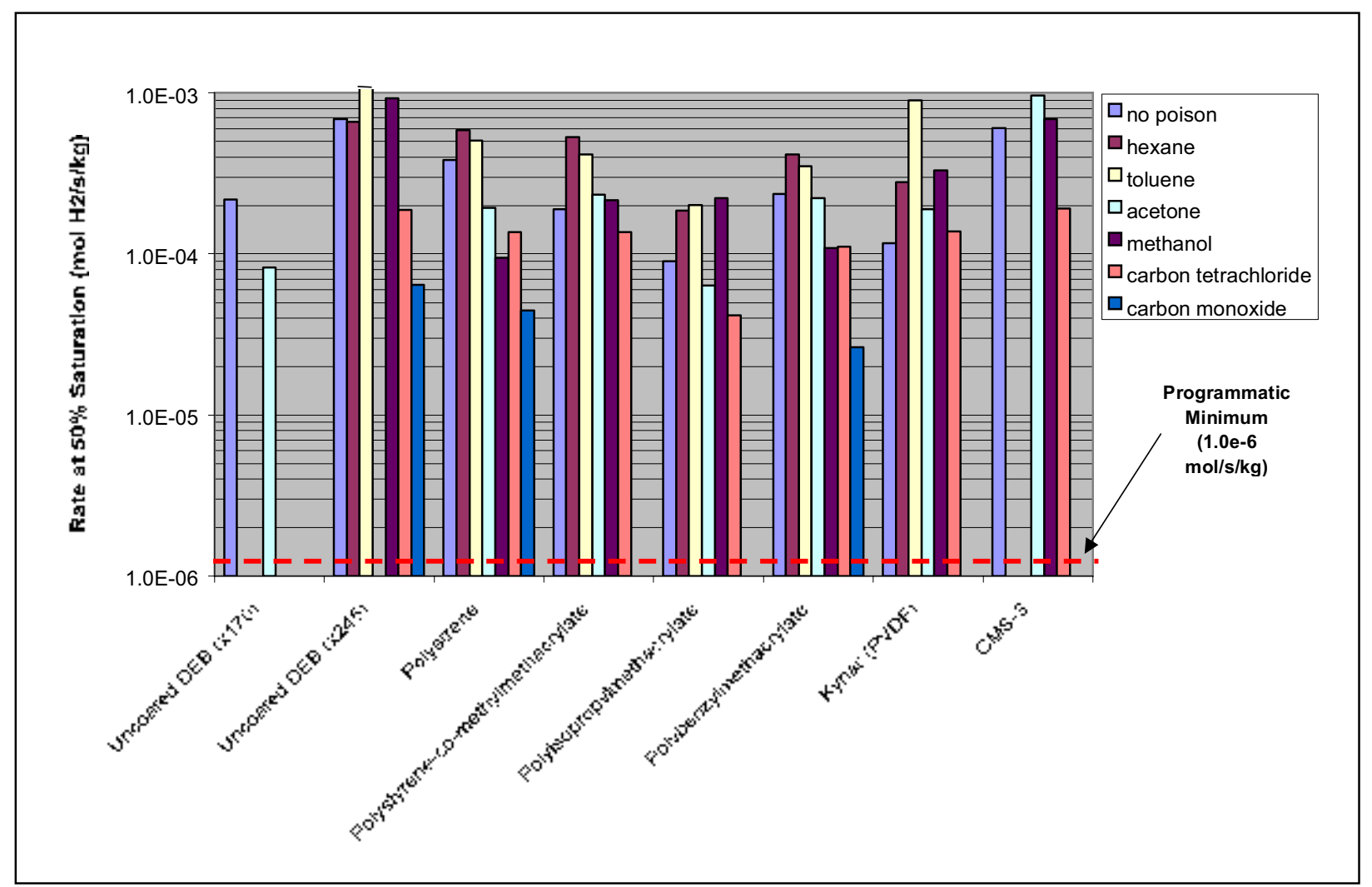

Figure 21. Effect of poisons on hydrogen getter rates in an atmosphere of $5 \% \mathrm{H}_{2}$ in nitrogen at a temperature of $77^{\circ} \mathrm{F}\left(25^{\circ} \mathrm{C}\right)$.

Table 12. Effect of carbon tetrachloride on hydrogen removal rates $\left(\right.$ mole $\left.\mathrm{H}_{2} \mathrm{~s}^{-1} \mathrm{~kg}^{-1}\right)$ of DEB and coated $\mathrm{DEB}$ at $160^{\circ} \mathrm{F}\left(71.1^{\circ} \mathrm{C}\right)$ in an atmosphere of $5 \%$ hydrogen in nitrogen. The minimum programmatic criterion is $1.0 \times 10^{-6} \mathrm{~mol} \mathrm{H}_{2} \mathrm{~s}^{-1} \mathrm{~kg}^{-1}$.

\begin{tabular}{lcc}
\hline \multicolumn{1}{c}{ Material } & No Poison & Carbon Tetrachloride \\
\hline Uncoated DEB (x170) & $6.81 \mathrm{E}-04$ & $4.42 \mathrm{E}-04$ \\
Polystyrene & $2.81 \mathrm{E}-04$ & $4.28 \mathrm{E}-04$ \\
Polystyrene-co-methylmethacrylate & $1.13 \mathrm{E}-04$ & $9.52 \mathrm{E}-05$ \\
Polyisopropylmethacrylate & $3.48 \mathrm{E}-04$ & $2.82 \mathrm{E}-04$ \\
Polybenzylmethacrylate & $1.16 \mathrm{E}-04$ & $4.24 \mathrm{E}-05$ \\
Kynar (PVDF) & $2.00 \mathrm{E}-04$ & $2.71 \mathrm{E}-04$ \\
CMS-3 & $6.50 \mathrm{E}-04$ & $6.27 \mathrm{E}-04$ \\
\hline
\end{tabular}

in polybenzylmethacrylate-coated DEB appears to be slightly diminished. However, at $160^{\circ} \mathrm{F}\left(71.1^{\circ} \mathrm{C}\right)$, all materials exhibit removal rates that exceed the programmatic minimum in the presence of carbon tetrachloride by at least 1 order of magnitude.

These test results, in conjunction with data collected to evaluate operating temperature range, were used to select 2 coated getters (polystyrene-coated DEB and polybenzylmethacrylate-coated DEB) for additional testing, as described in the following section. Uncoated DEB was also the subject of continued 


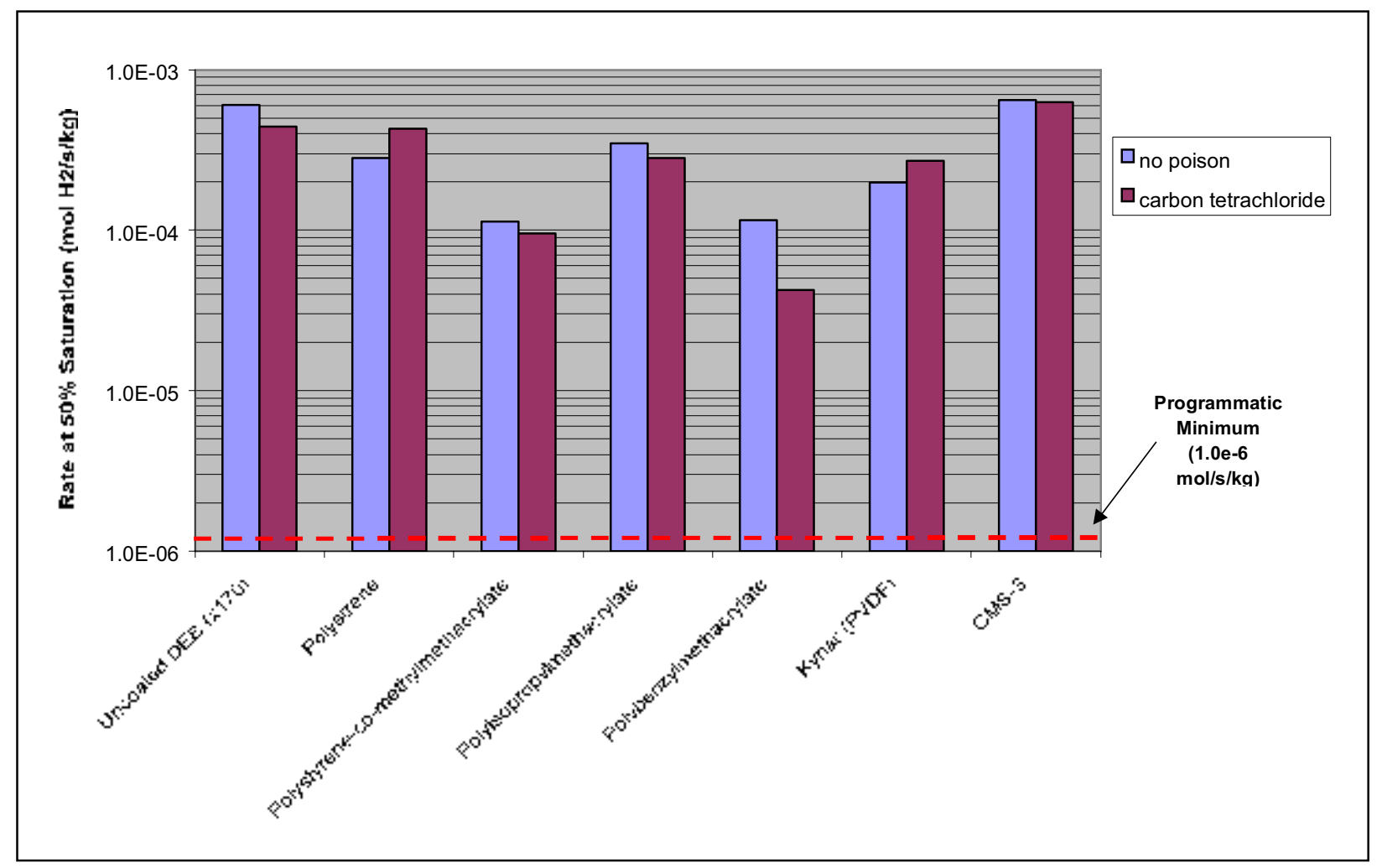

Figure 22. Effect of carbon tetrachloride on hydrogen getter rates in an atmosphere of $5 \% \mathrm{H}_{2}$ in nitrogen at a temperature of $160^{\circ} \mathrm{F}\left(71.1^{\circ} \mathrm{C}\right)$.

testing as a control measure. A comparison of hydrogen removal rates for these three materials in the presence and absence of $1,000 \mathrm{ppm}$ carbon tetrachloride is presented in Table 13. The following may be concluded from these data:

1. Hydrogen removal rates are greatest in uncoated DEB and progressively decrease in polystyreneand polybenzylmethacrylate-coated DEB, respectively.

2. In comparing the hydrogen removal rate in an inert atmosphere versus an atmosphere containing carbon tetrachloride, the largest rate decrease is displayed by uncoated DEB. Rates for polystyreneand polybenzylmethacrylate-coated DEB exhibit less of an effect from carbon tetrachloride, in that order.

3. The hydrogen removal rate in an atmosphere of carbon tetrachloride is approximately the same for all three materials.

It is of note that these results (Table 13) are consistent with the permeability data presented in Table 4. The data presented in Table 4 were generated with a pressure differential of $20 \mathrm{psi}$ in an atmosphere of 1,000 ppm carbon tetrachloride. In contrast, the dynamic test apparatus used for Phase 2 employed no pressure differential. 
Table 13. Comparison of hydrogen removal rates $\left(\right.$ mole $\left.\mathrm{H}_{2} \mathrm{~s}^{-1} \mathrm{~kg}^{-1}\right)$ in the presence and absence of $1,000 \mathrm{ppm}$ carbon tetrachloride. Temperature is $77^{\circ} \mathrm{F}\left(25^{\circ} \mathrm{C}\right)$ and the atmosphere is $5 \%$ hydrogen in nitrogen. Minimum programmatic criterion is $1.0 \times 10^{-6} \mathrm{~mol} \mathrm{H}_{2} \mathrm{~s}^{-1} \mathrm{~kg}^{-1}$.

\begin{tabular}{lcccc}
\hline \multicolumn{1}{c}{ Material } & No Poison & $\begin{array}{c}\text { Carbon } \\
\text { Tetrachloride }\end{array}$ & $\begin{array}{c}\text { Rate Ratio: } \\
\mathrm{CCl}_{4} / \text { No Poison }\end{array}$ & $\begin{array}{c}\text { Rate Ratio: } \\
\text { No Poison/CCl }\end{array}$ \\
\hline Uncoated DEB (x245) & $6.91 \mathrm{E}-04$ & $1.89 \mathrm{E}-04$ & 0.27 & 3.66 \\
Polystyrene & $3.83 \mathrm{E}-04$ & $1.37 \mathrm{E}-04$ & 0.36 & 2.80 \\
Polybenzylmethacrylate & $2.36 \mathrm{E}-04$ & $1.11 \mathrm{E}-04$ & 0.47 & 2.12 \\
\hline
\end{tabular}

4.4.1.4.2 Hydrogen in Air-Rate measurements were performed on uncoated DEB, polystyrene-coated DEB, and polybenzylmethacrylate-coated DEB in an atmosphere of $3 \% \mathrm{H}_{2}$ in air at a temperature of $77^{\circ} \mathrm{F}\left(25^{\circ} \mathrm{C}\right)$ in the presence of the organic poisons listed in Table 10. The results are summarized in Table 14 and plotted in Figure 23. Toluene, acetone, and methanol actually enhance removal rates for all materials with one exception. The apparent increase in rate exhibited by polystyrenecoated DEB in the presence of methanol is at the upper limit of uncertainty. Hexane does not affect the removal rates for uncoated DEB and enhances removal rates for polystyrene-coated DEB and polybenzylmethacrylate-coated DEB. The cause of this enhancement is unknown. Carbon tetrachloride does not affect the removal rate for uncoated DEB and polystyrene-coated DEB (within the limits of uncertainty). Carbon tetrachloride slightly diminishes the removal rate for polybenzylmethacrylate-coated DEB. The effect of carbon tetrachloride on removal rates of hydrogen in air is less pronounced than the effect on removal rates of hydrogen in nitrogen. At $77^{\circ} \mathrm{F}\left(25^{\circ} \mathrm{C}\right)$, all three materials exhibit removal rates that exceed the programmatic minimum by approximately 2 orders of magnitude.

Rate measurements were performed on uncoated DEB, polystyrene-coated DEB, and polybenzylmethacrylate-coated DEB in an atmosphere of $3 \% \mathrm{H}_{2}$ in air at a temperature of $160^{\circ} \mathrm{F}\left(71.1^{\circ} \mathrm{C}\right)$ in the presence of carbon tetrachloride. The effect of carbon tetrachloride at $160^{\circ} \mathrm{F}\left(71.1^{\circ} \mathrm{C}\right)$ is summarized in Table 15 and plotted in Figure 24. Carbon Tetrachloride does not exhibit a measurable effect on removal rates for hydrogen in air at $160^{\circ} \mathrm{F}\left(71.1^{\circ} \mathrm{C}\right)$.

4.4.1.5 Synergy of Poisons. Tests were performed on uncoated DEB (lot x245), polystyrene-, and polybenzylmethacrylate-coated DEB to evaluate the impact on hydrogen removal rate of a mixture of poisons known to inhibit getter performance. A carbon tetrachloride concentration of approximately $1000 \mathrm{ppm}$ mixed with a carbon monoxide concentration of approximately $1 \%$ in an atmosphere of $5 \% \mathrm{H}_{2}$ in nitrogen was used in testing. The results are summarized in Table 16 and plotted in Figure 25. The

Table 14. Effect of poisons on hydrogen removal rates $\left(\mathrm{mol} \mathrm{H}_{2} \mathrm{~s}^{-1} \mathrm{~kg}^{-1}\right)$ of uncoated DEB, polystyrenecoated DEB, and polybenzylmethacrylate-coated DEB at $77^{\circ} \mathrm{F}\left(25^{\circ} \mathrm{C}\right)$ in an atmosphere of $3 \%$ hydrogen in air. The hydrogen removal rate is reported for $50 \%$ capacity except for uncoated DEB with carbon monoxide (rate reported for $28 \%$ saturation) and polystyrene-coated DEB with carbon monoxide (rate reported for $43 \%$ saturation). The minimum programmatic criterion is $1.0 \times 10^{-6} \mathrm{~mol} \mathrm{H}_{2} \mathrm{~s}^{-1} \mathrm{~kg}^{-1}$.

\begin{tabular}{lccccccc}
\hline \multicolumn{1}{c}{ Material } & & & & & & \multicolumn{2}{c}{$\begin{array}{c}\text { Carbon } \\
\text { Carbon } \\
\text { monoxide } \\
(0.5 \%)\end{array}$} \\
\hline Uncoated DEB (x245) & $6.53 \mathrm{E}-04$ & $6.74 \mathrm{E}-04$ & $1.33 \mathrm{E}-03$ & $1.20 \mathrm{E}-03$ & $1.07 \mathrm{E}-03$ & $6.53 \mathrm{E}-04$ & $2.04 \mathrm{E}-05$ \\
Polystyrene & $3.81 \mathrm{E}-04$ & $6.57 \mathrm{E}-04$ & $9.82 \mathrm{E}-04$ & $6.77 \mathrm{E}-04$ & $5.08 \mathrm{E}-04$ & $2.61 \mathrm{E}-04$ & $1.32 \mathrm{E}-05$ \\
Polybenzylmethacrylate & $3.37 \mathrm{E}-04$ & $6.96 \mathrm{E}-04$ & $5.65 \mathrm{E}-04$ & $1.13 \mathrm{E}-03$ & $9.87 \mathrm{E}-04$ & $2.07 \mathrm{E}-04$ & $2.67 \mathrm{E}-05$ \\
\hline
\end{tabular}




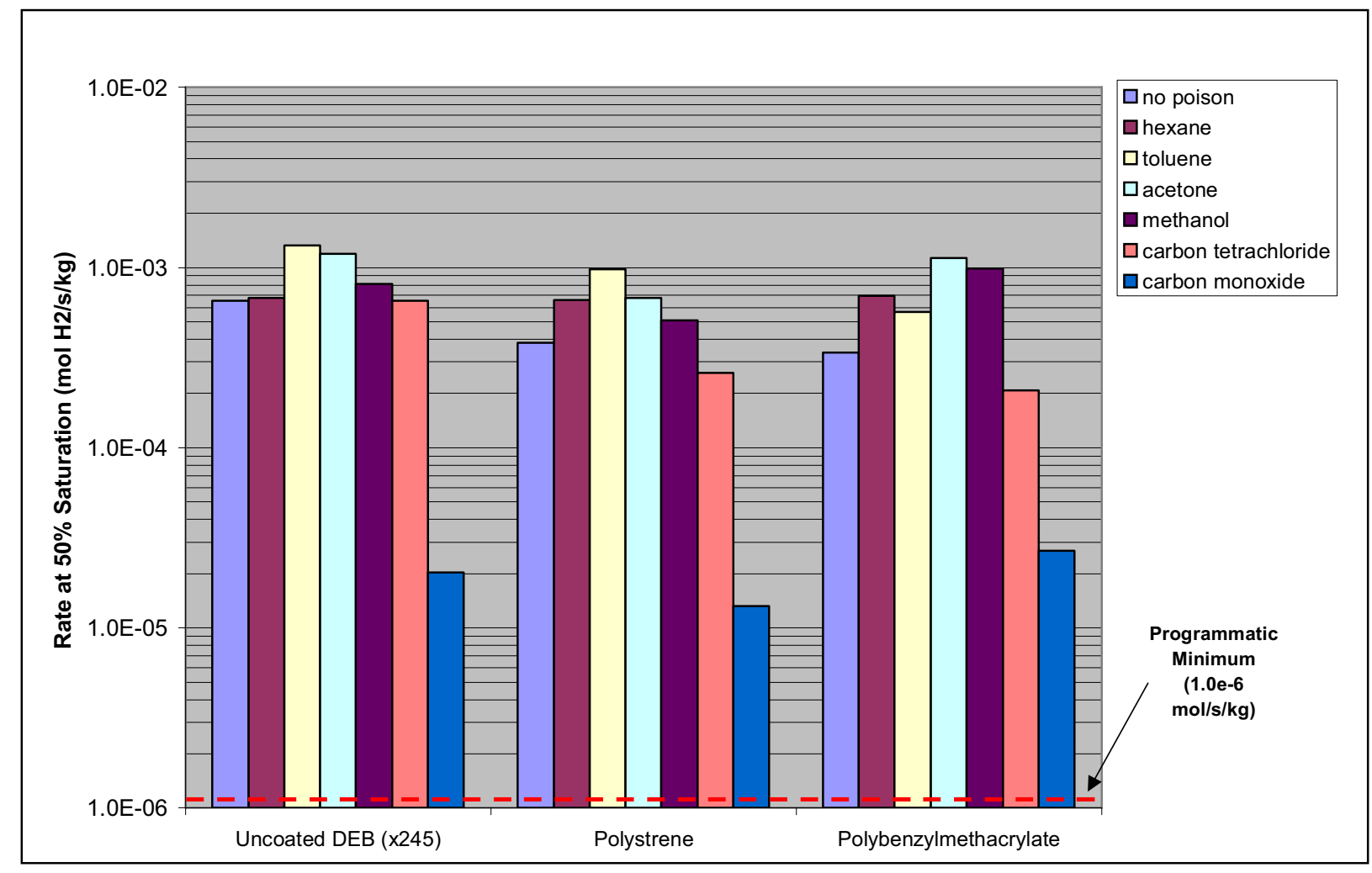

Figure 23. Effect of poisons on uncoated DEB (lot x245), polystyrene-coated DEB, and polybenzylmethacrylate-coated DEB getter rates in an atmosphere of $3 \% \mathrm{H}_{2}$ in air at a temperature of $77^{\circ} \mathrm{F}\left(25^{\circ} \mathrm{C}\right)$. The hydrogen removal rate is plotted as mole $\mathrm{H}_{2} \mathrm{~s}^{-1} \mathrm{~kg}^{-1}$ at $50 \%$ capacity except for uncoated DEB with carbon monoxide (rate reported for $28 \%$ saturation) and polystyrene-coated DEB with carbon monoxide (rate reported for $43 \%$ saturation).

Table 15. Effect of carbon tetrachloride on hydrogen removal rates (mole $\mathrm{H}_{2} \mathrm{~s}^{-1} \mathrm{~kg}^{-1}$ ) of uncoated DEB, polystyrene-coated $\mathrm{DEB}$, and polybenzylmethacrylate-coated $\mathrm{DEB}$ at $160^{\circ} \mathrm{F}\left(77.1^{\circ} \mathrm{C}\right)$ in an atmosphere of $3 \%$ hydrogen in air. The minimum programmatic criterion is $1.0 \times 10^{-6} \mathrm{~mol} \mathrm{H}_{2} \mathrm{~s}^{-1} \mathrm{~kg}^{-1}$.

\begin{tabular}{lcc}
\multicolumn{1}{c}{ Material } & No Poison & Carbon Tetrachloride \\
\hline Uncoated DEB (x245) & $7.34 \mathrm{E}-04$ & $6.85 \mathrm{E}-04$ \\
Polystyrene & $4.62 \mathrm{E}-04$ & $4.76 \mathrm{E}-04$ \\
Polybenzylmethacrylate & $4.68 \mathrm{E}-04$ & $5.68 \mathrm{E}-04$ \\
\hline
\end{tabular}

combination of the two poisons impact the hydrogen removal rate of all of the materials that were tested. Rates in uncoated DEB and polystyrene-coated DEB are reduced by approximately one order-ofmagnitude. The rate observed for polybenzylmethacrylate-coated DEB is reduced by approximately $70 \%$. However, despite these impacts, all three materials exhibit removal rates that exceed the programmatic minimum by at least one order-of-magnitude. 


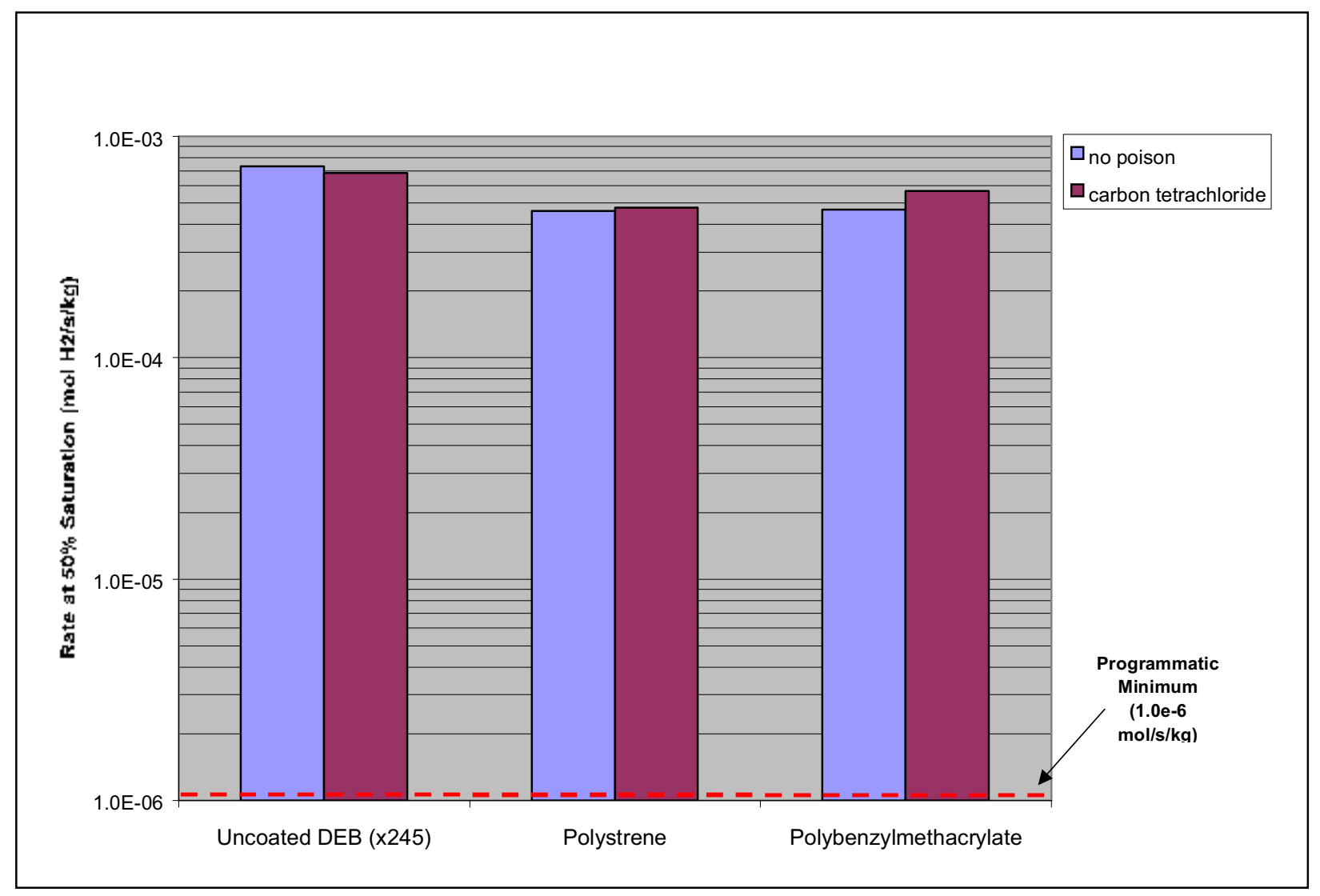

Figure 24. Effect of carbon tetrachloride on uncoated DEB (lot x245), polystyrene-coated DEB, and polybenzylmethacrylate-coated DEB getter rates in an atmosphere of $3 \% \mathrm{H}_{2}$ in air at a temperature of $160^{\circ} \mathrm{F}\left(71.1^{\circ} \mathrm{C}\right)$.

Table 16. Effect of carbon tetrachloride (1000 ppm) plus carbon monoxide (1\%) on hydrogen removal rates (mole $\mathrm{H}_{2} \mathrm{~s}^{-1} \mathrm{~kg}^{-1}$ ) of uncoated DEB, polystyrene-coated DEB, and polybenzylmethacrylate-coated DEB at $77^{\circ} \mathrm{F}\left(25^{\circ} \mathrm{C}\right)$ in an atmosphere of $5 \%$ hydrogen in nitrogen. Minimum programmatic criterion is $1.0 \times 10^{-6} \mathrm{~mol} \mathrm{H}_{2} \mathrm{~s}^{-1} \mathrm{~kg}^{-1}$.

\begin{tabular}{lcc}
\hline \multicolumn{1}{c}{ Material } & No Poison & $\begin{array}{c}\text { Carbon Tetrachloride }+ \text { Carbon } \\
\text { Monoxide }\end{array}$ \\
\hline Uncoated DEB (x245) & $6.91 \mathrm{E}-04$ & $8.91 \mathrm{E}-05$ \\
Polystyrene & $3.83 \mathrm{E}-04$ & $1.14 \mathrm{E}-05$ \\
Polybenzylmethacrylate & $2.36 \mathrm{E}-04$ & $8.03 \mathrm{E}-05$ \\
\hline
\end{tabular}

4.4.1.5.1 Free Liquids-The getter material will be operated in air-potentially resulting in formation of water vapor - up to the scaled loading for use in the TRUPACT-II. The total maximum quantity of water that could be produced by recombination of hydrogen with oxygen is calculated from the maximum level of hydrogen production that has been determined by the program $\left(1.2 \times 10^{-5}\right.$ mol $\mathrm{H}_{2} \mathrm{~s}^{-1}$ ) and the maximum amount of time specified for containment in the TRUPACT-II (60 days). The result is 62 moles, or 1.1 liters of liquid water. This Value is significantly below the limited mandated for the TRUPACT-II payload. 


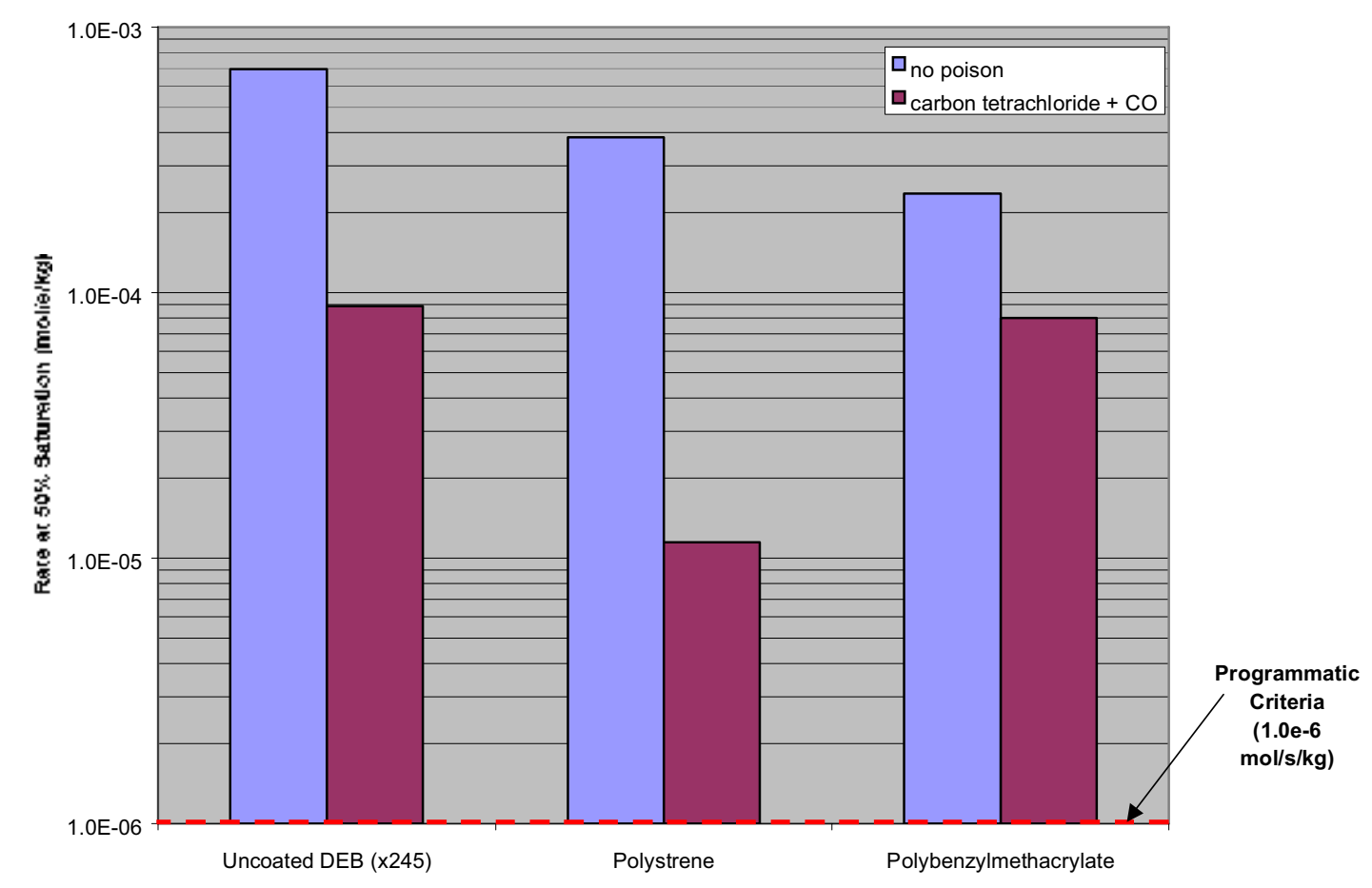

Figure 25. Effect of carbon tetrachloride (1000 ppm) plus carbon monoxide (1\%) on hydrogen removal rates (mole $\mathrm{H}_{2} \mathrm{~s}^{-1} \mathrm{~kg}^{-1}$ at $50 \%$ capacity) of uncoated DEB, polystyrene-coated DEB, and polybenzylmethacrylate-coated DEB at $77^{\circ} \mathrm{F}\left(25^{\circ} \mathrm{C}\right)$ in an atmosphere of $5 \%$ hydrogen in nitrogen.

Tests were performed on uncoated DEB (lot x245), polystyrene-, and polybenzylmethacrylatecoated DEB to evaluate the impact of water vapor on hydrogen removal rate. The tests were conducted at $77^{\circ} \mathrm{F}\left(25^{\circ} \mathrm{C}\right)$ in an atmosphere of $5 \%$ hydrogen in nitrogen that contained approximately $20,000 \mathrm{ppm}_{2} \mathrm{O}$ (relative humidity of 67\%). The hydrogen removal rate was measured at low getter capacity (approximately 5\%) and at approximately 50\% getter capacity to determine the impact of water formation. The results are summarized in Table 17. In the presence of water vapor, the hydrogen removal rate of uncoated DEB remained unchanged between 5\% and 50\% capacity. Rates decreased slightly for polystyrene- and polybenzylmethacrylate-coated DEB. Compared to tests conducted without water vapor, the hydrogen removal rate at $50 \%$ capacity of uncoated DEB and polystyrene-coated DEB increased by a factor of approximately two. The hydrogen removal rate of polybenzylmethacrylate-coated DEB was not affected by water vapor.

Table 17. Effect of water vapor (20,000 ppm, relative humidity of $67 \%)$ on hydrogen removal rates (mole $\mathrm{H}_{2} \mathrm{~s}^{-1} \mathrm{~kg}^{-1}$ ) of uncoated DEB, polystyrene-coated DEB, and polybenzylmethacrylate-coated DEB at $77^{\circ} \mathrm{F}\left(25^{\circ} \mathrm{C}\right)$ in an atmosphere of $5 \%$ hydrogen in nitrogen. Minimum programmatic criterion is $\underline{1.0 \times 10^{-6} \mathrm{~mol} \mathrm{H}_{2} \mathrm{~s}^{-1} \mathrm{~kg}^{-1} \text {. }}$

\begin{tabular}{lccc}
\hline & \multicolumn{2}{c}{ Water Vapor Present } & No Water Vapor \\
\hline \multicolumn{1}{c}{ Material } & 5\% DEB saturation & $50 \%$ DEB saturation & 50\% DEB saturation \\
\hline Uncoated DEB (x245) & $1.45 \mathrm{E}-03$ & $1.43 \mathrm{E}-03$ & $6.91 \mathrm{E}-04$ \\
Polystyrene & $1.00 \mathrm{E}-03$ & $8.14 \mathrm{E}-04$ & $3.83 \mathrm{E}-04$ \\
Polybenzylmethacrylate & $2.53 \mathrm{E}-04$ & $1.50 \mathrm{E}-04$ & $2.36 \mathrm{E}-04$ \\
\hline
\end{tabular}


4.4.1.6 Effect of Aging. Tests were performed on "aged" samples of uncoated DEB (lots x170 and x245), polystyrene-coated DEB, and polybenzylmethacrylate-coated DEB to evaluate the impact of longterm storage at elevated temperature on getter performance. These "aged" samples were evaluated for hydrogen removal rate and capacity after extended storage $(>60$ days $)$ at $160^{\circ} \mathrm{F}$ in air.

4.4.1.6.1 Capacity-Capacity measurements were performed on aged samples of uncoated DEB (lots x 170 and $\times 245$ ) and polystyrene-coated DEB in an atmosphere of $5 \% \mathrm{H}_{2}$ in $\mathrm{N}_{2}$ at a temperature of $77^{\circ} \mathrm{F}\left(25^{\circ} \mathrm{C}\right)$. The aged samples did not exhibit reduced capacity.

4.4.1.6.2 Rate-Rate measurements were performed on aged samples in an atmosphere of 5\% $\mathrm{H}_{2}$ in $\mathrm{N}_{2}$ at a temperature of $77^{\circ} \mathrm{F}\left(25^{\circ} \mathrm{C}\right)$ (Figure 26). The aging process imparts an insignificant decrease on removal rate for uncoated DEB (lots x170 and x245) and polystyrene-coated DEB. Aged polybenzylmethacrylate-coated DEB exhibits a $50 \%$ decrease in removal rate. Hydrogen removal rates for all three aged materials exceed the programmatic minimum by at least 2 orders of magnitude.

4.4.1.7 Effect of Pressure. Tests to evaluate impact of pressure on getter performance were performed by Savannah River Technology Center (SRTC) in a static system (no flowing gas). The rates of hydrogen removal by uncoated DEB (lot x245) and polystyrene-coated DEB were measured at total pressures of 0 psig and $50 \mathrm{psig}$ in atmospheres of $5.0 \% \mathrm{H}_{2}$ in nitrogen and $4.8 \% \mathrm{H}_{2}$ in air. Test results are summarized in Table 18. Pressure had no measurable effect on the hydrogen removal rate of uncoated

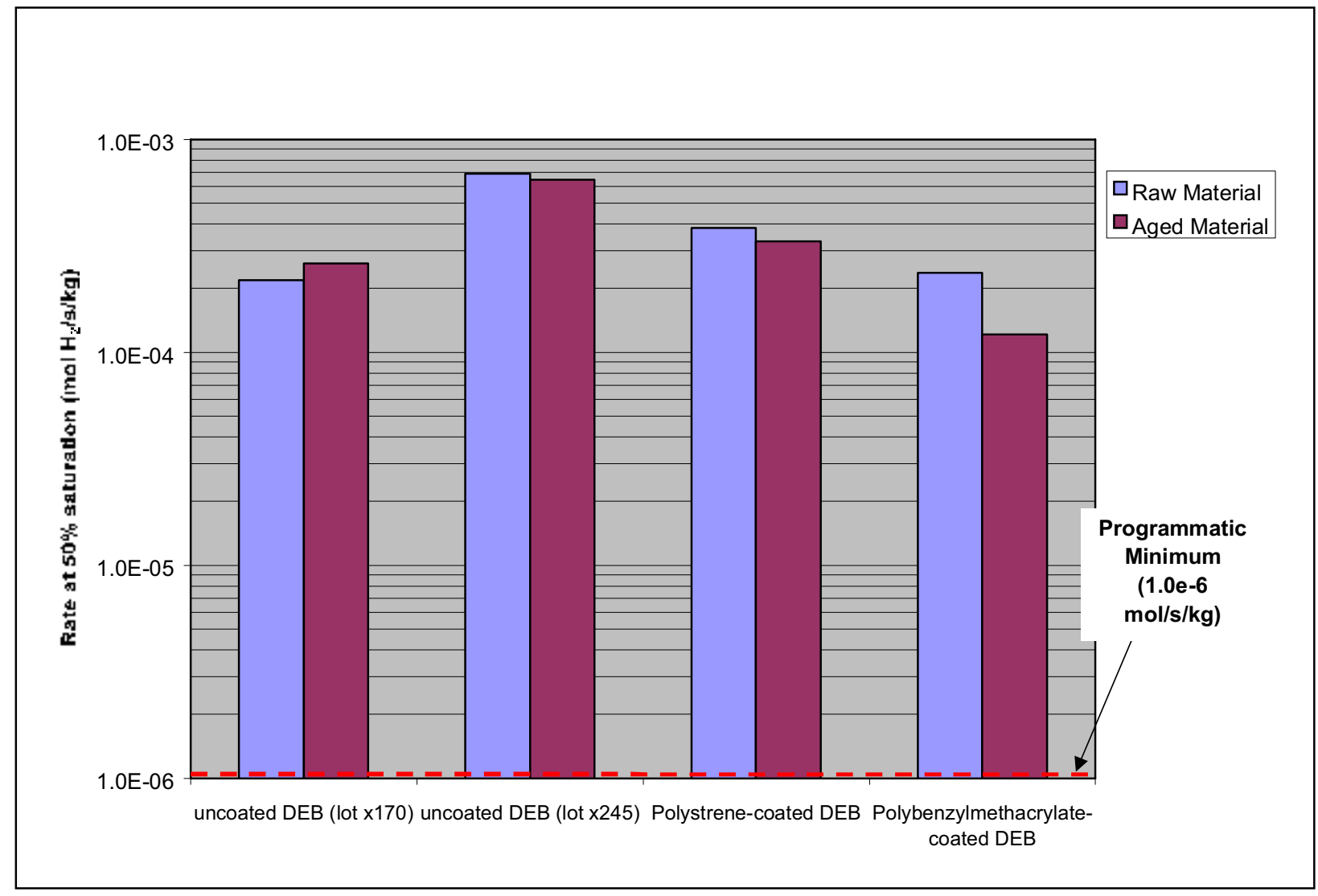

Figure 26. Effect of aging on hydrogen getter rates of uncoated DEB (lots x170 and x245), polystyrenecoated DEB, and polybenzylmethacrylate-coated DEB in an atmosphere of $5 \% \mathrm{H}_{2}$ in nitrogen at a temperature of $77^{\circ} \mathrm{F}\left(25^{\circ} \mathrm{C}\right)$. Samples were aged for 60 days at $160^{\circ} \mathrm{F}$ in air. 
Table 18. Effect of pressure on hydrogen removal rate (mole $\mathrm{H}_{2} \mathrm{~s}^{-1} \mathrm{~kg}^{-1}$ at $50 \%$ capacity) for uncoated DEB (lot x245) and polystyrene-coated DEB. Temperature is $77^{\circ} \mathrm{F}\left(25^{\circ} \mathrm{C}\right)$ and the atmosphere is $5 \%$ hydrogen in nitrogen and hydrogen in air. Tests performed by SRTC, uncertainty is $50 \%$. Minimum programmatic criterion is $1.0 \times 10^{-6} \mathrm{~mol} \mathrm{H}_{2} \mathrm{~s}^{-1} \mathrm{~kg}^{-1}$.

\begin{tabular}{crcc}
\hline Material & Pressure & $\mathrm{H}_{2}$ in Air & $\mathrm{H}_{2}$ in Nitrogen \\
\hline Uncoated DEB (x245) & 0 psig & $5.44 \mathrm{E}-03$ & $3.18 \mathrm{E}-03$ \\
Polystyrene-coated DEB & 50 psig & $4.94 \mathrm{E}-03$ & $1.55 \mathrm{E}-03$ \\
& 0 psig & $3.23 \mathrm{E}-03$ & $8.60 \mathrm{E}-04$ \\
& 50 psig & $9.02 \mathrm{E}-04$ & $2.99 \mathrm{E}-04$ \\
\hline
\end{tabular}

DEB in nitrogen or air. Pressure reduced the hydrogen removal rate of polystyrene-coated DEB by approximately $65 \%$ (nitrogen atmosphere) to $70 \%$ (in air). The impacts of pressure are negligible as both materials exhibit removal rates that exceed the programmatic minimum by at least $2 \frac{1}{2}$ orders-ofmagnitude.

4.4.1.8 Reversibility. The potential of hydrogen absorbers to release hydrogen at elevated temperature is known as reversibility. DEB is not subject to reversible release of hydrogen because the hydrogen is chemically reacted to form stable covalent bonds. A test of reversibility was conducted as required by the consolidated test plan to verify this statement. In this test, a sample of uncoated DEB getter was loaded with hydrogen to full capacity, flushed with nitrogen at room temperature, and then heated with continued nitrogen flushing to determine if hydrogen releases. In detail, a $0.50 \mathrm{~g}$ sample of uncoated DEB was sealed in the test column and flushed with nitrogen for approximately 120 minutes. Then the sample was heated to $70^{\circ} \mathrm{C}$ for approximately 120 minutes. In both portions of the test, effluent was monitored for hydrogen concentration. No hydrogen was detected in effluent gas at any portion of the test, indicating no release of hydrogen at room temperature or at $70^{\circ} \mathrm{C}$.

4.4.1.9 Effect of Radiation-SRTC. Tests to evaluate impact of pressure on getter performance were also performed by SRTC in a static system. Uncoated DEB (lot x245) and polystyrene-coated DEB were exposed to a radiation dose of $2.5 \times 10^{4} \mathrm{R}$ in a cobalt-60 gamma source. The hydrogen absorption rate and capacity of the sample were then measured in atmospheres of $5.0 \% \mathrm{H}_{2}$ in nitrogen and $4.8 \% \mathrm{H}_{2}$ in air in the standard manner employed by SRTC. Test results are summarized in Table 19. Radiation had no measurable effect on the hydrogen removal rate of either material.

4.4.1.10 Temperature Effect Calculation. The hydrogenation reaction of DEB getter and the recombination reaction to form water are exothermic and will provide thermal output. The heat generated by these reactions, and the potential impact on the TRUPACT-II payload, are calculated and discussed below.

Table 19. Effect of radiation on hydrogen removal rate (mole $\mathrm{H}_{2} \mathrm{~s}^{-1} \mathrm{~kg}^{-1}$ at $50 \%$ capacity) for uncoated DEB (lot $\mathrm{x} 245$ ) and polystyrene-coated DEB. Temperature is $77^{\circ} \mathrm{F}\left(25^{\circ} \mathrm{C}\right)$ and the atmosphere is $5 \%$ hydrogen in nitrogen and hydrogen in air. Tests performed by SRTC, uncertainty is $50 \%$. Minimum programmatic criterion is $1.0 \times 10^{-6} \mathrm{~mol} \mathrm{H}_{2} \mathrm{~s}^{-1} \mathrm{~kg}^{-1}$.

\begin{tabular}{clcc} 
Material & & $\mathrm{H}_{2}$ in Air & $\mathrm{H}_{2}$ in Nitrogen \\
\hline Uncoated DEB (x245) & Unirradiated & $5.44 \mathrm{E}-03$ & $3.18 \mathrm{E}-03$ \\
& Irradiated & $4.87 \mathrm{E}-03$ & $3.48 \mathrm{E}-03$ \\
Polystyrene-coated DEB & Unirradiated & $3.23 \mathrm{E}-03$ & $8.60 \mathrm{E}-04$ \\
& Irradiated & $2.19 \mathrm{E}-03$ & $1.22 \mathrm{E}-03$ \\
\hline
\end{tabular}


The hydrogenation reaction generates approximately $125 \mathrm{~kJ} \mathrm{~mol}^{-1}$ and the recombination reaction generates $286 \mathrm{~kJ} \mathrm{~mol}^{-1}$ (liquid water). Heat generation for 60 days at maximum hydrogen production $\left(1.2 \times 10^{-5} \mathrm{~mol} \mathrm{H}_{2} \mathrm{~s}^{-1}\right)$ for each of these reactions is: (1) recombination $=3.4$ watts, and (2) hydrogenation of $\mathrm{DEB}=1.5$ watts.

The thermal output for the recombination reaction is greater than that of the hydrogenation reaction. In a worse case scenario, with all of the produced hydrogen taking part in the recombination reaction, the $3.4 \mathrm{~W}$ of heat generated is significantly below the $40 \mathrm{~W}$ maximum authorized for the TRUPACT-II payload. In a situation with some amount of the produced hydrogen taking part in each of the reactions, the heat generation will be even less than $3.4 \mathrm{~W}$.

4.4.1.11 Evaluation of SRTC samples. Los Alamos National Laboratory (LANL) performed dynamic tests on the polymer getter and Savannah River Technology Center (SRTC) performed static tests on the DEB getter (uncoated and coated with polystyrene). Test parameters for measuring hydrogen removal rate included atmosphere $\left(5 \% \mathrm{H}_{2}\right.$ in nitrogen and $3 \% \mathrm{H}_{2}$ in air), temperature $(160,77$, and $\left.-20^{\circ} \mathrm{F}\right)$, and presence of poison (1000 ppm carbon tetrachloride). Test results for polymer and DEB getters are presented in Tables 20 and 21, respectively. Dynamic testing (Table 20) verifies that polymer getter exceeds the programmatic minimum at the specified conditions.

Test results comparing DEB getter performance as determined by dynamic and static test methods are presented in Figures 27 and 28. In an atmosphere of nitrogen ( \pm carbon tetrachloride) and at a temperature of $160^{\circ} \mathrm{F}\left(71^{\circ} \mathrm{C}\right)$, hydrogen removal rates are approximately $15 x$ (polystyrene-coated DEB) to 30x (uncoated DEB) faster as determined by the static method compared to the dynamic testing method.

In air ( \pm carbon tetrachloride) and at a temperature of $160^{\circ} \mathrm{F}\left(71^{\circ} \mathrm{C}\right)$, the rates are approximately $5 \mathrm{x}$ (polystyrene-coated DEB) to $10 \mathrm{x}$ (uncoated DEB) faster as determined by the static method compared to the dynamic testing method. At $77^{\circ} \mathrm{F}\left(25^{\circ} \mathrm{C}\right)$, the rates determined by the static method range from 0.5 to 20x faster compared to the dynamic method. At $23^{\circ} \mathrm{F}\left(-29^{\circ} \mathrm{C}\right)$, rates determined by the static method are approximately $10 \%$ as fast as rates determined in the dynamic method for uncoated DEB (air and nitrogen atmospheres) and polystyrene (nitrogen atmosphere). At this temperature, the rates determined for polystyrene-coated DEB in air are approximately equal in both methods.

Table 20. Hydrogen removal rate (mole $\mathrm{H}_{2} \mathrm{~s}^{-1} \mathrm{~kg}^{-1}$ at $50 \%$ capacity) for polymer-zeolite getter in an atmosphere of $5 \% \mathrm{H}_{2}$ in nitrogen and $3 \% \mathrm{H}_{2}$ in air at temperatures of 160 to $-20^{\circ} \mathrm{F}\left(71.1\right.$ to $\left.-28.9^{\circ} \mathrm{C}\right)$. Minimum programmatic criterion is $1.0 \times 10^{-6} \mathrm{~mol} \mathrm{H}_{2} \mathrm{~s}^{-1} \mathrm{~kg}^{-1}$.

\begin{tabular}{lcccc}
\hline \multirow{2}{*}{ Atmosphere } & \multicolumn{2}{c}{ Temperature } & \multicolumn{2}{c}{ Rate } \\
\cline { 2 - 5 } $5 \% \mathrm{H}_{2}$ / Nitrogen & $\left({ }^{\circ} \mathrm{F}\right)$ & $\left({ }^{\circ} \mathrm{C}\right)$ & No Poison & Carbon Tetrachloride \\
& 160 & 71 & $6.81 \mathrm{E}-04$ & $6.55 \mathrm{E}-04$ \\
& 77 & 25 & $5.93 \mathrm{E}-04$ & $6.11 \mathrm{E}-04$ \\
& 23 & -29 & $1.83 \mathrm{E}-04$ & $8.16 \mathrm{E}-05$ \\
$3 \% \mathrm{H}_{2} /$ Air & & & $1.38 \mathrm{E}-03$ \\
& 160 & 71 & $1.44 \mathrm{E}-03$ & $1.28 \mathrm{E}-03$ \\
& 77 & 25 & $1.28 \mathrm{E}-03$ & $1.23 \mathrm{E}-03$ \\
\hline
\end{tabular}


Table 21. Comparison of hydrogen removal rate (mole $\mathrm{H}_{2} \mathrm{~s}^{-1} \mathrm{~kg}^{-1}$ at $50 \%$ capacity) determined for uncoated DEB (lot x245) and polystyrene-coated DEB by dynamic and static test methods. Tests variables include atmosphere $\left(5 \% \mathrm{H}_{2}\right.$ in nitrogen and $3 \% \mathrm{H}_{2}$ in air), temperature $\left(160,77\right.$, and $\left.-20^{\circ} \mathrm{F}\right)$, and presence of poison (1000 ppm carbon tetrachloride). Minimum programmatic criterion is $1.0 \times 10^{-6} \mathrm{~mol} \mathrm{H}_{2} \mathrm{~s}^{-1} \mathrm{~kg}^{-1}$. Significances of highlighted values are discussed in the text.

\begin{tabular}{|c|c|c|c|c|c|c|c|c|}
\hline \multirow[b]{2}{*}{ Atmosphere } & \multicolumn{2}{|c|}{ Temperature } & \multicolumn{3}{|c|}{ Uncoated DEB, No Poison } & \multicolumn{3}{|c|}{ Uncoated DEB plus $\mathrm{CCl}_{4}$} \\
\hline & $\left({ }^{\circ} \mathrm{F}\right)$ & $\left({ }^{\circ} \mathrm{C}\right)$ & $\begin{array}{c}\text { Dynamic } \\
\text { Testing }\end{array}$ & $\begin{array}{c}\text { Static } \\
\text { Testing }\end{array}$ & $\begin{array}{c}\text { Ratio } \\
\text { Static/Dynamic } \\
\end{array}$ & $\begin{array}{c}\text { Dynamic } \\
\text { Testing }\end{array}$ & Static Testing & $\begin{array}{c}\text { Ratio } \\
\text { Static/Dynamic } \\
\end{array}$ \\
\hline \multirow[t]{3}{*}{ Vacuum } & 160 & 71 & 一 & $4.07 \mathrm{E}-02$ & - & 一 & $1.28 \mathrm{E}-02$ & 一 \\
\hline & 77 & $23^{\mathrm{a}}$ & - & $1.62 \mathrm{E}-03$ & - & - & $7.43 \mathrm{E}-04$ & - \\
\hline & 23 & -29 & - & $1.29 \mathrm{E}-05$ & - & - & $5.71 \mathrm{E}-06$ & - \\
\hline \multirow[t]{3}{*}{ Nitrogen } & 160 & 71 & $6.06 \mathrm{E}-04^{\mathrm{b}}$ & $1.75 \mathrm{E}-02$ & 28.9 & $4.42 \mathrm{E}-04^{\mathrm{b}}$ & $1.53 \mathrm{E}-02$ & 34.6 \\
\hline & 77 & $23^{\mathrm{a}}$ & $6.91 \mathrm{E}-04$ & $3.18 \mathrm{E}-03$ & 4.6 & $1.89 \mathrm{E}-04$ & $3.50 \mathrm{E}-03$ & 18.5 \\
\hline & 23 & -29 & $1.25 \mathrm{E}-04^{\mathrm{b}}$ & $6.68 \mathrm{E}-06$ & 0.1 & - & $1.72 \mathrm{E}-06$ & - \\
\hline \multirow[t]{5}{*}{ Air } & 160 & 71 & $7.34 \mathrm{E}-04$ & $7.83 \mathrm{E}-03$ & 10.7 & $6.85 \mathrm{E}-04$ & $6.28 \mathrm{E}-03$ & 9.2 \\
\hline & 77 & $23^{\mathrm{a}}$ & $6.53 \mathrm{E}-04$ & $5.44 \mathrm{E}-03$ & 8.3 & $6.53 \mathrm{E}-04$ & $4.49 \mathrm{E}-03$ & 6.9 \\
\hline & 23 & -29 & $5.17 \mathrm{E}-04$ & $5.38 \mathrm{E}-05$ & 0.1 & 一 & $8.19 \mathrm{E}-06$ & 一 \\
\hline & & & \multicolumn{3}{|c|}{ Polystyrene-coated DEB, No Poison } & \multicolumn{3}{|c|}{ Polystyrene-coated DEB plus $\mathrm{CCl}_{4}$} \\
\hline & & & \multicolumn{3}{|c|}{ Dynamic Testing } & \multicolumn{3}{|c|}{ Static Testing } \\
\hline \multirow[t]{4}{*}{ Vacuum } & 160 & 71 & & $3.14 \mathrm{E}-02$ & $\begin{array}{l}\text { Ratio Static/ } \\
\text { Dynamic }\end{array}$ & $\begin{array}{l}\text { Dynamic } \\
\text { Testing }\end{array}$ & Static Testing & $\begin{array}{l}\text { Ratio Static/ } \\
\text { Dynamic }\end{array}$ \\
\hline & 77 & $23^{\mathrm{a}}$ & - & $4.80 \mathrm{E}-04$ & 一 & 一 & $7.56 \mathrm{E}-03$ & 一 \\
\hline & 23 & -29 & - & $2.33 \mathrm{E}-06$ & - & - & $1.56 \mathrm{E}-04$ & - \\
\hline & & & & & & & $3.85 \mathrm{E}-07$ & \\
\hline \multirow[t]{4}{*}{ Nitrogen } & 160 & 71 & $2.81 \mathrm{E}-04$ & $4.75 \mathrm{E}-03$ & - & - & - & - \\
\hline & 77 & $23^{\mathrm{a}}$ & $5.22 \mathrm{E}-04$ & $8.60 \mathrm{E}-04$ & 16.9 & $4.28 \mathrm{E}-04$ & $6.15 \mathrm{E}-03$ & 14.3 \\
\hline & 23 & -29 & $1.75 \mathrm{E}-05$ & $2.35 \mathrm{E}-06$ & 1.6 & $1.37 \mathrm{E}-04$ & $2.02 \mathrm{E}-04$ & 1.5 \\
\hline & & & & & 0.1 & - & $1.63 \mathrm{E}-06$ & - \\
\hline \multirow[t]{3}{*}{ Air } & 160 & 71 & $4.62 \mathrm{E}-04$ & $2.65 \mathrm{E}-03$ & - & - & - & - \\
\hline & 77 & $23^{\mathrm{a}}$ & $3.81 \mathrm{E}-04$ & $3.23 \mathrm{E}-03$ & 5.7 & $4.76 \mathrm{E}-04$ & $4.09 \mathrm{E}-03$ & 8.6 \\
\hline & 23 & -29 & $2.49 \mathrm{E}-04$ & $2.63 \mathrm{E}-04$ & 8.5 & $2.61 \mathrm{E}-04$ & $1.53 \mathrm{E}-03$ & 5.9 \\
\hline
\end{tabular}

In dynamic testing, uncoated DEB and polystyrene-coated DEB exhibit removal rates that exceed the programmatic minimum by at least one order-of-magnitude. The same conclusion may be drawn from results derived with static testing with the following exceptions (highlighted values in Table 21). The programmatic minimum is exceeded by approximately one-half order of magnitude at $23^{\circ} \mathrm{F}\left(-29^{\circ} \mathrm{C}\right)$ for uncoated DEB in a vacuum (with carbon tetrachloride) and in an atmosphere of nitrogen (without carbon tetrachloride). The programmatic minimum is exceeded by approximately $2 \mathrm{x}$ for:

- Uncoated DEB in an atmosphere of nitrogen (with carbon tetrachloride)

- $\quad$ Polystyrene-coated DEB in a vacuum (without carbon tetrachloride)

- $\quad$ Polystyrene-coated DEB in nitrogen (with and without carbon tetrachloride). 


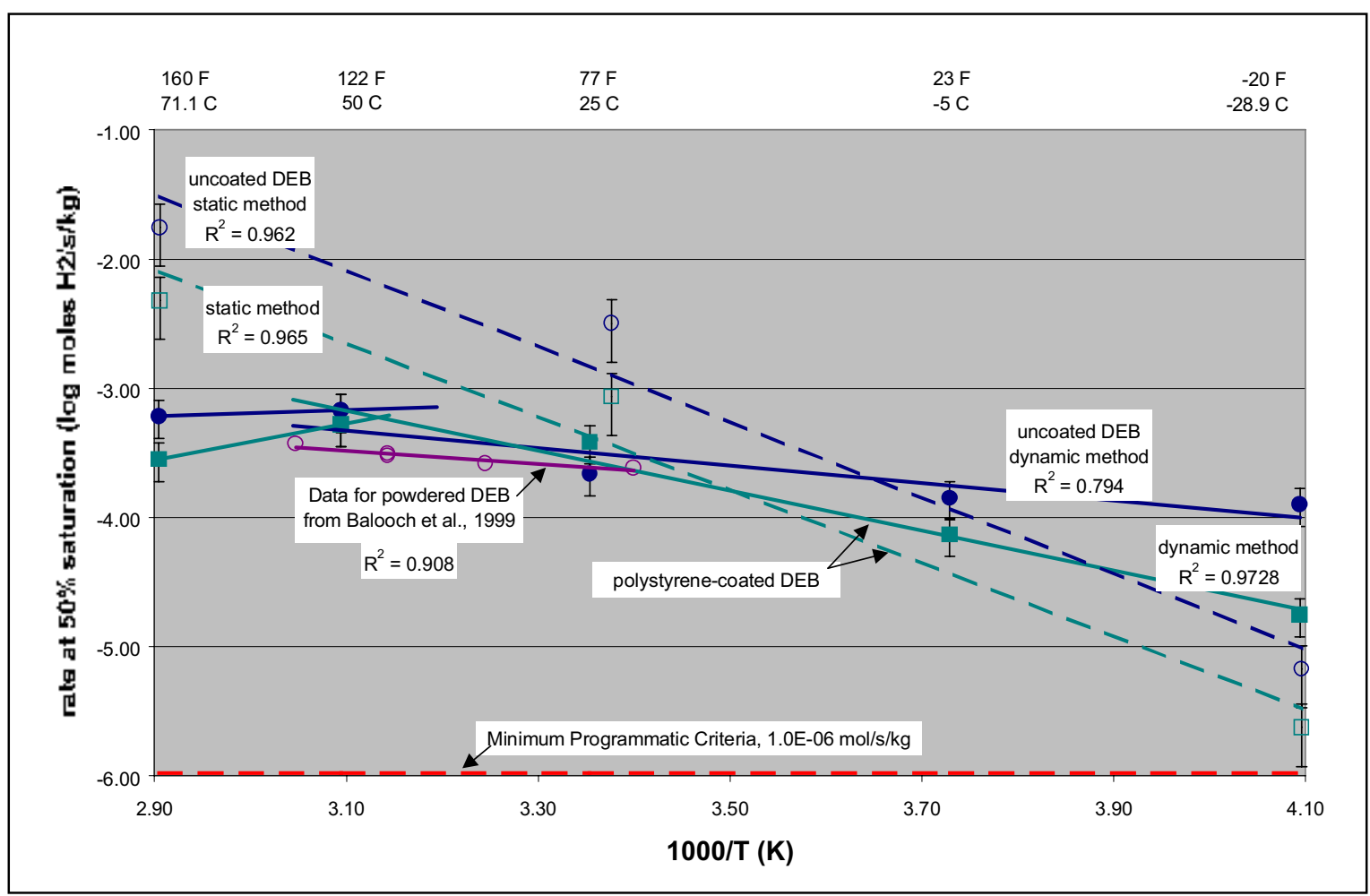

Figure 27. Arrhenius plot (hydrogen removal rate vs. temperature) determined for uncoated DEB and polystyrene-coated DEB by dynamic (solid lines and filled symbols) and static (dashed lines and open symbols) test methods. Tests were performed in an atmosphere of $5 \% \mathrm{H}_{2}$ in nitrogen at temperatures of 160 to $-20^{\circ} \mathrm{F}\left(71.1\right.$ to $\left.-28.9^{\circ} \mathrm{C}\right)$. The hydrogen removal rate is plotted as log mole $\mathrm{H}_{2} \mathrm{~s}^{-1} \mathrm{~kg}^{-1}$ at $50 \%$ capacity and the temperature is plotted as reciprocal Kelvin multiplied by 1000 . Error bars represent maximum uncertainty. Plotted for comparison are data for powdered DEB reported by Balooch et al., 1999 for the temperature range of 21 to $55^{\circ} \mathrm{C}$. Also plotted for comparison is the minimum programmatic criterion of $1.0 \times 10-6 \mathrm{~mol} \mathrm{H}_{2} \mathrm{~s}^{-1} \mathrm{~kg}^{-1}$.

In addition, static testing suggests that polystyrene-coated DEB fails to meet the programmatic minimum at $23^{\circ} \mathrm{F}\left(-29^{\circ} \mathrm{C}\right)$ in a vacuum with carbon tetrachloride. The reason for the differences between static and dynamic testing in these instances is not currently known. It is also not known why dynamic testing yields overall results that differ in detail from the static results reported herein but are consistent with the published values of Balooch et al. (1999). The data of Balooch et al. (1999) were also determined in a static test method. It is important to note, however, that the performance of DEB getter in air exceeds the programmatic minimum by approximately two orders-of-magnitude.

SRTC also performed capacity measurements on the DEB getter (uncoated and coated with polystyrene) using static test methods. Test results are presented in Table 22. Static capacity measurements of uncoated DEB are within $90-95 \%$ of the theoretical stoichiometric capacity of DEB $\left(10.86 \mathrm{~mol} \mathrm{~kg}^{-1}\right)$. Capacity measurements of polystyrene-coated DEB are within $72-82 \%$ of the stoichiometric capacity. Capacity measurements on irradiated samples of both getter materials provide similar results. The polystyrene coating is a very small fraction of the total mass of getter material, much less than $1 \%$ (by weight). Therefore, it is not known why polystyrene-coated DEB yields a smaller capacity compared to uncoated DEB and to the stoichiometric capacity. It is also currently not known why static measurements provide different capacity results compared to dynamic measurement. 


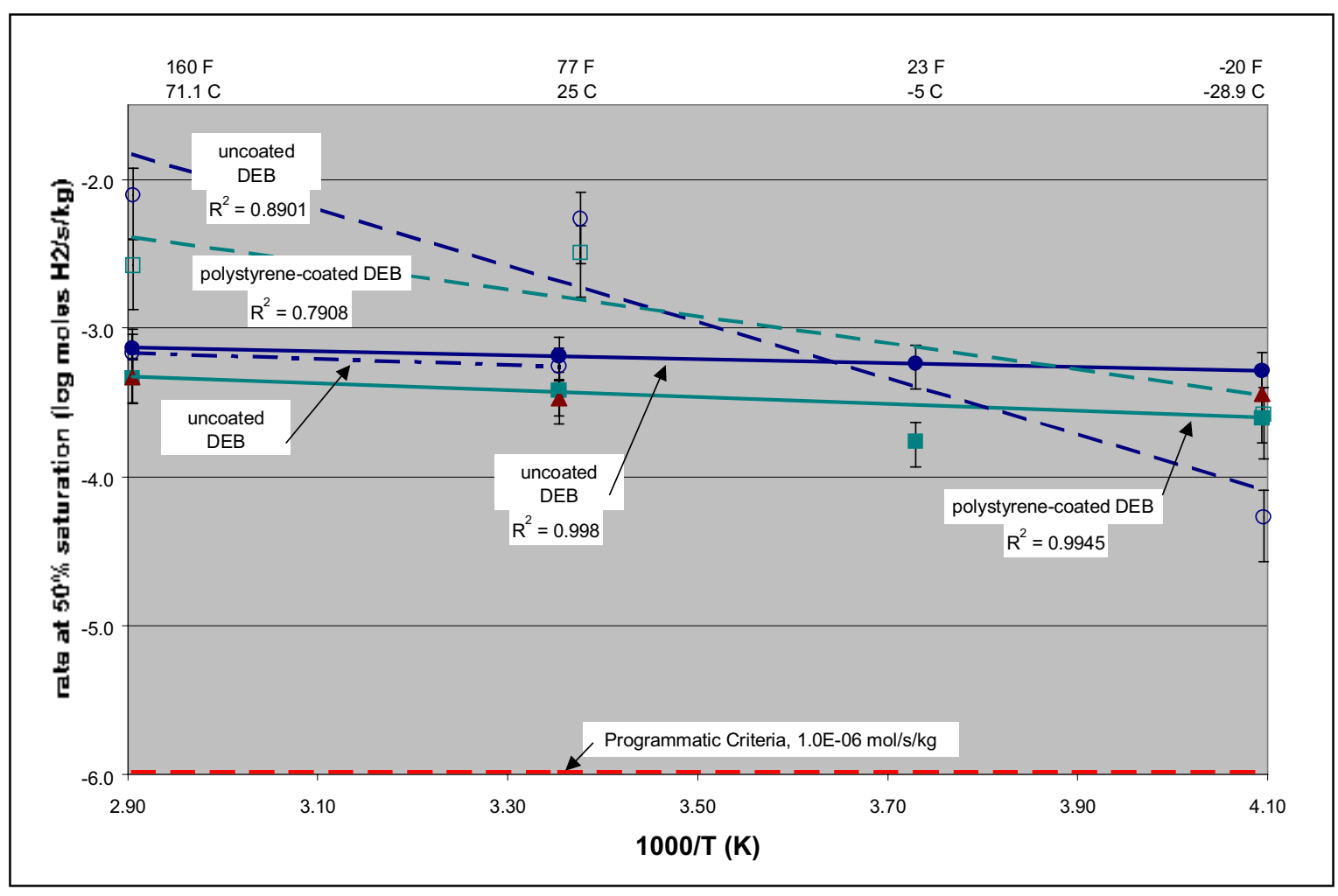

Figure 28. Arrhenius plot (hydrogen removal rate vs. temperature) determined for uncoated DEB and polystyrene-coated DEB by dynamic (solid lines and filled symbols) and static (dashed lines and open symbols) test methods. Tests were performed in an atmosphere of hydrogen in air at temperatures of 160 to $-20^{\circ} \mathrm{F}\left(71.1\right.$ to $\left.-28.9^{\circ} \mathrm{C}\right)$. The hydrogen removal rate is plotted as $\log \mathrm{mol} \mathrm{H}_{2} \mathrm{~s}^{-1} \mathrm{~kg}^{-1}$ at $50 \%$ capacity and the temperature is plotted as reciprocal Kelvin multiplied by 1000. Error bars represent maximum uncertainty. Plotted for comparison is the minimum programmatic criterion of $1.0 \times 10^{-6} \mathrm{~mol} \mathrm{H}_{2} \mathrm{~s}^{-1} \mathrm{~kg}^{-1}$.

Table 22. Capacity data $\left(\mathrm{mol} \mathrm{kg}^{-1}\right)$ for DEB samples as determined by SRTC in the static test method. The theoretical stoichiometric capacity of DEB is $10.86 \mathrm{~mol} \mathrm{~kg}^{-1}$. Uncertainty in static test method is $\pm 5 \%$

\begin{tabular}{lclcl}
\hline & Unirradiated & Method of $\mathrm{H}_{2}$ Addition & Irradiated & Method of $\mathrm{H}_{2}$ Addition \\
\hline Uncoated DEB & 10.34 & Expand rapidly and heat & 10.28 & Leak slowly and heat \\
& 9.67 & Leak slowly & & \\
Polystyrene-coated DEB & 8.88 & Expand rapidly and heat & - & - \\
& 7.86 & Expand rapidly & 8.27 & Expand rapidly $^{\mathrm{a}}$ \\
& 7.82 & Leak slowly & - & - \\
\hline
\end{tabular}

a. There was essentially no difference in the absorption curves for these two samples, but the irradiated sample test ran almost 3 times longer. 


\section{PHASE 3 TESTING}

The primary objective of Phase 3 was to demonstrate that the hydrogen getter materials will perform as anticipated when deployed in the TRUPACT-II. To achieve this objective, Phase 3 focused on getter assembly testing under scaled conditions that represent deployment in the TRUPACT-II.

Phase 3 testing had two basic components. LANL conducted the scaled tests and collected all of the data related thereto. INL received getter samples before and after being involved in the testing to determine the chemical changes that had occurred during the testing. NMR was used to determine the extent of hydrogenation which had occurred. In order do this a small apparatus was constructed at the INL to allow samples of getter to be exposed to known amounts of hydrogen delivered at different rates. NMR spectra of the various samples allowed for the determination of the extent of hydrogenation of the getter had occurred. In the following discussion a description of the INL work is given followed by the scaled Phase 3 testing at LANL.

\subsection{INL Mini-Test Apparatus}

A small system was constructed to examine the characteristics of the DEB getters. Figure 29 shows a sketch of the system.

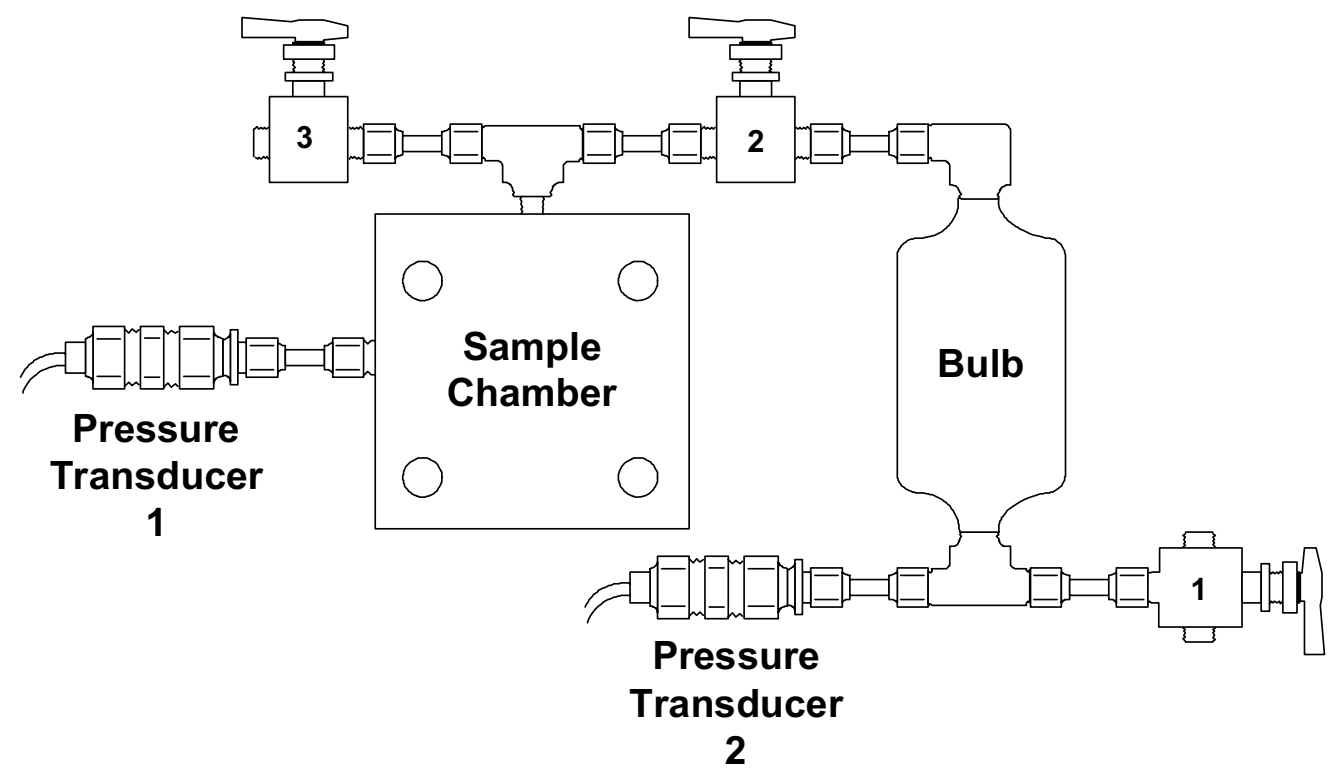

Figure 29. Small scale DEB getter testing apparatus.

The system is comprised of two chambers separated by a valve. To operate the system the four bolts on sample chamber are removed and the sample of DEB getter is placed in the chamber. The lid is then securely fastened. The whole system is evacuated by switching valve 1 to the port connected to the vacuum (with valve 2 open and valve 3 shut). After evacuation, valve 2 is closed. Then hydrogen is introduced to the bulb by switching to the other port that is connected to a pure hydrogen tank. Then valve 1 is cycled to the vacuum and back to the hydrogen to ensure that the bulb contains only pure hydrogen. Finally, valve 1 is shut, pressures of both transducers are recorded and then valve 2 is opened allowing the hydrogen to enter the sample chamber. The reaction of the getter with the hydrogen removes it from the chamber and lowers the pressure. 
All of the measurement parameters are recorded using a National Instruments Lab View ${ }^{\mathrm{TM}}$ interface. A plot of a typical operational cycle follows the changes in pressure. Knowing the amount of DEB getter and the volumes of both the sample chamber and bulb components allows the calculation of the amount of hydrogen consumed by the getter. This can then be compared with the theoretical amounts. Finally, valve 2 in Figure 29 was replaced with a needle valve that allowed the rate at which the hydrogen entered the sample chamber to be varied. This turned out to be a very important factor that affected the performance of the DEB.

\subsection{INL Mini-Test Apparatus Results And Discussion}

Figure 30 shows the results of a typical operational cycle when hydrogen is suddenly introduced to the getter bed. The upper trace is that of the pressure transducer of the bulb. The hydrogen pressure started out high and when the valve was switched to open, it dropped rapidly, stabilized briefly while the getter started to work, and then followed the pressure of the sample chamber transducer (lower trace), since both transducers were measuring the same total system pressure at that point in time.

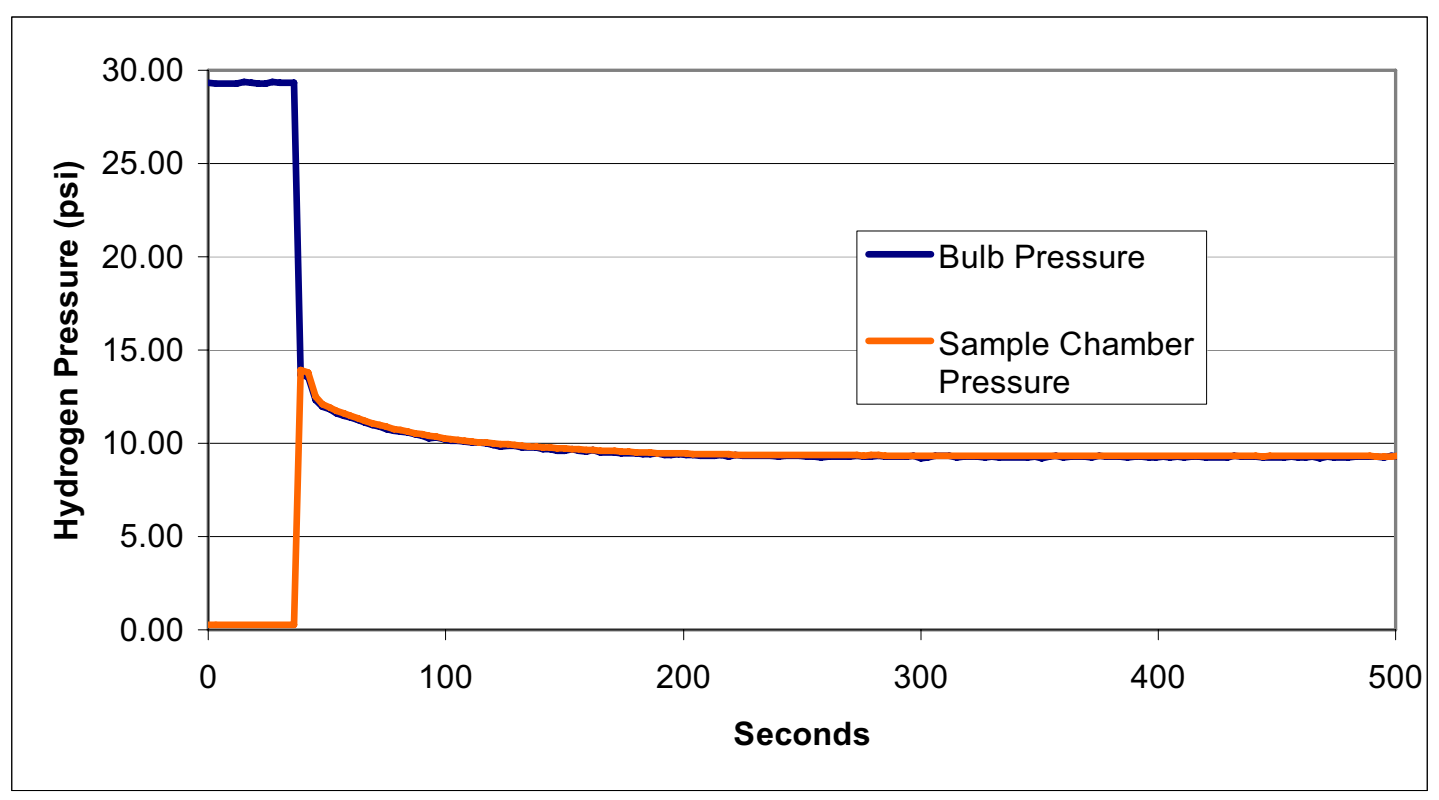

Figure 30. Profile of a typical getter run.

The lower trace follows the gas pressure in the sample chamber that has been evacuated. It rose suddenly with hydrogen introduction, stabilized during the getter induction period and then decreased as hydrogen was removed. The plot shows DEB's short induction time and quick hydrogen removal property. Within a few hundred seconds most of the hydrogen was consumed.

\subsubsection{Hydrogen Sorption Using Nuclear Magnetic Resonance (NMR) Spectroscopy}

In the presence of a strong magnetic field the energies of the nuclei of certain elements are split into two or more quantized levels. Transitions among the resulting magnetically induced energy levels can be brought about by absorption of electromagnetic radiation of suitable frequency, just as electronic transitions are caused by the absorption of ultraviolet or visible radiation. Neighboring similar atoms influence the energies of these transitions. Thus nuclear magnetic resonance (NMR) spectroscopy is an analytical technique that allows one to identify the electronic 'neighborhood' that atoms reside within and to quantify the number of atoms in that electronic 'neighborhood'. 
Fortuitously, the symmetric structure of DEB makes it possible to easily identify each of the hydrogens in the proton NMR spectrum. Figure 31 is a schematic diagram of the hydrogens on the unreacted DEB molecule and labels those that are in similar environments with the same numbers. Thus, in the NMR spectrum, there are four types of hydrogens - four (1's, four 2 's, four (3's, and two (4's.

The peaks in the NMR spectrum are assigned according to known structure libraries, spiking compounds of known composition, and experience. The NMR spectrum in Figure 32 is a partial spectrum of the unreacted DEB in which the peaks have been assigned numbers connecting them to the molecular drawing in Figure 31. The (1's show up as a series of peaks between 7.4 and $7.5 \mathrm{ppm}$. The four $\mathbf{3}$ 's show up as a nice strong single peak at about $7.33 \mathrm{ppm}$. And the 2's and (4's are part of the structure in the $7.0 \mathrm{ppm}$ region. The peak at $7.1 \mathrm{ppm}$ and some of the structure in the $7.0 \mathrm{ppm}$ region are from the toluene-d8 that was spiked into the sample for instrument calibration. Fortunately, the 2's and 4's are not important with regards to the reactions that the getter undergoes during hydrogen uptake (hydrogenation).

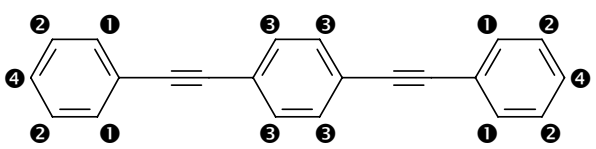

Figure 31. Schematic diagram of the NMR equivalent hydrogen atoms on the unreacted DEB getter.

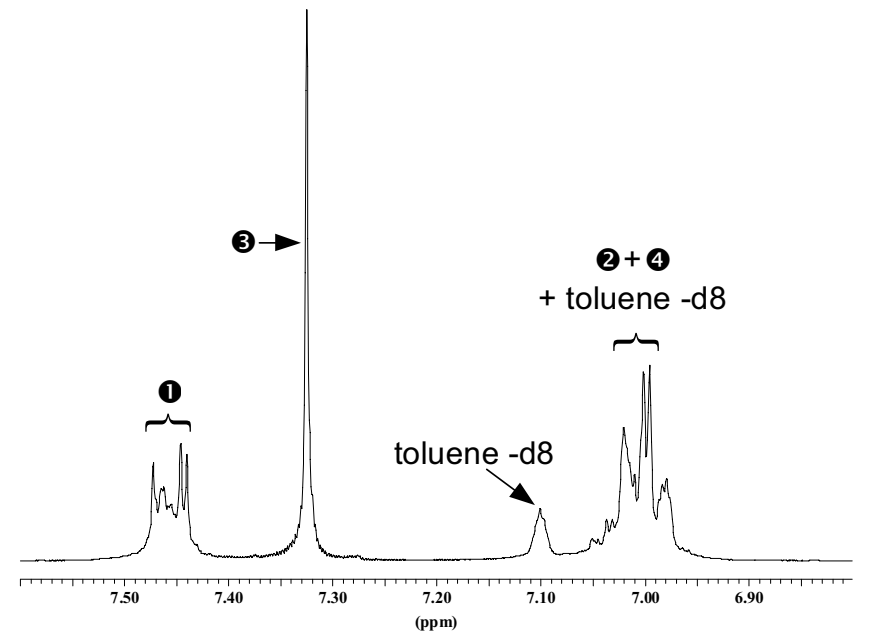

Figure 32. NMR spectral assignment of the hydrogens on the DEB as diagramed in Figure 31.

The exact reaction mechanism for catalytic hydrogenation of the triple bonds remains to be determined for DEB. Figure 33a represents the range of some possible outcomes. If only one of the alkyne bonds is broken and a hydrogen is added to each of the carbons involved, the hydrogens of type 5 would result. Such a change would affect the original neighboring ( 's and 3's to give what we have called $\boldsymbol{7}$ 's and $\boldsymbol{9}$ 's; all three of these changes would become quite obvious in the proton NMR spectrum. If however, the alkynes are completely hydrogenated to alkane bonds then there will be four new hydrogens added to the structure, designated 6's in Figure 33a. Then corresponding original (D's and 3's would be unique and are labeled with 8's and 10's in Figure 33a. Finally, it would be possible to definitively detect any loss of aromaticity in any of the rings if any of that should occur (such reactions are very hard to obtain under normal reaction conditions such as are present in these tests).

A preliminary spectrum to test this thinking was obtained with a sample of DEB that had been exposed to a saturating level of hydrogen. The results are shown in Figure 34. The analysis of this particular sample indicates that virtually all of the alkyne bonds were completely hydrogenated. Thus all of the (1's and 3's of Figure 31 were converted to 8's and 10's, Figure 33b. The final structure is shown in Figure 33b. No intermediate structures are indicated and no involvement of the aromatic rings was 
observed. Furthermore, by integrating the areas under the peaks it is possible to state that $95 \%$ of the hydrogen capture capacity of this sample was consumed.

The above results are for a sample that was part of the previous phases of this program. It was produced by very slowly introducing the hydrogen to the getter. The NMR spectrum in Figure 35 shows what happens when the hydrogen is introduced to the getter all at once (about $25 \mathrm{psi} / \mathrm{sec}$ ).

33 a.

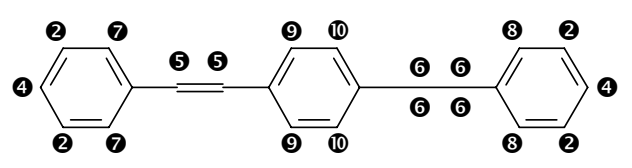

$33 \mathrm{~b}$.

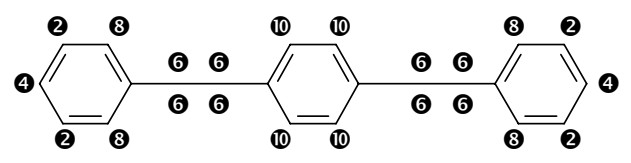

Figure 33. Schematic diagram of the potential NMR equivalent hydrogen atoms on the reacted DEB getter.

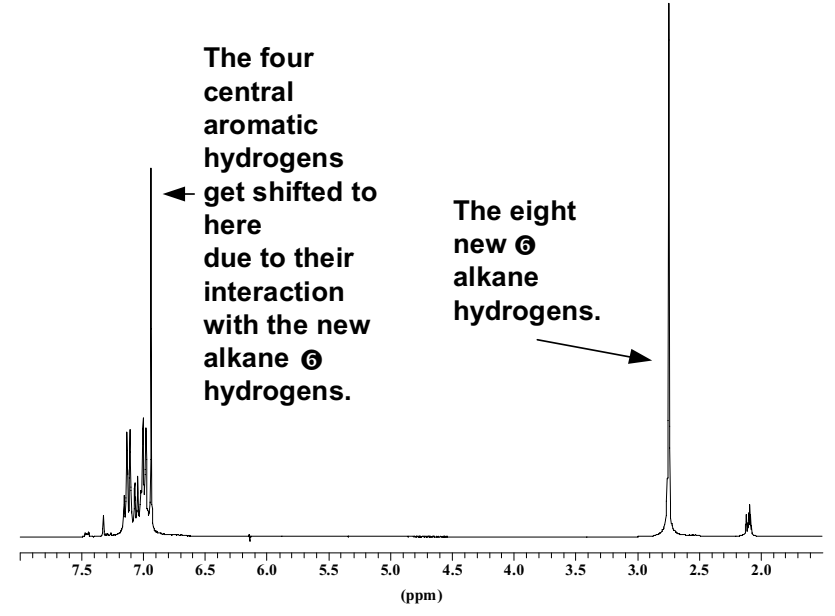

Figure 34. NMR spectrum with assigned peaks of DEB getter that has been saturated with hydrogen.



Figure 35. DEB getter NMR of 'all at once' introduction of the hydrogen. (15664-71-1, 88\% hydrogenated).

When the hydrogen is allowed to leak at the rate of $1 \mathrm{psi} / 138 \mathrm{sec}(1 \mathrm{psi} / 2.3 \mathrm{~min})$ into the sample chamber very slowly, the profile of the experiment changes. The NMR of DEB getter with slow hydrogen introduction is shown in Figure 36. Figure 37 shows the differences. 
The upper (blue) curve is the bulb pressure. Note the steady decline as a result of the needle valve being opened slightly allowing the hydrogen to transfer to the sample chamber at a slow steady pace of $0.007 \mathrm{psi} / \mathrm{sec}$. The pink (lower) curve shows the pressure profile in the sample chamber. It is initially at a vacuum. The there is a nearly flat region. This corresponds to the getter consuming the hydrogen at a rate similar to what is coming into the chamber. As the getter is used up the getter cannot keep up with the rate of hydrogen introduction and the pressure increases until it coincides with the bulb pressure, indicating that the entire system is at equilibrium.

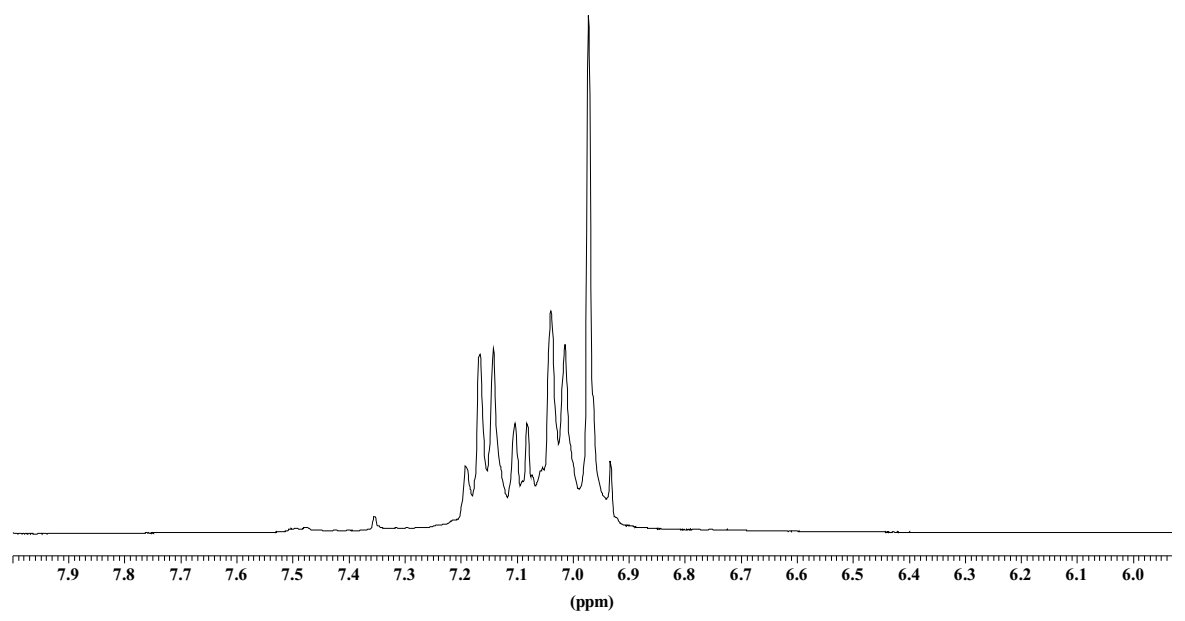

Figure 36. NMR of DEB getter with slow introduction of the hydrogen. (15664-75-1, 98\% hydrogenated).

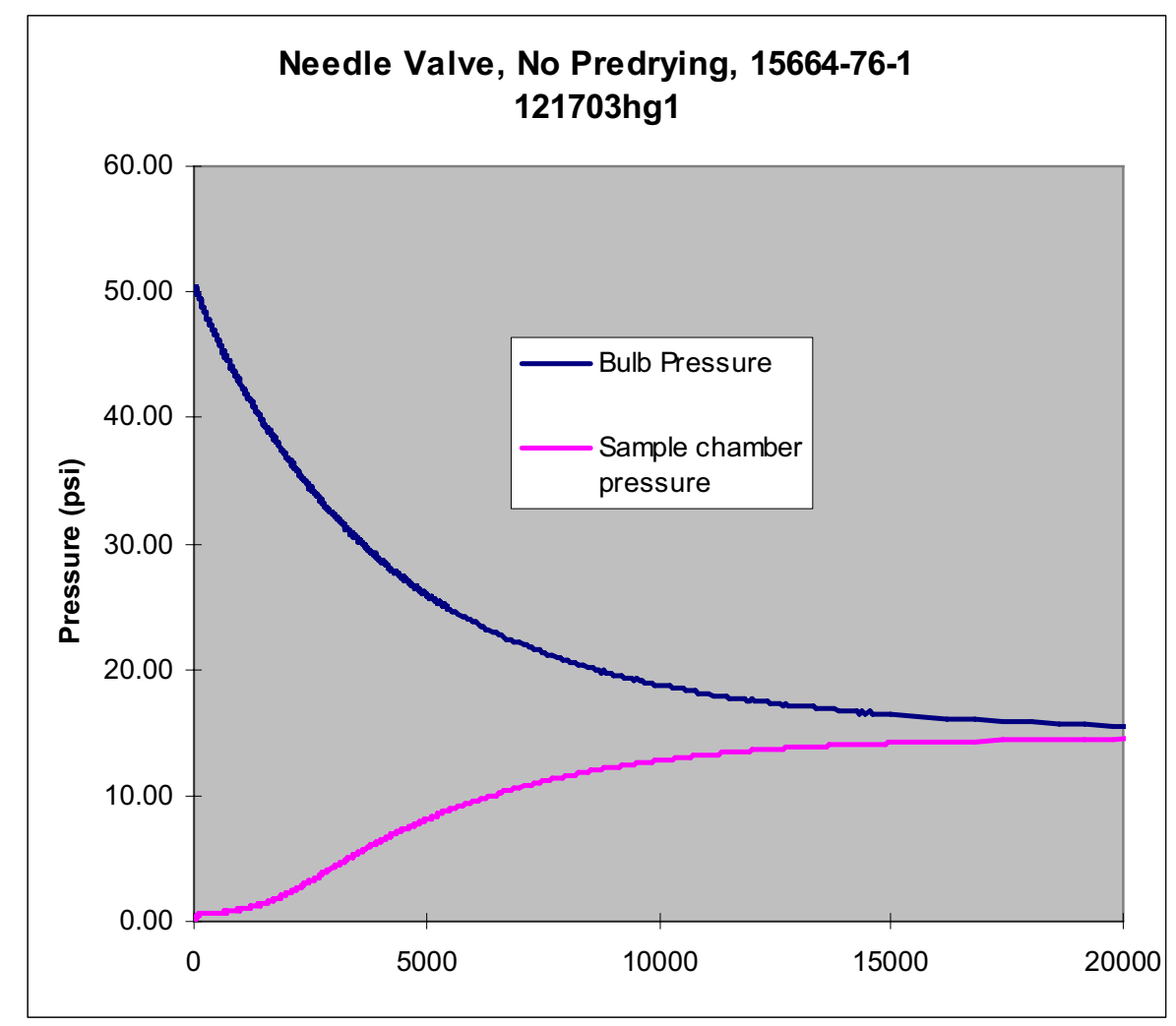

Figure 37. Pressure profiles with slow introduction of hydrogen. 
The amount of hydrogen captured can be calculated from the pressure changes over the course of the experiments. Large differences were observed between the two rates of hydrogen introduction. When the hydrogen is added suddenly, a much smaller quantity of hydrogen is captured compared with what is theoretically possible (based upon the 4 moles of hydrogen to 1 mole of DEB estimate previously discussed). Yields of about $63 \%$ were observed. However, when the hydrogen was allowed to bleed onto the getter bed at much slower rates, conversions of $90+\%$ were observed. Thus it is important that the getter encounters the hydrogen at slower rates in order to maximize its hydrogen capacity.

We have had a hard time determining exactly what happens when the getter is exposed to the hydrogen all at once. Observations at Los Alamos, Savannah River, and INL indicate that when the materials are added to the sample chamber they are separate granules as seen in Figure 2. However, after the sudden exposure to hydrogen, DEB granules appear to be melted or sintered together to form a rigid structure. This change possibly alters the morphology of the granules. The heat generated by the reaction of the getter to the high rate of addition could melt microareas of the material. This could produce DEB rich areas that are catalyst poor. This would result in portions of the DEB not reacting with the hydrogen. The result would be lower conversion rates such as those observed. Different lots and different preparations of the getter (such as vacuum drying) did not improve the conversion rates for runs made with high hydrogen feedstreams.

\subsection{Phase III Test Design}

The design and implementation of Phase III testing was based on results from the Phase 2 testing, recommendations from the American Society of Mechanical Engineers (ASME) Peer Review Panel (ASME 2002a, 2002b), and discussions with the Waste Isolation Pilot Plant (WIPP) operations personnel regarding getter deployment. Input received from the WIPP operations group ${ }^{\mathrm{b}}$ regarding handling considerations for getters led to use of a single deployment configuration, as follows:

- $\quad$ Getters will be deployed in configurations with only one layer of payload containers (i.e., either in a HalfPACT or in a TRUPACT-II (TP-II) with seven drums or one standard waste box).

- The deployed getter assembly will be placed on top of the payload container assembly in the form of a horizontal structure with containers or cans containing the getter material. This assembly will have vertical access for the current payload assembly guide tubes and Adjustable Center of Gravity Lift Fixture (ACGLF) arms to facilitate easy removal of the getter assembly and the payload at the WIPP site (i.e., the guide tubes pass through the getter assembly structure and the ACGLF lifts the entire assembly [drums + getters] out of the package).

The Phase 3 test plan $^{\mathrm{c}}$ was based on the above considerations, yielding the test matrix provided in Table 23. Note that budget cuts eliminated 3 of the 5 tests that were originally planned. A performance specification, expected to be part of a future TRUPACT-II SAR amendment for the use of getters, is shown in Table 24.

b. Hydrogen Gas Getters Evaluation Program Meeting, September 10-11, 2002, Carlsbad, New Mexico.

c. Kaszuba, J.P., Peterson, E., Mroz, E., Stone, M. Haga, M., and Devarakonda, M., 2003, "Phase 3 Hydrogen Gas Getter Test Plan", LANL, INL, and Washington TRU Solutions, June 2003. 
Table 23. Phase 3 test plan matrix.

\begin{tabular}{lllllll}
\hline $\begin{array}{l}\text { Test } \\
\text { No. }\end{array}$ & \multicolumn{1}{c}{ Purpose } & \multicolumn{1}{c}{$\begin{array}{c}\text { Test } \\
\text { Apparatus }\end{array}$} & $\begin{array}{c}\text { Getter } \\
\text { Material }\end{array}$ & Temperature & Poison & Implementation \\
\hline $1 \quad \begin{array}{l}\text { Does getter work } \\
\text { under "routine" } \\
\text { conditions? }\end{array}$ & $\begin{array}{l}\text { Belljar w/ 1 } \\
\text { drum }\end{array}$ & DEB & $77^{\circ} \mathrm{F}$ & None & Test completed \\
2 & $\begin{array}{l}\text { Same as Test No. 1 } \\
\text { Belljar w/ 1 } \\
\text { drum }\end{array}$ & VEI & $77^{\circ} \mathrm{F}$ & None & Test completed \\
$\begin{array}{l}\text { Does getter work at } \\
\text { cold temperature in } \\
\text { an atmosphere } \\
\text { containing } \\
\text { inorganic poison? }\end{array}$ & $\begin{array}{l}\text { Belljar w/ 1 } \\
\text { drum }\end{array}$ & DEB & $-20^{\circ} \mathrm{F}$ & $\begin{array}{l}\text { Carbon } \\
\text { tetrachloride }\end{array}$ & $\begin{array}{l}\text { Test cancelled } \\
\text { due to budget } \\
\text { cut. }\end{array}$ \\
$\begin{array}{l}\text { Same as Test No. 3 } \\
\text { Belljar w/ 1 }\end{array}$ & VEI & $-20^{\circ} \mathrm{F}$ & $\begin{array}{l}\text { Carbon } \\
\text { tetrachloride }\end{array}$ & $\begin{array}{l}\text { Test cancelled } \\
\text { due to budget } \\
\text { cut }\end{array}$ \\
& $\begin{array}{l}\text { drum } \\
\text { Does getter sinter at } \\
\text { higher temperature, } \\
\text { leading to adverse } \\
\text { impact on rates? }\end{array}$ & $\begin{array}{l}\text { Benchtop, } \\
\text { simultaneous } \\
\text { with belljar } \\
\text { tests }\end{array}$ & DEB/VEI & $160^{\circ} \mathrm{F}$ & None & $\begin{array}{l}\text { Test cancelled } \\
\text { due to budget } \\
\text { cut }\end{array}$ \\
\hline
\end{tabular}

Notes and Assumptions

\begin{tabular}{|c|c|c|c|}
\hline No. & Note & Assumption & Explanation \\
\hline 1 & $\begin{array}{l}\text { Getter } \\
\text { Material }\end{array}$ & $\begin{array}{l}\text { Uncoated DEB getter } \\
\text { VEI getter }\end{array}$ & $\begin{array}{l}\text { Based on the Phase } 2 \text { test results and } \\
\text { recommendations of the ASME panel, coated } \\
\text { DEB will was not investigated further. }\end{array}$ \\
\hline 2 & $\begin{array}{l}\text { Getter } \\
\text { Assembly }\end{array}$ & $\begin{array}{l}\text { The getter assembly for each } \\
\text { test is the same. The assembly } \\
\text { will approximate the following } \\
\text { actual deployment: a getter } \\
\text { superstructure of horizontally } \\
\text { placed "cans" of } \\
\text { approximately } 4 \text {-inch diameter } \\
\text { and } 12 \text {-inch length, and 6-inch } \\
\text { minimum axis separation, with } \\
\text { vertical access for both } 3 \text { and } 4 \\
\text { point ACGLF arms. }\end{array}$ & $\begin{array}{l}\text { Getter deployment structure is based on } \\
\text { discussions with WIPP operations personnel. }\end{array}$ \\
\hline 3 & Test Duration & $\begin{array}{l}\text { The duration for all tests is } \\
60 \text { days, unless hydrogen } \\
\text { thresholds of } 5 \% \text { are exceeded } \\
\text { during testing. }\end{array}$ & $\begin{array}{l}\text { Per the TRUPACT-II SAR, } 60 \text { days is the } \\
\text { longest shipping time. }\end{array}$ \\
\hline 4 & $\begin{array}{l}\text { Test } \\
\text { Atmosphere }\end{array}$ & $\begin{array}{l}\text { An atmosphere of air will be } \\
\text { used for each of the tests. }\end{array}$ & $\begin{array}{l}\text { This atmosphere is expected for TRUPACT-II } \\
\text { shipments. }\end{array}$ \\
\hline
\end{tabular}


Notes and Assumptions

\begin{tabular}{|c|c|c|c|}
\hline No. & Note & Assumption & Explanation \\
\hline \multirow[t]{2}{*}{5} & $\begin{array}{l}\text { Poison (NOT } \\
\text { TESTED) }\end{array}$ & $\begin{array}{l}\text { Carbon tetrachloride will be } \\
\text { introduced into the test vessel } \\
\text { at an initial concentration of } \\
1,000 \mathrm{ppm} \text {. Carbon } \\
\text { tetrachloride will not be } \\
\text { replenished during the test. }\end{array}$ & $\begin{array}{l}\text { Based on Phase } 2 \text { results, carbon tetrachloride } \\
\text { appears to be the worst-case VOC. Based on } \\
\text { process knowledge, carbon monoxide is not } \\
\text { expected in any significant amounts in the } \\
\text { inventory (containers are filtered and expected } \\
\text { to be under aerobic conditions). }\end{array}$ \\
\hline & & & $\begin{array}{l}\text { A carbon tetrachloride concentration of } \\
1,000 \text { ppm bounds the TRU waste inventory } \\
\text { of Waste Types I, II, and III based on } \\
\text { available headspace gas sampling results (8). }\end{array}$ \\
\hline 6 & $\begin{array}{l}\text { Hydrogen } \\
\text { Generation } \\
\text { Rate }\end{array}$ & $\begin{array}{l}\text { The hydrogen generation rate } \\
\text { is based on } 40 \text { watts and is } \\
6.46 \mathrm{E}-07 \text { mole per second per } \\
\text { drum. }\end{array}$ & $\begin{array}{l}\text { The hydrogen generation rate is based on } \\
\text { matrix-depleted G values in the TRUPACT-II } \\
\text { SAR and a payload of seven drums, which } \\
\text { results in the maximum hydrogen generation } \\
\text { rate per drum and will provide bounding test } \\
\text { conditions. }\end{array}$ \\
\hline 7 & $\begin{array}{l}\text { Test } \\
\text { Configuration }\end{array}$ & $\begin{array}{l}\text { The free volume inside the } \\
\text { one-drum belljar test apparatus } \\
\text { will be scaled to the free } \\
\text { volume within the inner } \\
\text { containment vessel of the } \\
\text { TRUPACT-II. }\end{array}$ & $\begin{array}{l}\text { The getter deployment configuration tested } \\
\text { will be the same as that expected to be } \\
\text { deployed and results from the test will be } \\
\text { representative. }\end{array}$ \\
\hline 8 & Temperature & $\begin{array}{l}\text { Tests were performed at room } \\
\text { temperature }\left(70^{\circ} \mathrm{F}\right) \text {. Low } \\
\text { temperature test }\left(-20^{\circ} \mathrm{F}\right) \text { were } \\
\text { cancelled due to budget cuts. }\end{array}$ & $\begin{array}{l}\text { Based on Phase } 2 \text { results, getter performance } \\
\text { is expected to be better at high temperatures. } \\
\text { Instead of performing belljar tests at high } \\
\text { temperature }\left(160^{\circ} \mathrm{F}\right) \text {, data from Tests } \\
\text { Nos. } 1 \text { - } 5 \text { and Phase } 2 \text { results will be } \\
\text { evaluated to demonstrate getter performance } \\
\text { at high temperatures. }\end{array}$ \\
\hline
\end{tabular}

Table 24. Hydrogen gas getter performance specification.

\begin{tabular}{ll}
\hline \multicolumn{1}{c}{ Parameter } & \multicolumn{1}{c}{ Specification } \\
\hline Usage and Location & Inside the inner containment vessel of the TRUPACT-II \\
Operating Temperature Range & $-20^{\circ} \mathrm{F}$ to $+160^{\circ} \mathrm{F}$ \\
Pressure & 0 to $50 \mathrm{psig}$ \\
Reversibility & No desorption of hydrogen \\
Getter Rate and Capacity & $6.46 \times 10^{-7}$ mole per second per drum for 60 days \\
Free Liquids & Free liquids to be insignificant ( $\leq 1 \%$ of payload containers $)$ \\
Temperature Effect from Getter & No impact on operating temperature range of $-20^{\circ} \mathrm{F}$ to $+160^{\circ} \mathrm{F}$ \\
Passive Versus Active Getters & Only passive getters \\
Potential Poisons & Must be effective in the presence of gases and volatile organic \\
& compounds expected in payload \\
Compatibility & Non-reactive (except with hydrogen); nonpyrophoric; non-gas \\
& generating; compatible with carbon steel, stainless steel, butyl \\
& O-rings, aluminum, and ABS plastic \\
\hline
\end{tabular}


Phase III tests used aspects of the Gas Generation Test Program (GGTP) of the LANL TRU Waste Characterization/Certification Project. Elements of the GGTP were used because GGTP technology was approved by the NRC for use at WIPP and because this technology was successfully employed in the WIPP program. In the GGTP, hydrogen gas generation rates were determined for transuranic waste using gas generation test canisters (GGTC, herein referred to as "belljars"). The belljar is a stainless canister that encapsulates a 55-gallon waste drum and accumulates the gases generated from the drum. In this manner, off-gases generated from the waste drum are measured and hydrogen generation rate of the drum calculated.

For Phase III, a belljar was used as a scale replica of the TP-II. The free volume inside the belljar test apparatus was scaled to the free volume within the inner containment vessel (ICV) of the TP-II. As specified in Table 25, the void space in the inner containment vessel of a TP-II is 2.68 times greater than the volume of a payload of seven 55-gallon drums. A GGTP-style bell jar and a drum equipped with a composite drum filter (diffusivity of $1.16 \mathrm{E}-05 \mathrm{~mol} / \mathrm{s} / \mathrm{mf}$ ) were scaled to these dimensions in order to test the getter assembly under conditions that represent deployment. The resultant dimensions for the bell jar and drum are listed in Table 25.

The target hydrogen generation rate, assuming 40 watts per TP-II and a hydrogen G-value of 1.09, is $4.54 \mathrm{E}-06$ moles per second or 23.54 moles in 60 days in a TP-II. Since the rate per drum is simply a function of the number of drums per TP-II, the hydrogen generation rate for each of seven drums in a TP-II shipment is $6.49 \mathrm{E}-07$ moles per second. Scaling this rate to GGTP-style tests with a drum of appropriate dimensions (Table 25) yields a hydrogen generation rate of $2.60 \mathrm{E}-07$ moles per second per test drum (Table 26).

A conceptual design that illustrates these dimensions, the scaled gas generation rate, and other information (e.g., $\mathrm{H}_{2}$ source, $\mathrm{H}_{2}$ gas analysis, and temperature-pressure measurements) is presented in Figure 38. Industrial grade hydrogen $(99.95 \%$ pure) was introduced into the drum for each test via an Omega flow meter adjusted to the proper rate. Continuous hydrogen measurements were made in each of the three drums with a Dual Loop Hydrogen Analyzer manufactured by Meggitt Safety Systems, Inc. Temperature was monitored inside each belljar, on the external surface of each belljar, and in test room using Omega type T thermocouples. Pressure was monitored inside each belljar and in the test room using Omega pressure transducers. Not illustrated is the computer data logging system that was employed to record ambient temperature, belljar temperatures, pressure inside the belljar, ambient pressure, flow rate of injected hydrogen, and concentration of hydrogen as continuously monitored by the Meggitt hydrogen sensors. The data logging system consisted of FieldPoint ${ }^{\mathbb{O}}$ data logging modules that collected data from the various sensors and transmitted these data via Ethernet to a central computer. The computer processed these data using

Table 25. Design specifications.

Specifications for TPII containing 7 drums

headspace (void space) in the ICV of TPII = 3906 liters

volume of seven 55-gal drums $=1456$ liters

ratio of headspace volume in ICV: volume of seven 55-gal drums $=2.68$

Dimensions of GGTP-style BELL JAR Tests Scaled to TPII Containing 7 Drums

bell jar volume $=304$ liters

drum volume $=82.6$ liters

headspace volume of bell jar containing 1 drum $=221.4$ liters

ratio of bell jar headspace volume: drum volume $=2.68$ 
Table 26. Scaling of hydrogen generation rate.

$\mathrm{H}_{2}$ generation in TPII

$\mathrm{H}_{2}$ generation per each of seven 55 gallon drums

scaled drum vol

ratio of scaled drum to 55-gal drum

scaled $\mathrm{H}_{2}$ generation
$4.54 \mathrm{E}-06 \mathrm{~mol} / \mathrm{s} / \mathrm{drum}$

$6.49 \mathrm{E}-07 \mathrm{~mol} / \mathrm{s} / \mathrm{drum}$

$82.6 \mathrm{~L}$

0.40

$2.60 \mathrm{E}-07 \mathrm{~mol} / \mathrm{s} / \mathrm{drum}$

$1.56 \mathrm{E}-05 \mathrm{~mol} / \mathrm{minute}$

$0.35 \mathrm{cc} / \mathrm{min}$

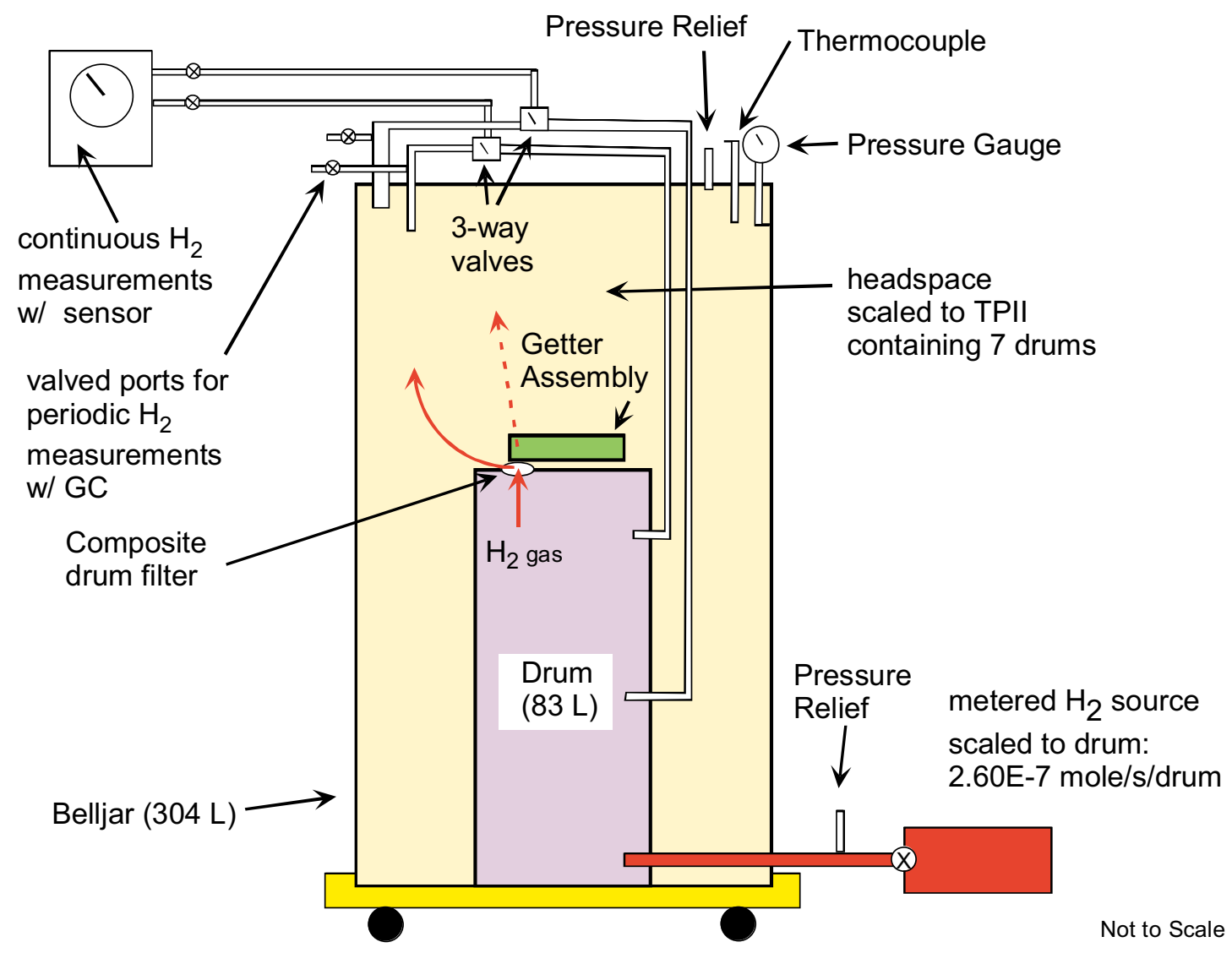

Figure 38. Conceptual design, not engineering drawings.

LabView $^{\odot}$ software. The photograph in Figure 39 shows the three assembled apparatus. The instrumented bell jars are placed over and secured around the 55 gallon drums that have been cut and reassembled to the proper scale. The photograph in Figure 40 shows the arrangement of the getter assembly on the top of the drum and also shows the water droplets in the DEB containing bell jars after a test was completed.

Hydrogen concentration was continuously monitored in the drum headspace during the entire test. Samples of the belljar and drum headspace were periodically collected using the sampling procedures described in Gas Test Canister Operations (TWCP-DTP-1.2-056). These samples were analyzed for hydrogen and oxygen using gas chromatography as described in Gas Chromatography Determination of Hydrogen in Gas Generation Test Canisters (TWCP-DTP-1.2-057,R.3). Headspace samples were collected daily in the first week of each test, twice during the second week of each test, and weekly 


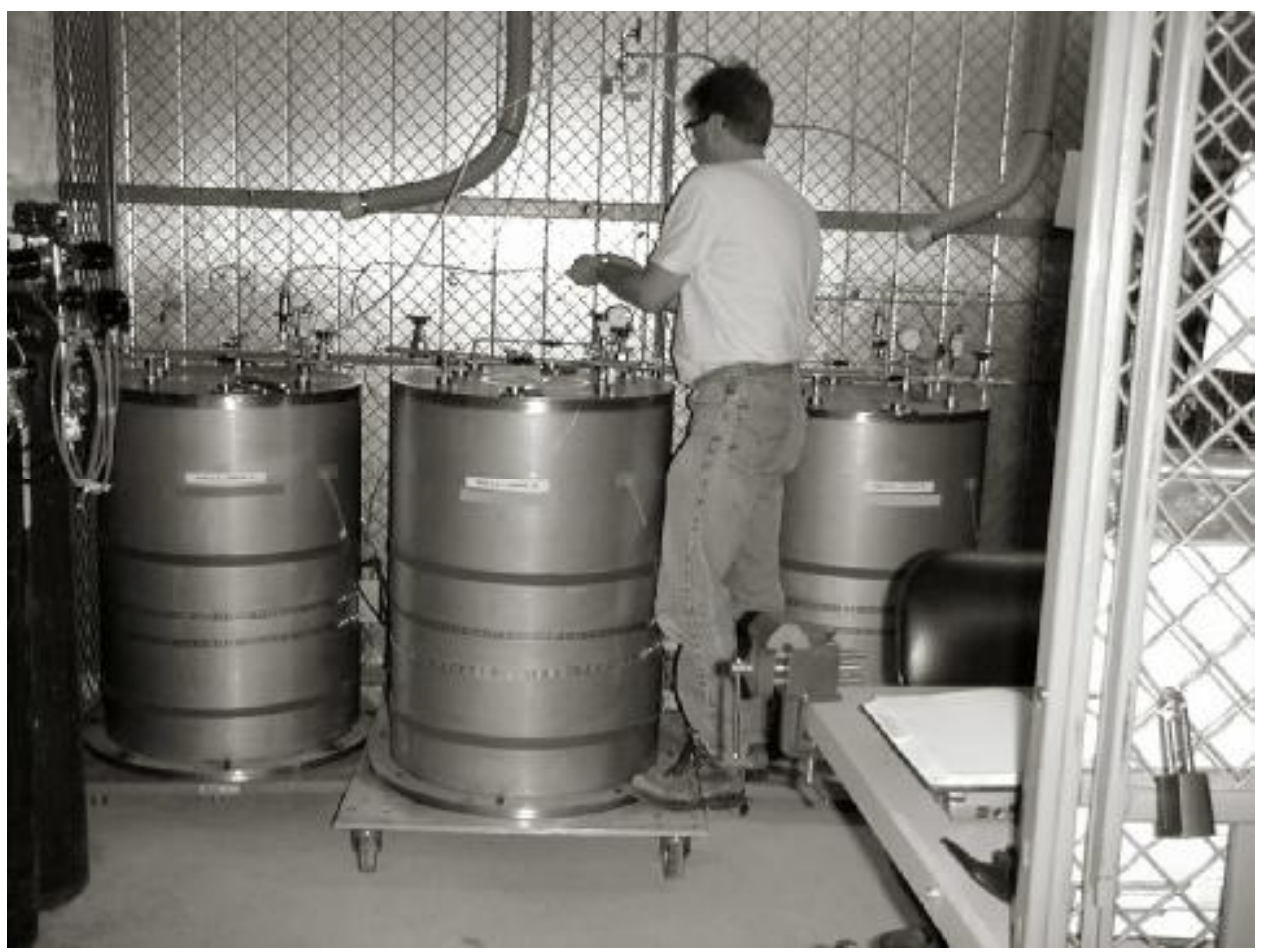

Figure 39. Photograph of the instrumented bell jars.

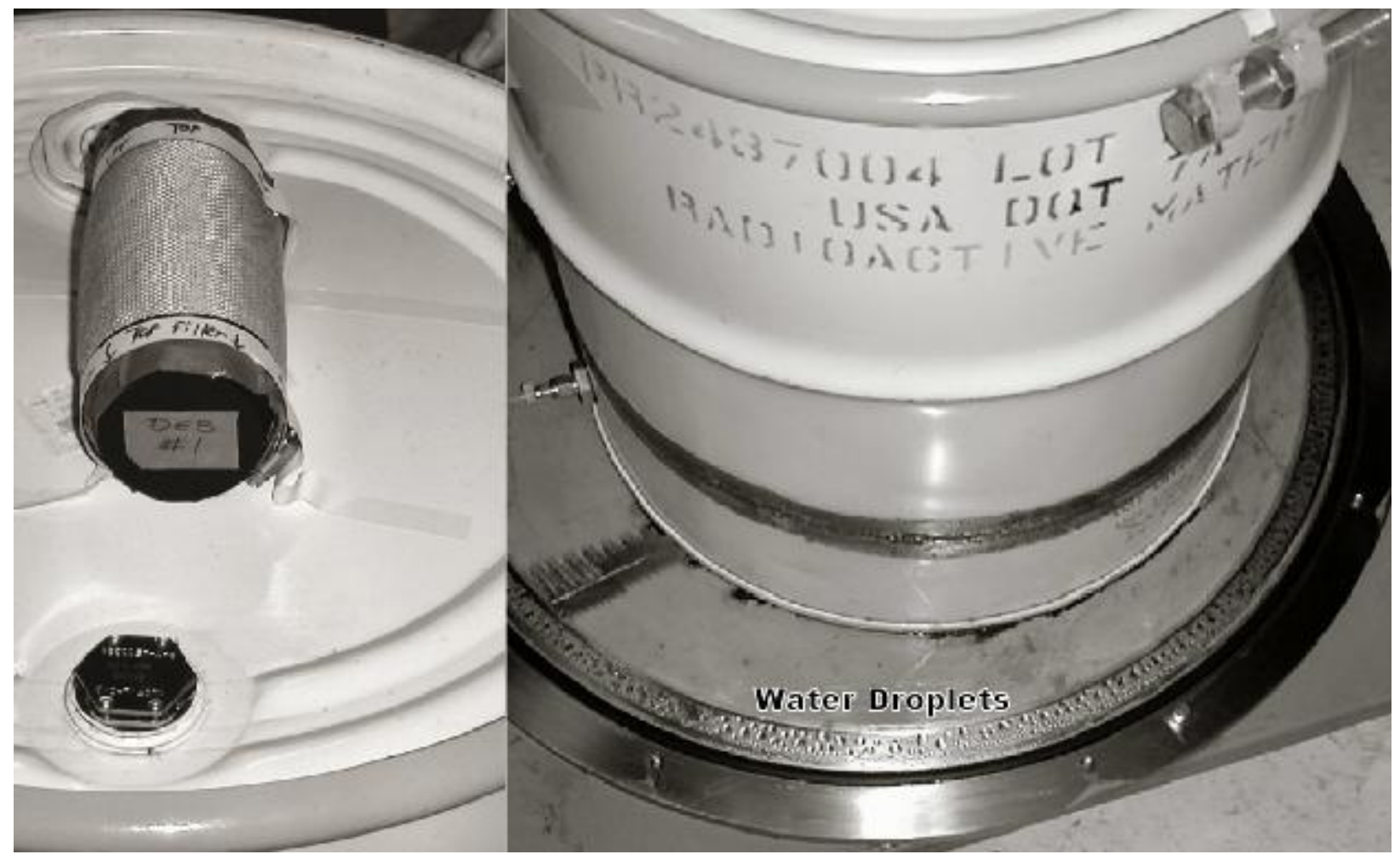

Figure 40. Two views of the scaled setup. The left photo shows the arrangement of the getter on the top of the drum. The right photo shows the drum after the run. Note the water droplets near the bottom of the drum. 
thereafter. Maximum uncertainties (1 standard deviation) determined for hydrogen and oxygen analyses are $3.4 \%$ and $1.8 \%$, respectively. Several different standards were used during different phases of the tests, depending on the relative concentrations of hydrogen and oxygen present. The standards used and detailed information regarding uncertainties for different intervals of the tests are presented in Table 27.

The relevant design information for the DEB and VEI getter materials are presented in Table 28 . The two types of getters were packaged slightly differently from each other. The DEB getter was wrapped in a KimWipe ${ }^{\circledR}$ and then surrounded by a wire screen. The ends of the screen were plugged with rubber stoppers. The VEI getter had an additional layer of molecular sieves to help scavenge the water that was produced by the recombination reaction; this layered assembly was the same configuration employed in Phase II testing (see Figure 41). Relevant specifications for these getter assemblies are presented in Table 29.

Table 27. Hydrogen and oxygen standards and uncertainties.

\begin{tabular}{lcccccc}
\hline $\begin{array}{l}\text { Period of Test } \\
\text { (days) }\end{array}$ & $0-29$ & $1-10$ & $15-63$ & $0-29$ & $1-10$ & $15-63$ \\
Standard & $100 \mathrm{ppm} \mathrm{H}_{2}$ & $\begin{array}{l}1000 \mathrm{ppm} \\
\mathrm{H}_{2}\end{array}$ & $\begin{array}{l}10,000 \mathrm{ppm} \\
\mathrm{H}_{2}\end{array}$ & $17 \% \mathrm{O}_{2}$ & $16 \% \mathrm{O}_{2}$ & $15 \% \mathrm{O}_{2}$ \\
\# analyses & 5 & 6 & 10 & 7 & 6 & 11 \\
$\begin{array}{l}\text { Average } \\
\begin{array}{l}\text { Standard } \\
\text { deviation }\end{array}\end{array}$ & 102 & 1010 & 10,118 & 16.9 & 16.2 & 14.7 \\
$\begin{array}{l}\% \text { standard } \\
\text { deviation }\end{array}$ & 3.5 & 20.0 & 297.8 & 0.3 & 0.3 & 0.1 \\
\hline
\end{tabular}

Table 28. Design information

\begin{tabular}{|c|c|c|c|c|}
\hline & $\begin{array}{l}\text { Total mol } \\
\quad \mathrm{H}_{2} \\
\text { Generated } \\
\text { in } 60 \text { days } \\
\end{array}$ & $\begin{array}{c}\text { Mass of DEB Needed } \\
\text { to Absorb 2x of } \\
\text { Maximum } \mathrm{H}_{2} \text { Produced } \\
(\mathrm{kg})\end{array}$ & $\begin{array}{c}\text { Mass of VEI Needed to } \\
\text { Absorb } 2 \mathrm{x} \text { of } \\
\text { Maximum } \mathrm{H}_{2} \text { Produced } \\
(\mathrm{kg})\end{array}$ & $\begin{array}{c}\text { Mass of Molecular } \\
\text { Sieve } \\
\text { Accompanying VEI } \\
(\mathrm{kg})\end{array}$ \\
\hline $\begin{array}{l}7 \text { drums in } \\
\text { TPII }\end{array}$ & 3.36 & 0.62 & 1.14 & 1.03 \\
\hline \multirow{2}{*}{$\begin{array}{l}\text { scaled drum } \\
(82.6 \mathrm{~L}) \text { in } \\
\text { belljar }\end{array}$} & 1.34 & 0.25 & 0.46 & 0.41 \\
\hline & & & DEB Specifications & VEI Specifications \\
\hline stoichiometry & \multicolumn{2}{|c|}{ fraction $\mathrm{DEB} /(\mathrm{g} / \mathrm{mol}$ of $\mathrm{DEB})$} & $2.69 \mathrm{E}-03$ & - \\
\hline \multirow[t]{3}{*}{ capacity } & \multicolumn{2}{|c|}{$\mathrm{mol} \mathrm{H}_{2} / \mathrm{mol} \mathrm{DEB}$} & 4 & - \\
\hline & \multicolumn{2}{|c|}{$\mathrm{mol} \mathrm{H}_{2} / \mathrm{g}$ DEB } & $1.08 \mathrm{E}-02$ & - \\
\hline & \multicolumn{2}{|c|}{$\mathrm{mol} \mathrm{H}_{2} / \mathrm{kg} \mathrm{DEB}$} & 10.78 & 5.88 \\
\hline
\end{tabular}




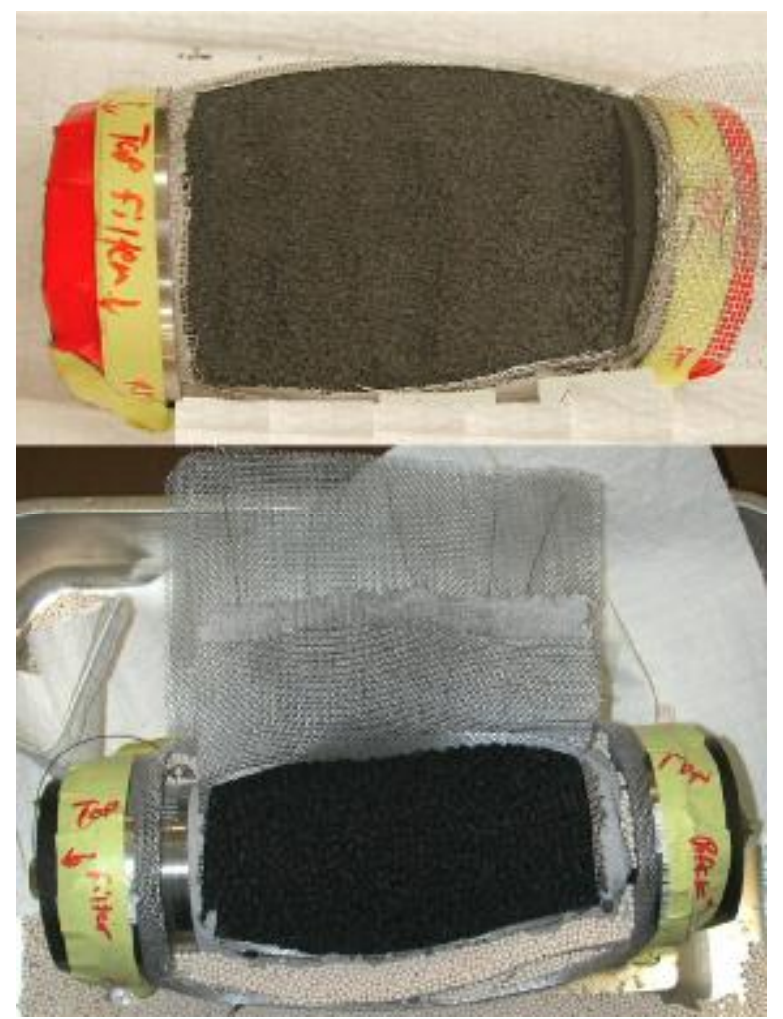

Figure 41. Getter assemblies. Top: DEB and Bottom: VEI.

Table 29. Specifications for getter assemblies, as built.

\begin{tabular}{|c|c|c|c|}
\hline & DEB Assembly & VEI Assembly & $\begin{array}{l}\text { Molecular Sieve } \\
\text { (part of VEI } \\
\text { assembly) }\end{array}$ \\
\hline Specifications & $\begin{array}{c}\text { Honeywell } \\
\text { FM\&T Lot x229 }\end{array}$ & $27 \mathrm{TS} 138$ & $\begin{array}{l}\text { Acros Tupe } 13 z, 8-12 \\
\text { mesh, Lot } \\
\text { A019863401 }\end{array}$ \\
\hline Mass of material (g) in "inner" cylinder & 250 & 460 & 0 \\
\hline Length of inner cylinder (inches) & 4.5 & 7.06 & NA \\
\hline Diameter of inner cylinder (inches) & 2.5 & 2.5 & NA \\
\hline $\begin{array}{l}\text { Mass of molecular sieve in outer } \\
\text { annulus }\end{array}$ & NA & NA & 410 \\
\hline Length of outer annulus (inches) & NA & NA & 7.25 \\
\hline Diameter of outer annulus (inches) & NA & NA & 3.5 \\
\hline
\end{tabular}

Both getter systems are based upon the catalytic reaction of the hydrogen with carbon triple or double bonds. Figure 42 shows the hydrogenation reaction associated with the DEB getter. 


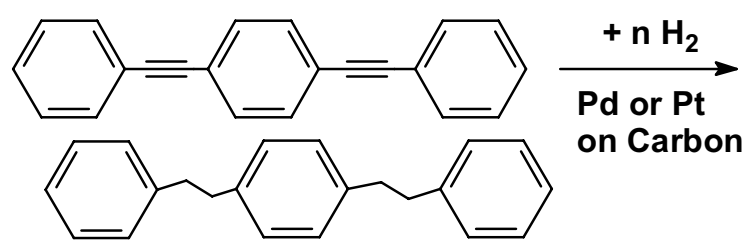

Figure 42. DEB getter hydrogenation reaction.

The reaction mechanism of the TRUGETTER is given in Figure 43.

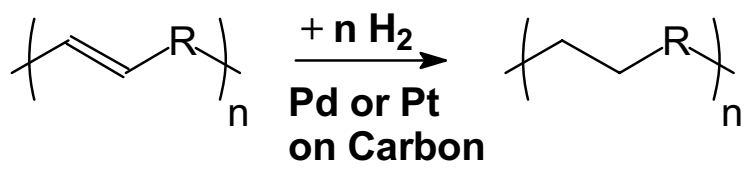

Figure 43. TRUGETTER hydrogenation reaction.

Both of the getters contain a palladium or platinum catalyst that will catalyze the recombination of hydrogen and oxygen to form water. The recombination reaction is shown in Figure 44.

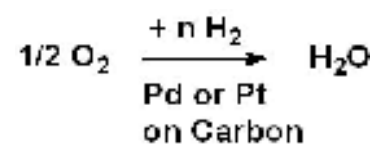

Figure 44. Recombination reaction.

\subsection{Phase III Test Results and Discussion}

The two getters (DEB and VEI) were evaluated in tests run with a belljar atmosphere containing air for 63.9 days at ambient temperature $\left(15-27^{\circ} \mathrm{C}\right)$ and a scaled hydrogen generation rate. A replicate test was simultaneously run with DEB to take advantage of a third available belljar.

\subsubsection{Hydrogen Generation Rate}

Table 30 summarizes the rate at which hydrogen was introduced into the drums of each of the three tests. Figures 45, 46, and 47 are graphic presentations of the mass of hydrogen introduced into the drums for the 63.9 days of the three tests. The target hydrogen generation rate of $2.60 \mathrm{E}-07 \mathrm{~mol} \mathrm{H}_{2} / \mathrm{second}$ ( $0.35 \mathrm{cc} \mathrm{H}_{2} /$ minute) was achieved in all three tests.

\subsubsection{Temperature-Pressure History and Integrity of Test Systems}

Figures 48, 49, and 50 illustrate the temperature and pressure history of the DEB test, the replicate DEB test, and the VEI test, respectively. Gaps in recorded data (2.4 to 3.2, 31.1 to 32.2, and 49.9 to 51.2 days) are due to short term failures in the automated data logging system. The data gaps total 3.2 days and comprise $5 \%$ of the total duration of the test. Tables 31,32 , and 33 present correlation coefficients for temperatures and pressures that were measured and recorded by the data logging system during the DEB test, the replicate DEB test, and the VEI test, respectively. A correlation coefficient is a number between -1 and 1 which measures the degree to which two variables are linearly related. If there is perfect linear relationship with positive (or negative) slope between the two variables, the correlation 
coefficient is 1 (or -1). A correlation coefficient of 0 means there is no linear relationship between the variables. Several relationships are evident upon examination of Figures 48, 49, and 50 and Tables 31, 32, and 33 .

1. For all three tests, the temperature inside the belljar and the temperature of the exterior surface of the belljar are within $1^{\circ} \mathrm{C}$ of each other. Since the uncertainty in temperature measurement is $\pm 1{ }^{\circ} \mathrm{C}$, these two temperatures are essentially equal.

2. For all three tests, ambient temperature was 2 to $5^{\circ} \mathrm{C}$ greater than the belljar temperatures. The placement of the thermocouple in the test room accounted for approximately $2^{\circ} \mathrm{C}$ of this difference. The remainder of this temperature difference is due to a lag between the ambient temperature and the temperature in the belljar. The belljars were not separately heated or cooled. Instead, the ambient temperature in the test room controlled the temperature of these test vessels. Since the belljar contains a large thermal mass of stainless steel, belljar temperatures lagged behind ambient test room temperature. Changes in test room temperature were due to diurnal changes of approximately $2^{\circ} \mathrm{C}$ and passage of weather fronts that lead to temperature changes of up to $2^{\circ} \mathrm{C}$.

Table 30. Summary of hydrogen introduced into drums of DEB and VEI tests.

\begin{tabular}{lrrc} 
Mean Rate, All Tests & $2 \sigma$, DEB Test & $2 \sigma$, VEI Test & $2 \sigma$, Duplicate DEB Test \\
\hline $2.60 \mathrm{E}-07 \mathrm{~mol} \mathrm{H}_{2} /$ second & $2.97 \mathrm{E}-08$ & $5.94 \mathrm{E}-08$ & $1.49 \mathrm{E}-08$ \\
$1.56 \mathrm{E}-05 \mathrm{~mol} \mathrm{H}_{2} /$ minute & $1.78 \mathrm{E}-06$ & $3.55 \mathrm{E}-06$ & $8.89 \mathrm{E}-07$ \\
$0.35 \mathrm{cc} \mathrm{H} /$ minute & 0.04 & 0.08 & 0.02 \\
\hline
\end{tabular}

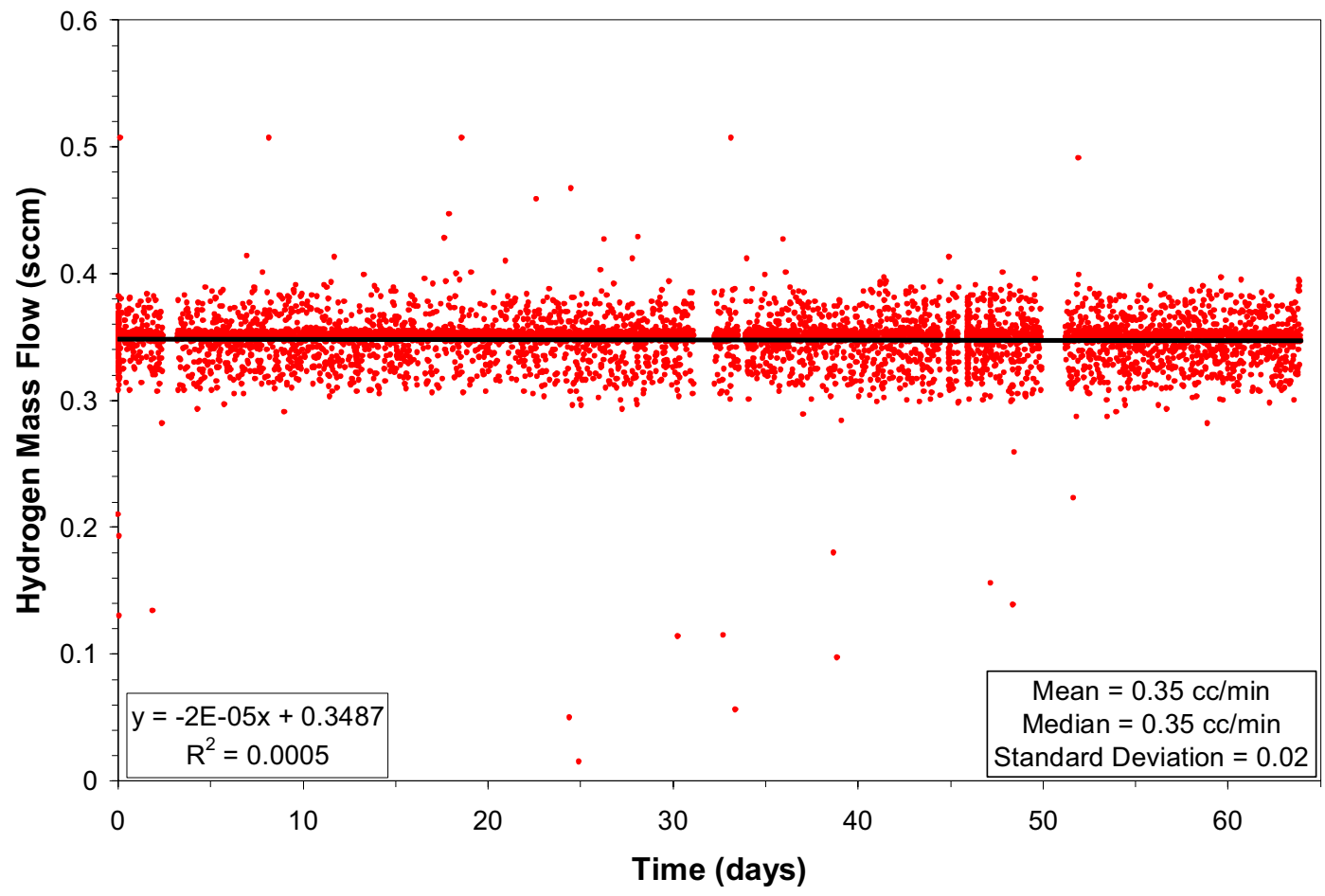

Figure 45. Hydrogen introduced into drum of DEB test, as recorded by data logging system. The relevant statistics for these data are presented in boxes at lower left and lower right. A total of 5993 data points were collected over the 63.9 days of the test. Data gaps in the record were due to short term failures in the automated data logging system. These gaps comprise $5 \%$ of the total duration of the experiment. 


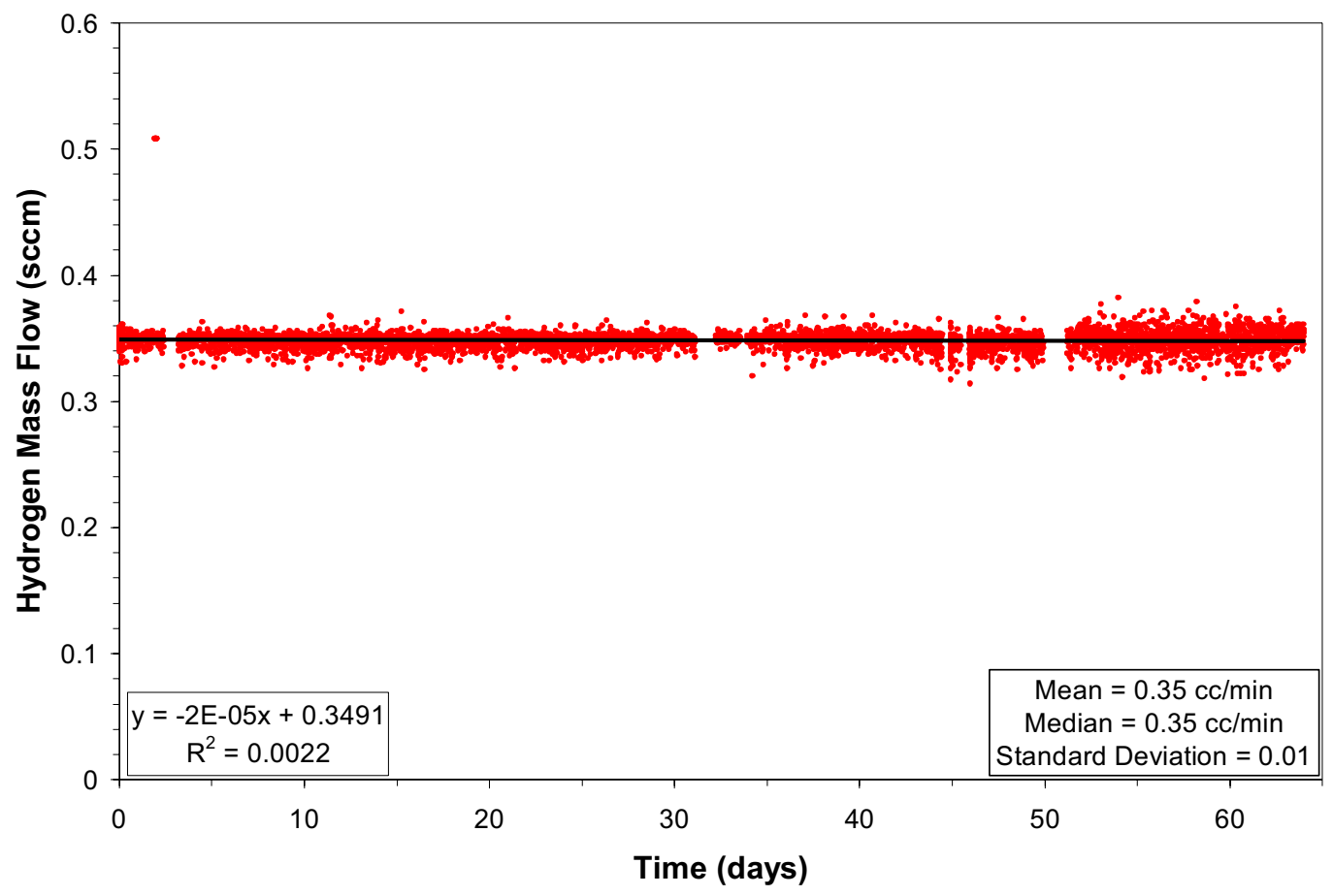

Figure 46. Hydrogen introduced into drum of duplicate DEB test. Refer to Figure 45 caption for information.

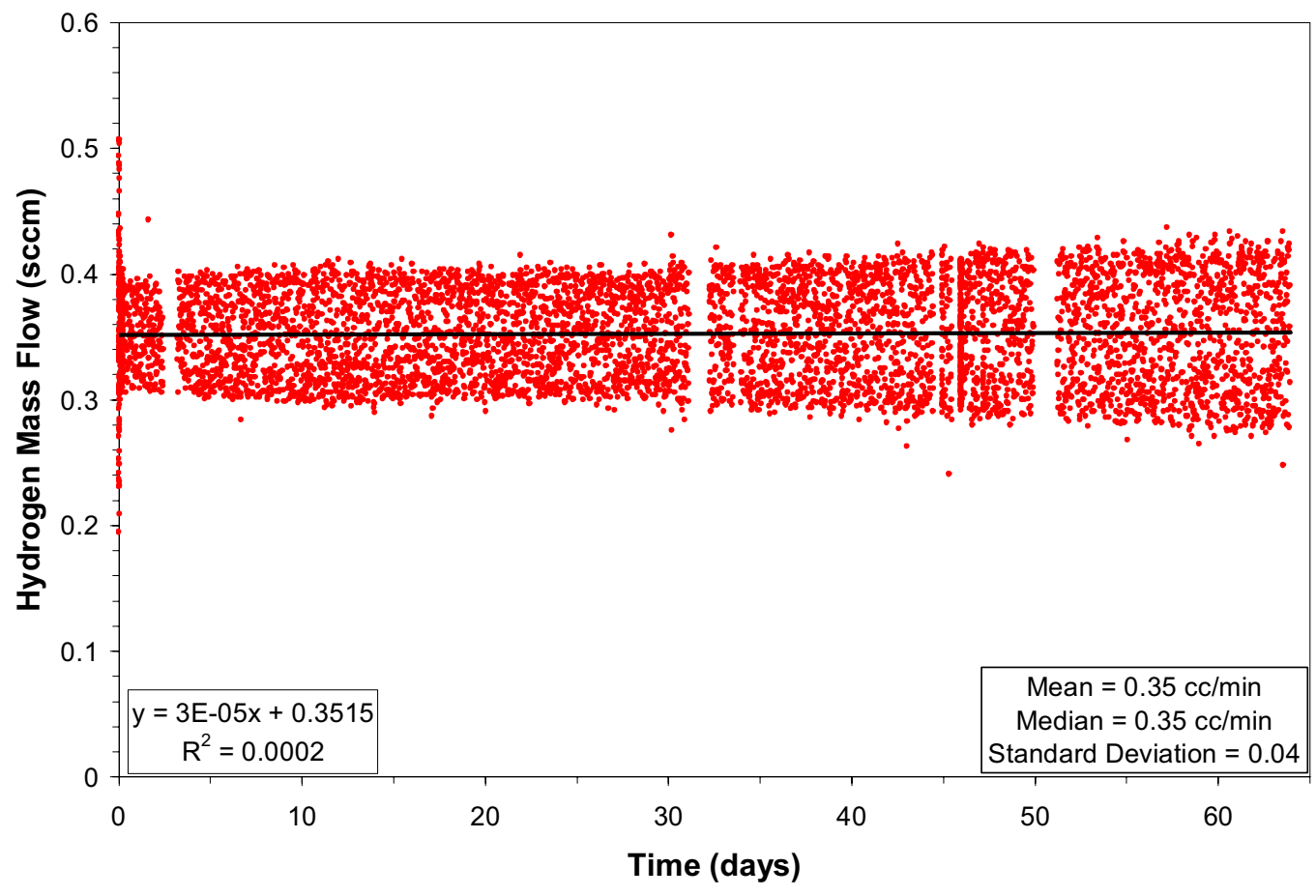

Figure 47. Hydrogen introduced into drum of VEI test. Refer to Figure 45 caption for information. 




Figure 48. Temperature $\left({ }^{\circ} \mathrm{C}\right.$ )-pressure (psi absolute) history of DEB test. Recorded data are illustrated for internal temperature of belljar, exterior surface temperature of belljar, ambient temperature, internal pressure of belljar, and ambient pressure. Correlation coefficients (Table 31) between internal temperature and pressure of belljar (T-P) and between internal pressure of belljar and ambient pressure (P-P) are provided in boxes at top of diagram for intervals of 0 to $2.4,3.2$ to $31.1,32.2$ to 49.9 , and 51.2 to 63.9 days.

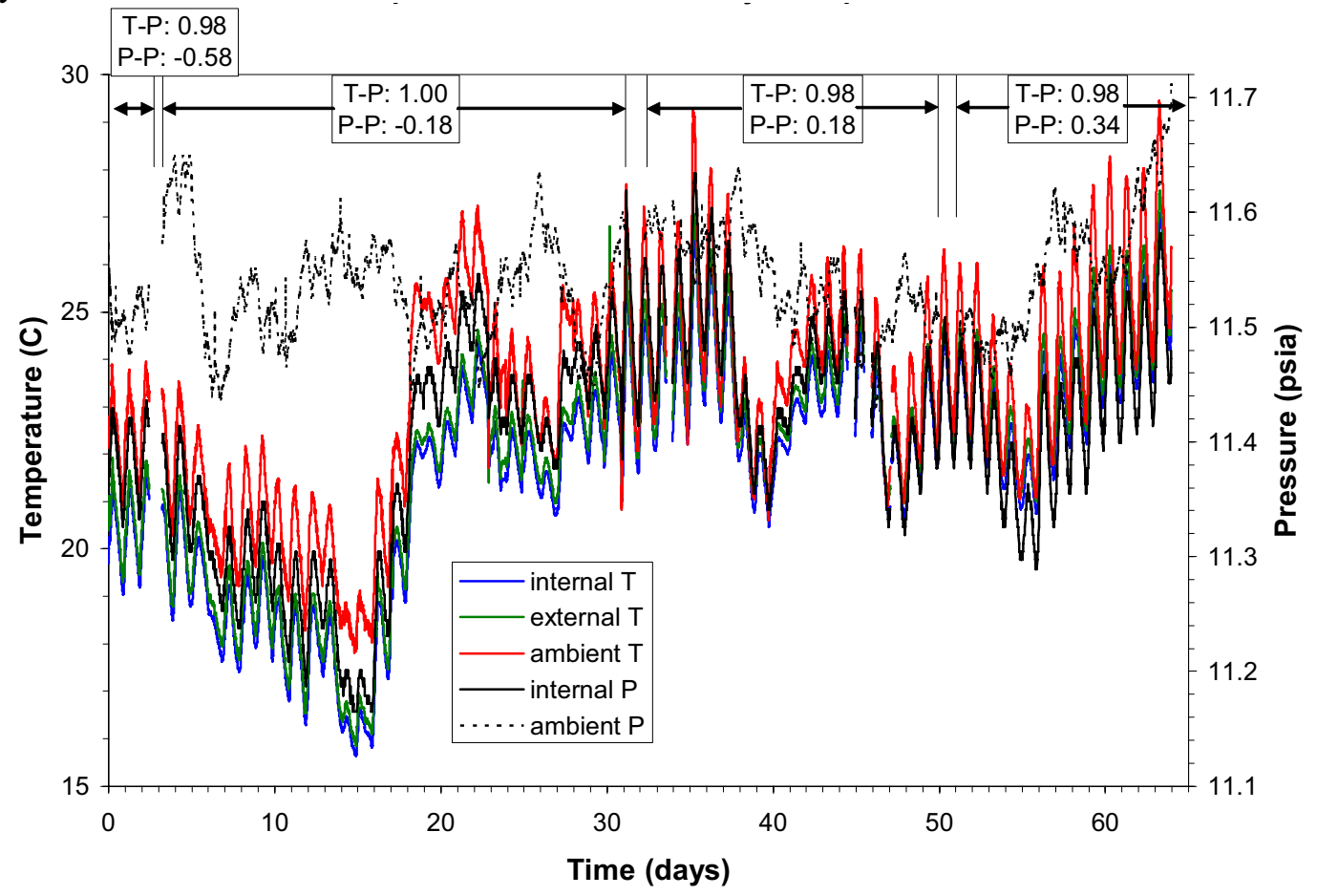

Figure 49. Temperature $\left({ }^{\circ} \mathrm{C}\right)$-pressure (psi absolute) history of replicate DEB test. See Figure 48 for explanation. 


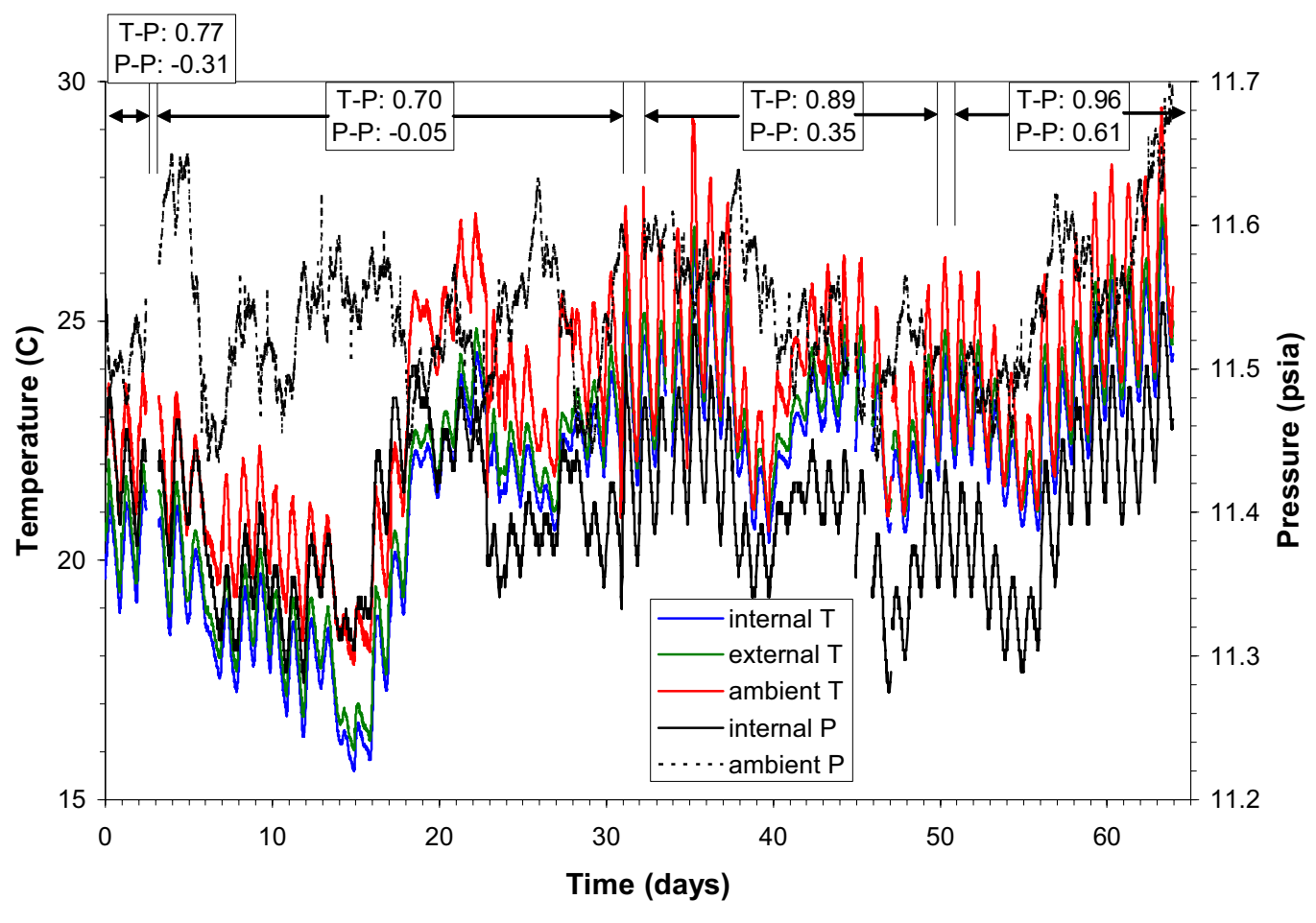

Figure 50. Temperature $\left({ }^{\circ} \mathrm{C}\right)$-pressure (psi absolute) history of VEI test. See Figure 48 for explanation.

Table 31. Correlation coefficients for DEB test.

\begin{tabular}{lcccc}
\hline \multicolumn{1}{c}{ Data Type } & \multicolumn{4}{c}{ Correlation Coefficient in Specified Interval } \\
\hline & $0-2.4$ days & 3.2 to 31.1 days & 32.2 to 49.9 days & 51.2 to 63.9 days \\
\hline $\begin{array}{l}\text { internal belljar } \\
\text { temperature - belljar } \\
\text { exterior surface } \\
\text { temperature }\end{array}$ & 0.96 & 1.00 & 1.00 & 1.00 \\
$\begin{array}{l}\text { internal belljar } \\
\text { temperature - ambient } \\
\text { temperature }\end{array}$ & 0.89 & 0.97 & 0.95 & 0.95 \\
$\begin{array}{l}\text { internal belljar } \\
\text { temperature - internal } \\
\text { belljar pressure }\end{array}$ & 0.99 & 0.84 & 0.89 & 0.98 \\
$\begin{array}{l}\text { internal belljar pressure - } \\
\text { ambient pressure }\end{array}$ & -0.55 & -0.20 & 0.40 & 0.28 \\
\hline
\end{tabular}


Table 32. Correlation coefficients for replicate DEB test.

\begin{tabular}{|c|c|c|c|c|}
\hline \multirow[t]{2}{*}{ Data Type } & \multicolumn{4}{|c|}{ Correlation Coefficient in Specified Interval } \\
\hline & $0-2.4$ days & 3.2 to 31.1 days & 32.2 to 49.9 days & 51.2 to 63.9 days \\
\hline $\begin{array}{l}\text { internal belljar } \\
\text { temperature - belljar } \\
\text { exterior surface } \\
\text { temperature }\end{array}$ & 0.96 & 1.00 & 0.99 & 1.00 \\
\hline $\begin{array}{l}\text { internal belljar } \\
\text { temperature - ambient } \\
\text { temperature }\end{array}$ & 0.94 & 0.97 & 0.95 & 0.96 \\
\hline $\begin{array}{l}\text { internal belljar } \\
\text { temperature - internal } \\
\text { belljar pressure }\end{array}$ & 0.98 & 1.00 & 0.98 & 0.98 \\
\hline $\begin{array}{l}\text { internal belljar pressure - } \\
\text { ambient pressure }\end{array}$ & -0.58 & -0.18 & 0.18 & 0.34 \\
\hline
\end{tabular}

Table 33. Correlation coefficients for VEI test.

\begin{tabular}{lcccc}
\hline \multicolumn{1}{c}{ Data Type } & \multicolumn{4}{c}{ Correlation Coefficient in Specified Interval } \\
\hline & $0-2.4$ days & 3.2 to 31.1 days & 32.2 to 49.9 days & 51.2 to 63.9 days \\
\hline $\begin{array}{l}\text { internal belljar } \\
\text { temperature - belljar } \\
\text { exterior surface } \\
\text { temperature }\end{array}$ & 0.96 & 1.00 & 0.99 & 1.00 \\
$\begin{array}{l}\text { internal belljar } \\
\text { temperature - ambient } \\
\text { temperature }\end{array}$ & 0.93 & 0.97 & 0.94 & 0.95 \\
$\begin{array}{l}\text { internal belljar } \\
\text { temperature - internal } \\
\text { belljar pressure }\end{array}$ & 0.77 & 0.70 & 0.89 & 0.96 \\
$\begin{array}{l}\text { internal belljar pressure - } \\
\text { ambient pressure }\end{array}$ & -0.31 & -0.05 & 0.35 & 0.61 \\
\hline
\end{tabular}

3. For all three tests, internal and external belljar temperatures are strongly correlated (correlation coefficients of 0.96 to 1.00). The weaker correlation between belljar temperatures and ambient temperature (correlation coefficients of 0.89 to 0.97 ) are due to the temperature lag between temperature in the test room and in the belljar.

4. For both DEB tests and for the second half of the VEI test, temperature and pressure within the belljar are strongly correlated (correlation coefficients ranging from 0.84 to 1.00 ). In the first half of the VEI test, temperature and pressure within the belljar were not as strongly correlated (correlation coefficients 0.70 to 0.77 ). From these relationships, we conclude that pressure cycles in each of the three tests are the result of temperature cycles.

5. For all three tests, pressure within the belljar does not correlate with ambient pressure (correlation coefficients range from -0.58 to 0.61 ). In conjunction with the previous observation, we take these 
data as evidence that the test vessel was a closed system, effectively isolated from the atmosphere of the test room.

\subsubsection{Hydrogen Evolution in Drums and Belljars}

Analytical results for gas samples from the belljar and drum headspace of the two DEB tests and the VEI test are presented in Figures 51 through 56. Each of these figures plots concentration of hydrogen (millimol) and oxygen (mol) as measured in the gas samples as well as the amount of hydrogen (mol) injected into the drum and oxygen ( $\mathrm{mol}$ ) consumed during the test. The test results are presented in units of moles, instead of \% oxygen and parts per million (ppm) hydrogen, to facilitate mass balance and promote understanding of reaction mechanism.

In all tests, the concentration of hydrogen in the headspace of belljars containing DEB and VEI did not exceed 5 volume percent (vol\%). The amount of hydrogen within the headspace of each of the belljars remained approximately 2 orders-of-magnitude below the $5 \mathrm{vol} \%$ threshold for the duration of the test. After the initial 15 to 20 days of the DEB tests (i.e., 25 to $30 \%$ into each of the tests), the hydrogen concentration plateaued at $0.04 \mathrm{vol} \%$ in the DEB test and at $0.02 \mathrm{vol} \%$ in the duplicate DEB test. After the initial 15 to 20 days of the VEI test, the hydrogen concentration plateaued at $0.01 \mathrm{vol} \%$.

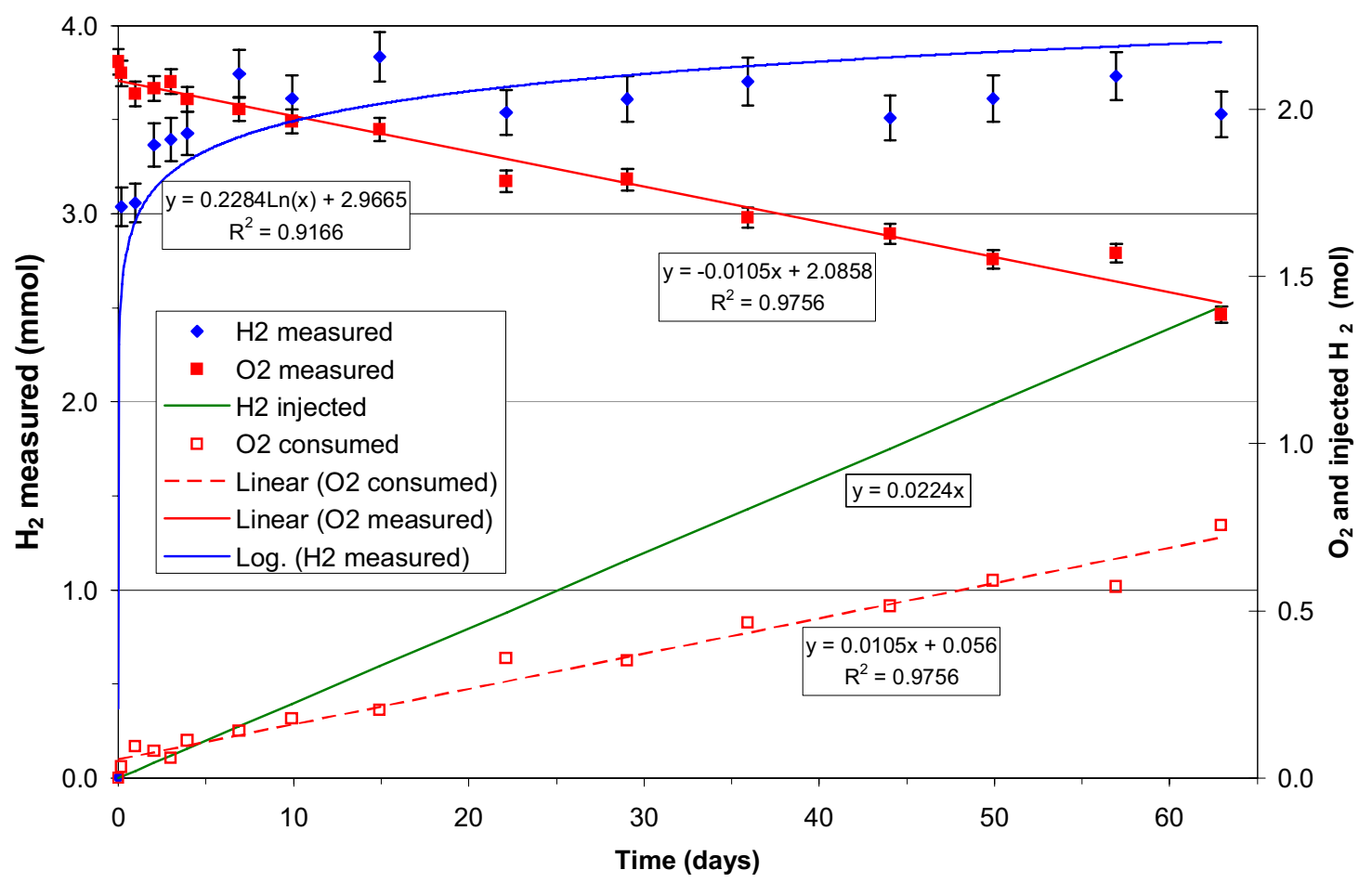

Figure 51. Gas evolution as a function of time for ICV (headspace) of belljar containing DEB. Millimoles of hydrogen measured in this headspace are plotted against axis on left, moles of hydrogen injected into test vessel and moles of oxygen measured/consumed in belljar headspace are plotted against axis on right. Error bars depict uncertainties per Table 27. If no error bars are present, then uncertainty is smaller than size of symbol. A logarithmic curve fit has been applied to the analytical hydrogen data whereas a linear curve fit has been applied to the other data sets. Equations and $\mathrm{R}^{2}$ values for each of the curve fits are plotted next to the respective curves. For the volume of the belljar headspace, 0.5 mol hydrogen yields 5 vol\% hydrogen. 


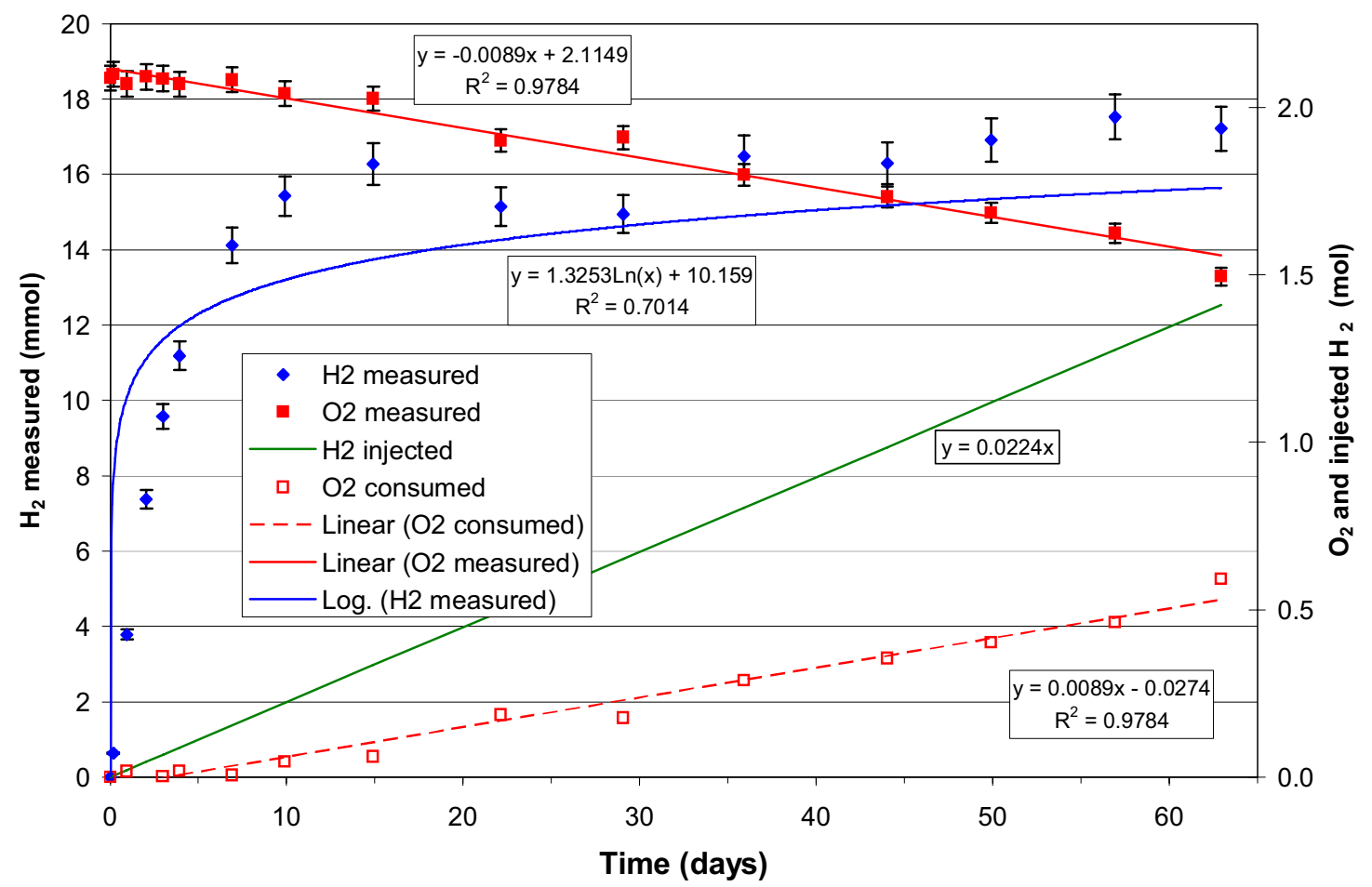

Figure 52. Gas evolution as a function of time for headspace of drum within belljar containing DEB. See caption to Figure 51 for explanation. For the volume of the drum headspace, 0.2 mol hydrogen yields 5 vol\% hydrogen.

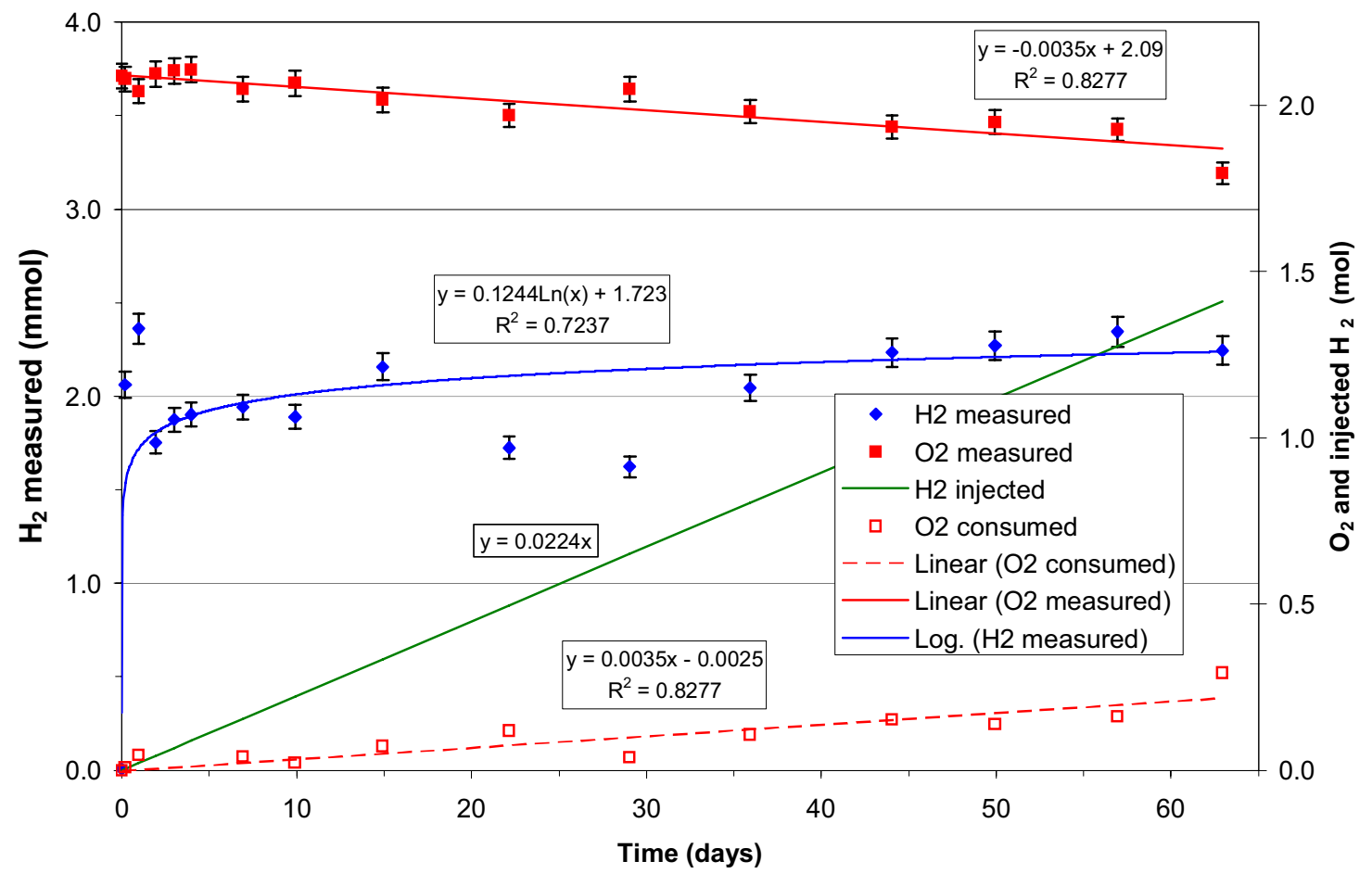

Figure 53. Gas evolution as a function of time for ICV (headspace) of replicate belljar test containing DEB. See caption to Figure 51 for explanation. 


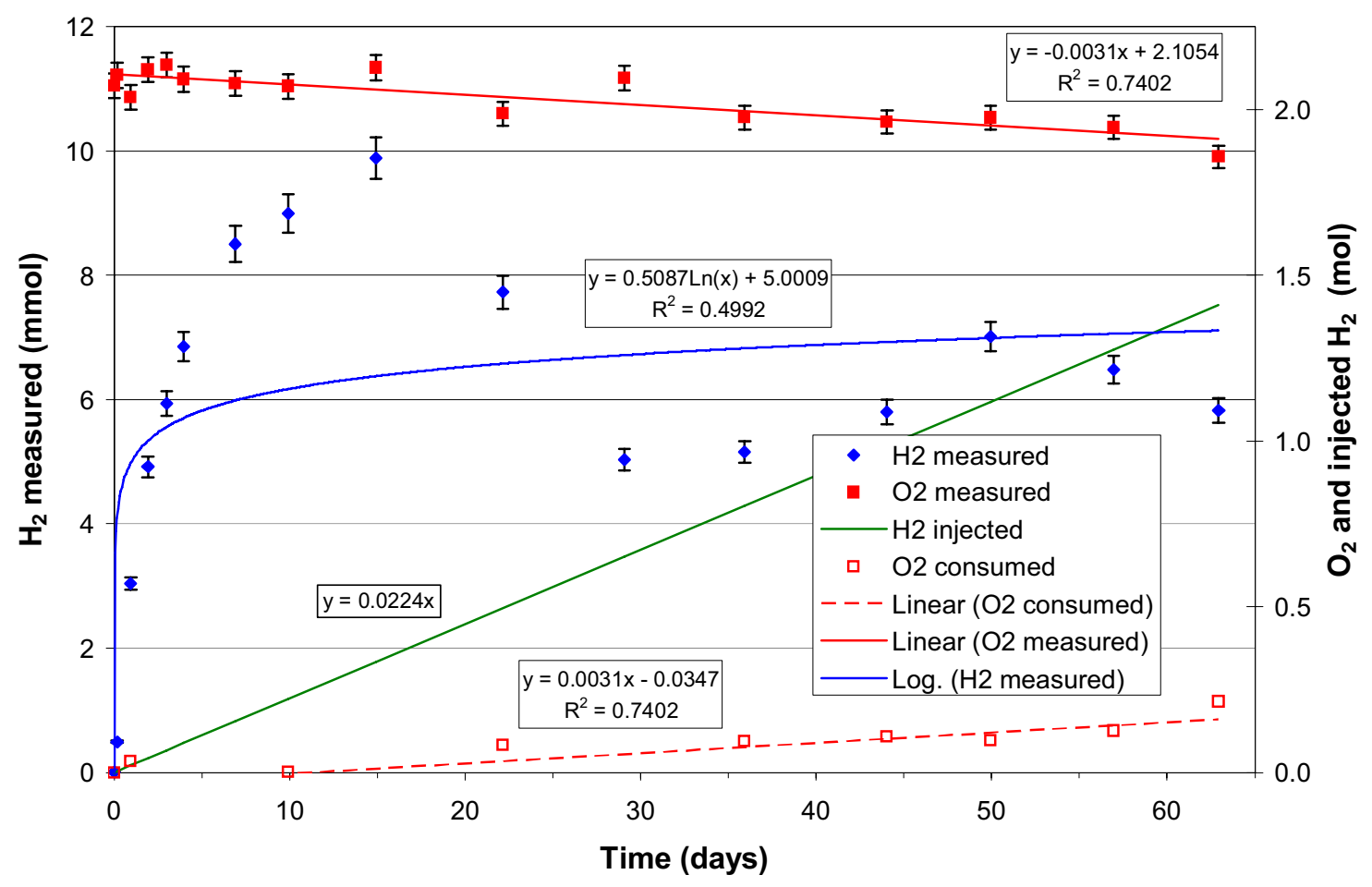

Figure 54. Gas evolution as a function of time for headspace of drum within replicate belljar test containing DEB. See caption to Figure 51 for explanation. For the volume of the drum headspace, 0.2 mol hydrogen yields 5 vol $\%$ hydrogen.

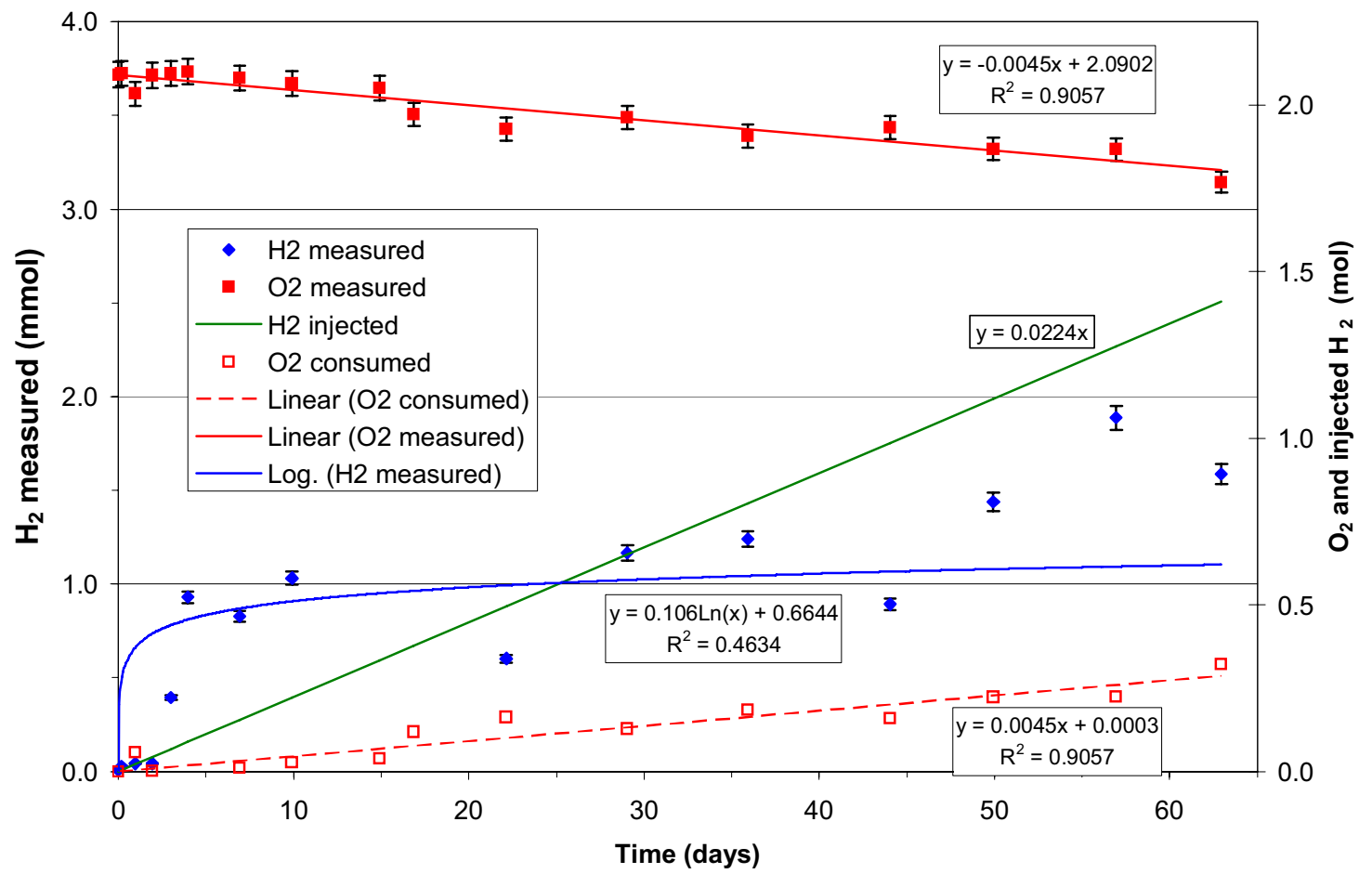

Figure 55. Gas evolution as a function of time for ICV (headspace) of belljar containing VEI. See caption to Figure 51 for explanation. 


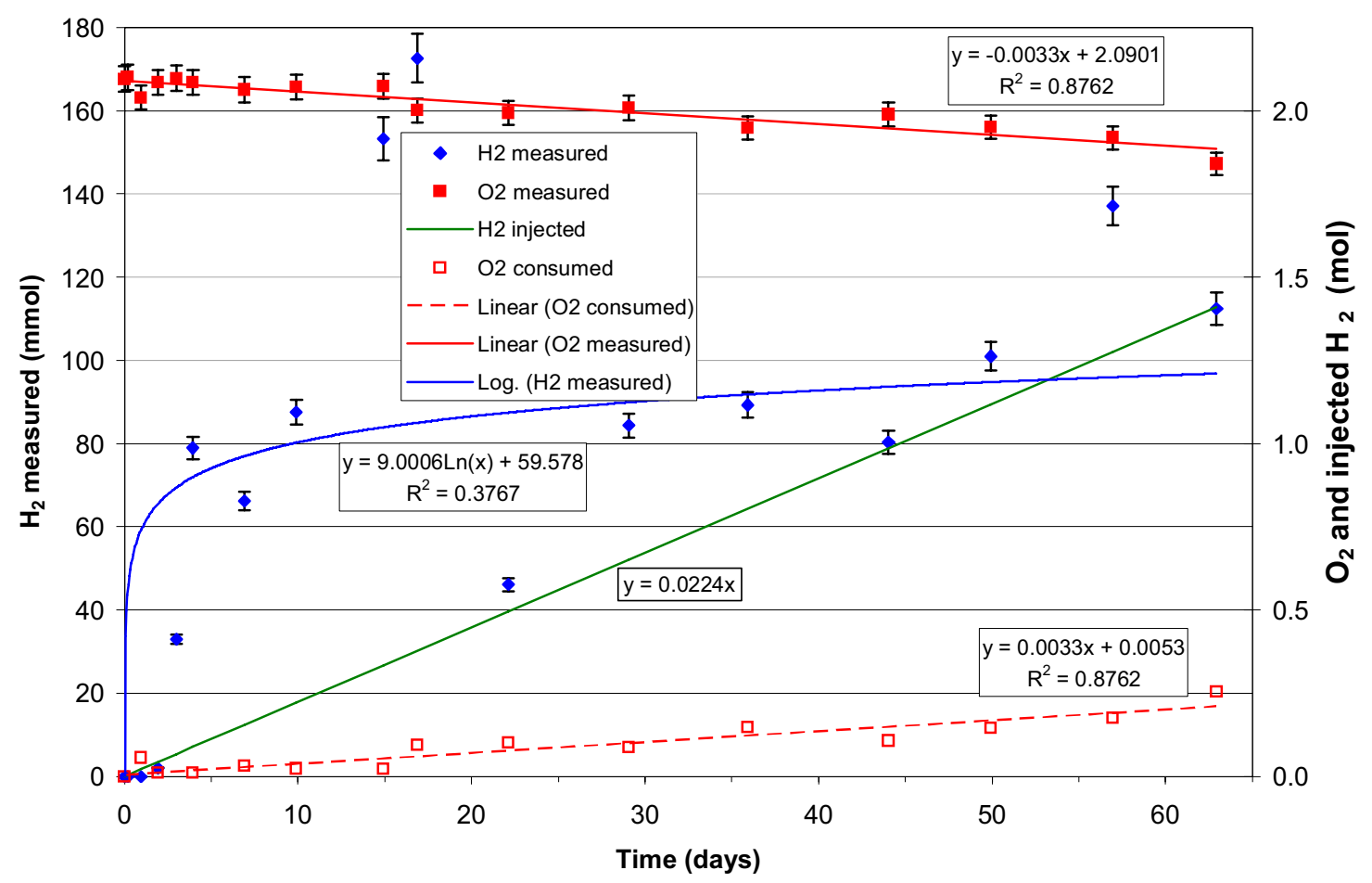

Figure 56. Gas evolution as a function of time for headspace of drum within belljar containing VEI. See caption to Figure 51 for explanation. For the volume of the drum headspace, 0.2 mol hydrogen yields $5 \mathrm{vol} \%$ hydrogen.

In all tests, the concentration of hydrogen in the drums also did not exceed 5 vol\%. Hydrogen concentrations in the drums displayed greater variability than observed in the belljars. The amount of hydrogen within the drums in the tests containing DEB remained approximately 1 order-of-magnitude below the $5 \mathrm{vol} \%$ threshold. After the initial 15 to 20 days of the DEB tests, the hydrogen concentration plateaued at approximately $0.4 \mathrm{vol} \%$ in the DEB test and at $0.2 \mathrm{vol} \%$ in the duplicate DEB test.

Hydrogen concentrations in the duplicate DEB test also display a maxima of $0.25 \mathrm{vol} \%$ at day 15 and a minima of $0.12 \mathrm{vol} \%$ at day 30 . The amount of hydrogen within the drum in the VEI test plateaued at $2.5 \mathrm{vol} \%$ in the second half of the 60 day test. Elevated hydrogen concentrations approaching $5 \mathrm{vol} \%$ were observed at days 15 and 55 of this test.

In addition, the following relationships are also evident:

- $\quad$ Oxygen is depleted in the drum and in the belljar of both DEB and VEI tests. The rate of oxygen depletion is linear, consistent with a zeroth order kinetic rate law. Linear fits of the data sets yield correlation coefficients ranging from 0.74 to 0.98 .

- The rate of hydrogen buildup in the belljar headspace containing DEB is logarithmic (correlation coefficients of 0.97 in the primary test and 0.73 in the replicate, see Figures 51 and 53).

- The rate of hydrogen buildup in the belljar headspace containing VEI is not approximated by a simple curve fit. An attempted logarithmic fit yields a correlation coefficient of 0.32 (Figure 55).

In the belljar headspace of the DEB test, the rate of oxygen consumption is proportional to the rate of hydrogen introduced into the test. The proportionality approaches a ratio of 0.5 (Figure 51), a value 
expected with the catalytic recombination of hydrogen with oxygen to form water. The relative ratio of oxygen consumption to the rate of hydrogen introduced into the duplicate DEB test is only $1 / 3$ of that expected for catalytic recombination (Figure 53). Similar relationships are observed for the drums in the tests containing DEB. The ratio of oxygen consumption to hydrogen production approaches 0.5

(Figure 52) in the DEB test but in the duplicate DEB test is only $1 / 3$ of that expected for catalytic recombination (Figure 54). The ratio of oxygen consumption to hydrogen production in the VEI test is also only $1 / 3$ of that expected for catalytic recombination (Figures 55 and 56).

Liquid water was condensed on the base of the belljar and on the drum of the DEB test (Figure 40). In addition, the belljar emitted an audible hiss when the lines were disconnected. In both DEB tests, the rust and corrosion were present on the drum welds, bottom of drum, by the drum filter, and on the rim of the bung. These observations are consistent with consumption of oxygen and exposure of the drum and belljar to water vapor. No free water or drum corrosion was noted in the VEI test. In combination with the analytical data, these observations indicate that catalytic recombination was the predominant mechanism for hydrogen consumption in the DEB test. Catalytic recombination was also important in the replicate DEB test and in the VEI test.

Figures 57, 58, and 59 illustrate the relationships between temperature and the continuously measured hydrogen concentration in the drums of the DEB test, the replicate DEB test, and the VEI test, respectively. Also plotted for comparison are results of the hydrogen analyses using gas chromatography as well as the correlation coefficients between temperature and hydrogen concentration that were

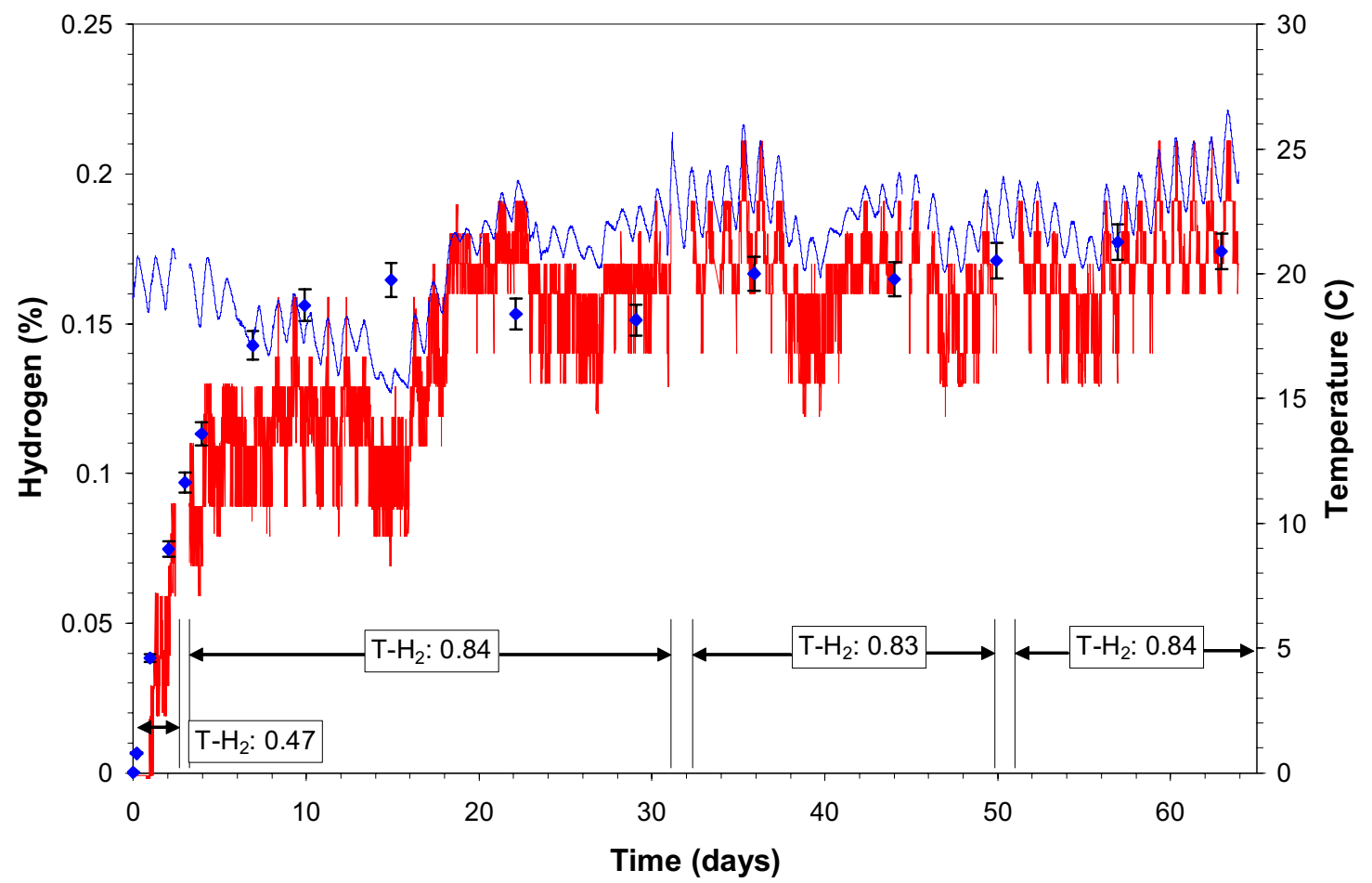

Figure 57. Hydrogen (in units of \%, left axis) in drum of DEB test (red line) compared to system temperature $\left({ }^{\circ} \mathrm{C}\right.$ on the right axis) in test vessel (blue line). Also plotted are the hydrogen analyses obtained with gas chromatography (blue diamonds). Correlation coefficients between temperature and the continuously measured hydrogen concentration (from Table 31) are provided in boxes labeled $\mathrm{T}-\mathrm{H}_{2}$ for intervals of 0 to $2.4,3.2$ to $31.1,32.2$ to 49.9 , and 51.2 to 63.9 days. Uncertainty in the hydrogen data that was continuously measured by the Meggitt sensors is $\pm 6 \%$. 


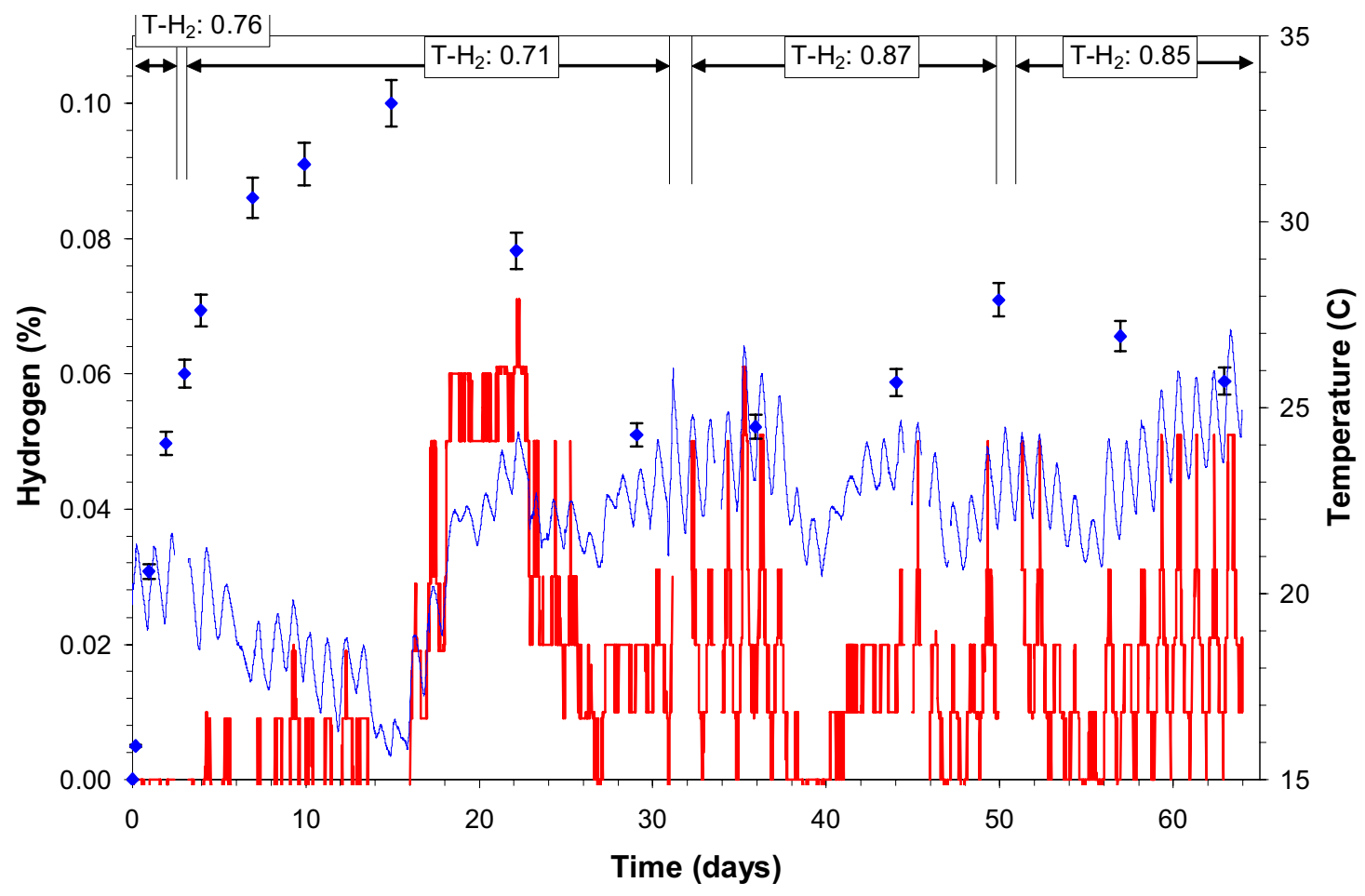

Figure 58. Hydrogen in drum of replicate DEB test. See caption of Figure 57 for explanation; correlation coefficients between temperature and the continuously measured hydrogen concentration (from Table 32) are provided in boxes labeled $\mathrm{T}-\mathrm{H}_{2}$ for intervals of 0 to $2.4,3.2$ to $31.1,32.2$ to 49.9 , and 51.2 to 63.9 days. Accuracy of Meggitt sensors drifted during course of the test. Final calibration of the sensors indicate uncertainty in the continuously measured hydrogen data of up to $-8 \%$.

measured and recorded by the data logging system. Several relationships are evident in these figures. In the DEB test, the results of the hydrogen analyses made with the Meggitt sensors and the gas chromatograph agree very well (Figure 57). One prominent outlier is on day 14.9. The reason for this discrepancy in the data is not known. During the first 4.2 days of the DEB test (Figure 57), the hydrogen concentration increases from $0 \%$ to approximately $0.11 \%$. After approximately 4.2 days, the mean hydrogen concentration plateaus and cycles in positive correlation with temperature. We take this observation as evidence that the first 4.2 days of the DEB test represent a period of time in which the drum-belljar system is reaching steady state. After 4.2 days, hydrogen input into the drum, diffusion of hydrogen from the drum through the bung filter into the belljar, and consumption of hydrogen by getter material within the belljar are at steady state. From this time forward, hydrogen concentration in the drum is controlled by temperature. Diurnal temperature cycles as well as broad temperature patterns are mirrored in the hydrogen data of both DEB tests.

The hydrogen data in the replicate DEB test displays a greater disparity between hydrogen analyses with the Meggitt hydrogen sensors and the gas chromatograph (Figure 58). This discrepancy is likely due to the very low levels of hydrogen present in this test. The detection limit of the Meggitt sensor is approximately $0.1 \%$, whereas hydrogen measured during the course of the replicate test never exceeded this threshold. The different levels of hydrogen in these two tests may be due to physical heterogeneities present in test vessels of this complexity. Small differences in packaging and handling of the DEB, in accumulation of $\mathrm{H}_{2} \mathrm{O}$ during catalytic recombination, and in diffusivity of the bung filters may have all contributed. However, it must be noted that exceedingly small levels of hydrogen are present in drums of 


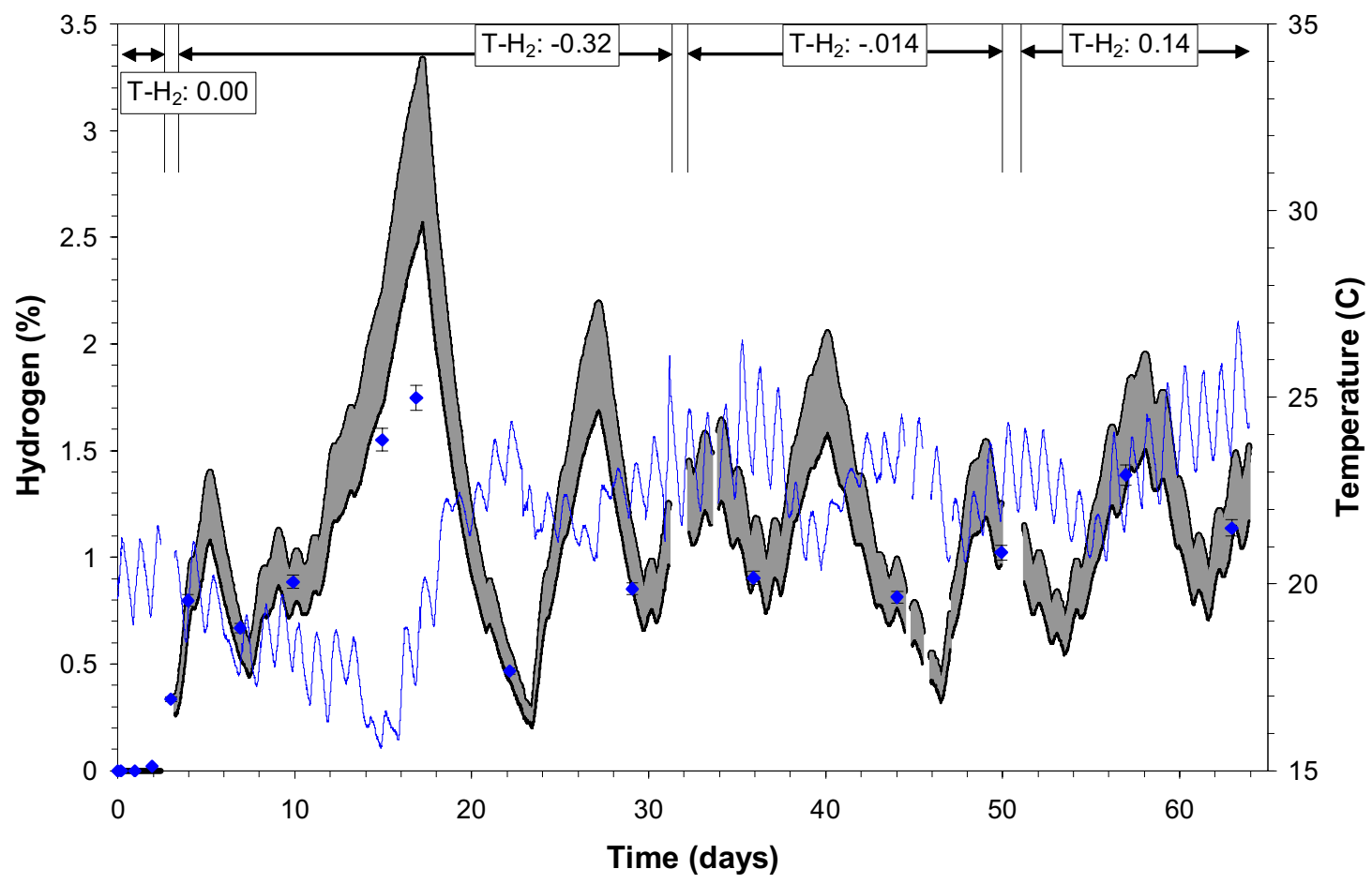

Figure 59. Hydrogen in drum of VEI test (black lines). See caption of Figure 57 for explanation; correlation coefficients between temperature and the continuously measured hydrogen concentration (from Table 33) are provided in boxes labeled T-H2 for intervals of 0 to 2.4, 3.2 to 31.1, 32.2 to 49.9, and 51.2 to 63.9 days. Accuracy of Meggitt sensors drifted during course of the test. Final calibration of the sensors indicate uncertainty in the continuously measured hydrogen data of up to $30 \%$, as indicated by shaded region between black lines.

both tests, $0.17 \%$ in the DEB test and $0.10 \%$ in the replicate test. In evaluating these analytical data, is not surprising that discrepancies exist. Comparing values of small numbers can lead to large apparent differences.

In the VEI test, the results of the hydrogen analyses made in the drum with the Meggitt sensors and with the gas chromatograph agree exceedingly well (Figure 59). One prominent outlier is on day 16.9. The reason for this discrepancy in the data is not known. The percent levels of hydrogen present in the drum of the VEI test are well within the range of accuracy of the Meggitt analyzer, hence the excellent agreement in the analytical results of the two methods. The hydrogen data in the VEI test do not correlate with temperature as observed in the DEB tests. The reasons for this phenomenon, for the percent levels of hydrogen in the drum compared to the small fraction of a percent of hydrogen in the drums of the DEB tests, and for the cycling observed in the hydrogen within the drum of the VEI test are unknown. One possibility is that the layered packaging of VEI getter within the molecular sieve and the accumulation of $\mathrm{H}_{2} \mathrm{O}$ in the sieve affect the dynamics of hydrogen diffusion between the drum and belljar ICV.

\subsection{NMR Testing Results}

NMR spectra (Figure 60) were taken of both getters: (1) before any exposure to hydrogen, (2) at the completion of the scaled experiments, and (3) fully saturated with hydrogen (in the mini-test apparatus). The over all conclusion is that the spectra of the control getters and that of the after testing are identical. This would indicate that all of the hydrogen gettering that took place was a result of recombination reactions. To further substantiate this conclusion was the facts that there were water pools 
and droplets on the base of the bell jars after the scaled testing of the DEB getters. In addition, there was rusting of the seam on the drums where they had been cut to scale and then rejoined. There was not water or rusting in the VEI getter bell jars, probably because of the molecular sieves contained in the getter assembly. The NMR spectra are shown below.

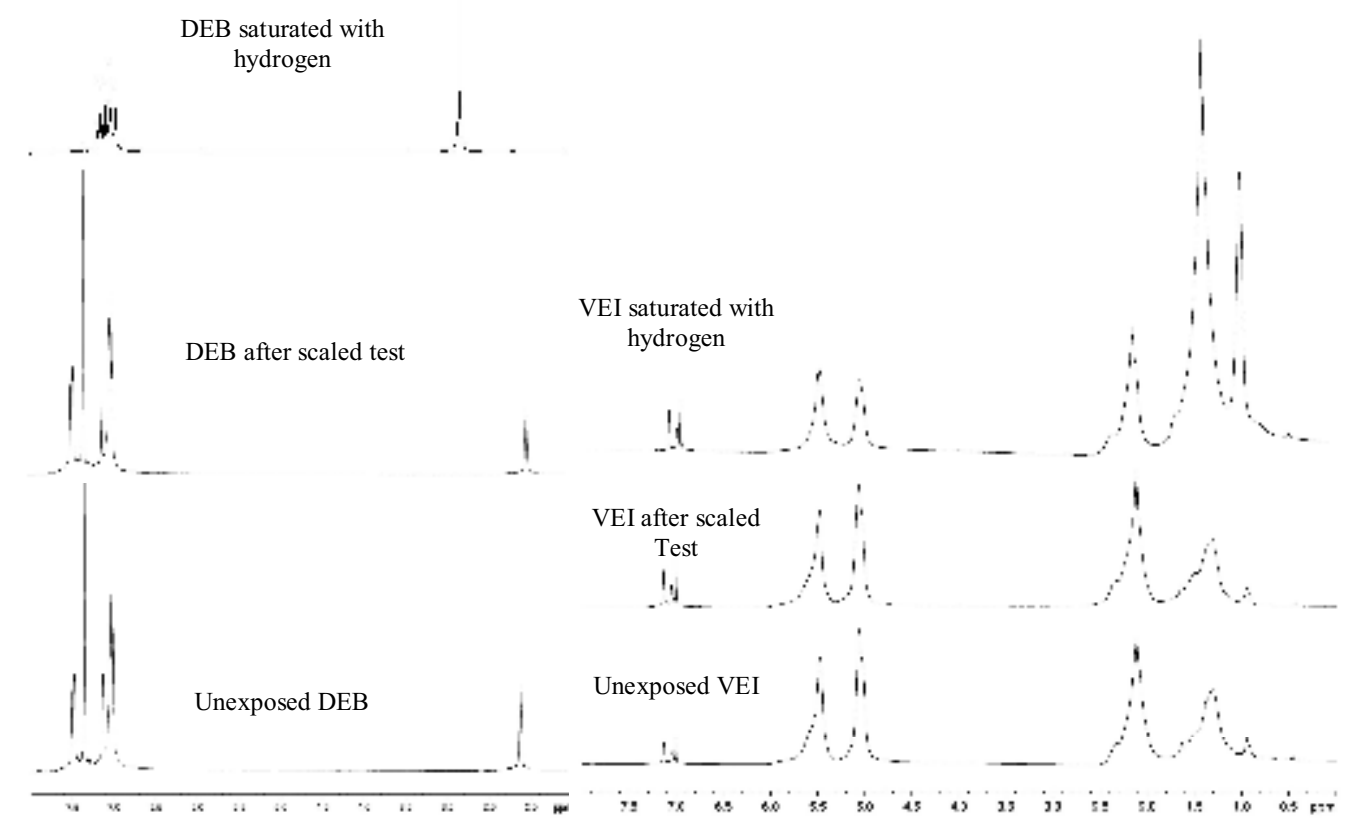

Figure 60. NMR spectra from unexposed getters, getters used in this set of tests, and samples of the two getters after they were saturated with hydrogen. No chemical changes in the getters were observed from these experiments. They show that all of the hydrogen removal under the experimental conditions was due to recombination of the hydrogen with the oxygen in the bell jars. This is further confirmed by the figure that shows the water droplets formed from the recombination reactions in one of the bell jars.

\subsection{Summary}

The amount of oxygen in the bell jar was enough to react with all of the hydrogen through the recombination mechanism over the experimental time period. This result suggests that the catalyst/carbon mixture may be all that is needed to safely remove the hydrogen in the shipping containers under current DOE and DOT requirements. 


\section{CONCLUSIONS}

The overall goal of this program was to investigate the potential for using hydrogen getter materials in TRUPACT containers to prevent the build up of hydrogen to a dangerous level. The hydrogen getter investigated by the INL/LANL team was a precious metal catalyzed hydrogenation system. It is a combination of palladium dispersed on carbon and a chemical named 1, 4-bis (phenylethynyl) benzene (DEB). The material is delivered as irregular shaped small particles approximately $1-2 \mathrm{~mm}$ in diameter. The triply-bonded carbon atoms in the DEB, in the presence of the palladium, irreversibly react with the hydrogen to form the corresponding saturated alkane compounds.

It is known that many catalyst systems can be negatively affected by exposure to certain chemical poisons. Since a number of potential catalyst poisons are present in the drums that also are producing the hydrogen, studies into the impact of the poisons on this specific getter and means for protecting the getter prompted this project. The INL/LANL team chose to encapsulate the getter particles with a semipermeable polymeric coating that would allow the hydrogen to enter and be retained. At the same time the polymeric coating inhibits, or at least reduces to an acceptable level, the entry of the poisons into the getter particles.

A Consolidated Testing Plan for the Phase 2 was developed and followed. The proposed getter formulations (coated and uncoated) were subjected to tests that determined the performance of the getters with regards to capacity, operating temperature range (with hydrogen in nitrogen and in air), hydrogen concentration, poisons, aging, pressure, reversibility, and radiation effects. The conclusions that can be made up to this point are: (1) All of the polymer coated materials performed well above the figure of merit, and (2) Even the uncoated getter performed above the figure of merit.

The conclusions that can be stated about the getter performance relative to the programmatically specified parameters include:

- $\quad$ Over the complete temperature range and maximum poison concentration $5.7 \mathrm{~kg}$ of getter provided the required capacity and rate

- In the temperature range of $160^{\circ} \mathrm{F}$ to $77^{\circ} \mathrm{F}$ the getter rates exceed the minimum programmatic requirement by at least $100 \mathrm{X}$

- In the temperature range of $23^{\circ} \mathrm{F}$ to $-20^{\circ} \mathrm{F}$ the getter rates exceed the minimum programmatic requirements by at least $10 \mathrm{X}$

- Reducing the hydrogen concentrations from 5\% to $1 \%$ in nitrogen had no significant effect on the rate

- Reaction rates are higher in air than in nitrogen due to recombination plus gettering reactions

- The gettering reaction was not found to be sensitive to pressure, radiation, and was shown not to be reversible

- Under the worst case conditions (low temperature, air, and in the presence of $\mathrm{CCl}_{4}$ ), the observed rate was greater than $8 \mathrm{X}$ the minimum programmatic requirement.

The design and implementation of Phase 3 testing was based on results from the Phase 2 testing, recommendations from an ASME Peer Review Panel, and discussions with WIPP operations personnel. Both DEB and VEI getters were tested in scaled replicas of TRUPACT-II containers. The tests were run 
with an atmosphere of air for 63.9 days at ambient temperature $\left(15-27^{\circ} \mathrm{C}\right)$ and a scaled hydrogen generation rate of $2.60 \mathrm{E}-07$ moles per second $(0.35 \mathrm{cc} / \mathrm{min})$. In addition, benchtop tests were performed to determine at a more detailed level the optimal conditions that achieved the maximum getter conversion rates. Our conclusions from both benchtop and larger scale testing are:

- The getter has the needed rate of conversion

- The getter can remove hydrogen to $>90 \%$ of theoretic calculated values

- $\quad$ The capacity of the getter suggested in the earlier phases will perform satisfactorily if the rate of introduction of the hydrogen to the getter happens slowly over the expected lifetime of the getter

- $\quad$ The getter as received by the producer is useable as received and no other preconditioning is needed.

Our conclusions from scaled tests are:

- Hydrogen was successfully "gettered" by both DEB and VEI getters. Hydrogen concentrations remained below $5 \mathrm{vol} \%$ (in air) for the duration of the tests.

- Catalytic reaction of hydrogen with carbon triple or double bonds in the getter materials did not take place. Instead, catalytic recombination was the predominant gettering mechanism in both getter materials as evidenced by (1) consumption of oxygen in the belljars; (2) production of free water in the belljars; and (3) absence of chemical changes in both getter materials as shown by NMR spectra. 


\section{REFERENCES}

American Society of Mechanical Engineers, July 2002a, "Technical Peer Review Report - Enhanced Polymer Hydrogen Gas Getter Material,” ASME/CRTD-RP-02-41, ASME International, Columbia, Maryland.

American Society of Mechanical Engineers, July 2002b, "Technical Peer Review Report - Polymer Encapsulation of Hydrogen Gas Getter," ASME/CRTD-RP-02-42, ASME International, Columbia, Maryland.

Balooch, M., W.-E. Wang, and J. R. Kirkpatrick, 2001 "Hydrogen Uptake Mechanism of a SiliconeRubber DEB Getter Mixture," Journal of Polymer Science: Part B: Polymer Physics 39, 425-431.

Balooch, M., W. E. Wang, and J. D. Lemay, 1999 "Thermochemical Properties of the Hydrogen Getter DEB," Journal of Nuclear Materials 270, 248-252.

NRC, 1996, Safety Analysis Report for the TRUPACT-II Shipping Package, Revision 16, NRC Docket No. 9218, Washington, D.C., U.S. Nuclear Regulatory Commission.

Sheppod, et al. (T. J. Sheppod, L. R. Gillion, and H. M. Smith), 1989, "Organic getter Materials for the Removal of Hydrogen and its Isotopes," Presented at the Fourth International Conference on the Effects of Hydrogen on the Behavior of Materials, Moran, Wyoming, September 12-15, 1989.

Smith, H. M., and T. J. Sheppod, 1990, "Hydrogen-Tritium Getters and Their Applications," Presented at the Radioluminescent Lighting Technology Transfer Conference, Annapolis, Maryland, September 25-26, 1990.

S. Uludag-Demirer, and A. R. Bowers, 2000. Adsorption/Reduction Reactions of Trichloroethylene by Elemental Iron in the Gas Phase: The Role of Water, Environ. Sci. Technol., 34, 4407-4412 